\title{
CABO VERDE TRANSITION FINANGE COUNTRY PILOT
}

Rachel Morris, Olivier Cattaneo, Konstantin Poensgen
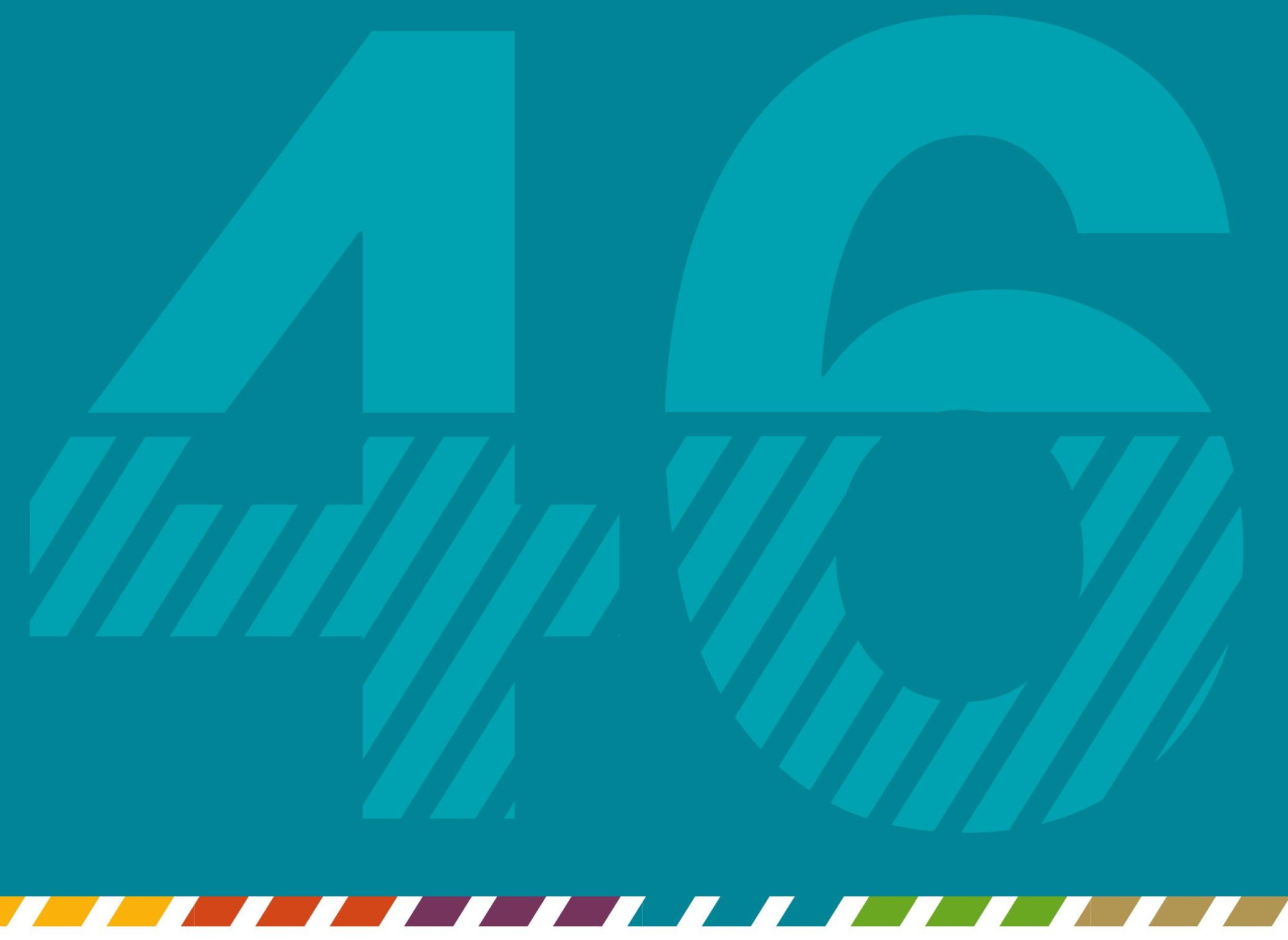

OECD DEVELOPMENT CO-OPERATION WORKING PAPER 46

Authorised for publication by Jorge Moreira da Silva, Director, Development Co-operation Directorate 



\section{Background}

In 2017, the OECD Development Assistance Committee (DAC) launched work to understand the implications of economic transition in developing countries and to agree best practices to support countries' development pathways in the Sustainable Development Goal (SDG) era (para 26). (OECD, 2017 $\left.{ }_{[1]}\right)$ During its 1 February 2018 meeting, OECD DAC members mandated the Development Co-operation Directorate (DCD) Secretariat to implement a roadmap on transition finance and how it relates to "countries most in need", including least developed countries (LDCs), low-income countries (LICs), small island developing states (SIDS), landlocked developing countries (LLDCs) and fragile/conflict affected states. (OECD, 2017 $[2]),\left(\right.$ OECD, 2018 $\left.{ }_{[3]}\right)$ A methodology paper is currently being developed in order to lay the ground for analytical work on transition finance in 2019-20 Programme of Work and Budget (PWB).

The transition finance agenda is an important emerging component of the Financing for Development Agenda. The Addis Ababa Action Agenda (AAAA) calls to promote "integrated national financing frameworks" (para 9) - or strategies to finance economic transition within the context of the 2030 Agenda for Sustainable Development. (United Nations, 2015 [4] $)$ The AAAA recognises that national financing strategies must be supported by international actors at all levels and tailored to different development contexts. As a growing diversity of country-led financing strategies and frameworks (e.g. medium-term revenue strategies, Voluntary National Reviews, UNDP Development Finance Assessments, IMF costing exercises) ${ }^{1}$ emerge, co-ordination among all development partners will be essential.

The Global Outlook on Financing for Sustainable Development provides the foundation of the OECD's holistic approach to Financing for Sustainable Development (FSD). (OECD, $\left.2019_{[5]}\right)$ It highlights the importance of data, policies and concrete solutions to navigate the new global development finance architecture, and to ultimately maximise all forms of finance in support of inclusive and sustainable development.

To implement this new work, the OECD DAC called for policy analysis and recommendations at country-level. The present country pilot on Cabo Verde was initiated to capture the key transition finance challenges facing LDC graduates as well as the specific vulnerabilities of SIDS.

A one week field mission (30 July - 3 August 2018) was carried out with the support of the Cabo Verde government (Ministry of Foreign Affairs and the Ministry of Finance and Planning). A wide array of actors were interviewed during the mission, including members of the Cabo Verdean government, OECD DAC donors, non-DAC providers, private sector actors, multilateral organisations, and civil society organisations.

A new transition finance toolkit approach is proposed to structure and highlight the outcomes of the Cabo Verde pilot and its applications to other developing countries experiencing transition challenges. The toolkit is comprised of three core components, "Assessing, Benchmarking and Counselling" or the ABC's approach. Each component seeks to address a set of targeted questions. The final section on counselling provides concrete recommendations and a way forward to move from Assessing and Benchmarking to action, outlined below: 
- Assessing: What is the transition context in the country? What role are DAC members and partners playing in the transition context? How has access to financing for sustainable development been impacted by the transition?

- Benchmarking: What are the substitution effects between public, private, domestic and international resources as the country transitions? How does this substitution of broader flows compare with country peers undergoing similar transitions? What lessons and best practices can be drawn from other country contexts?

- Counselling: How can development partners help the phasing out of Official Development Assistance (ODA) (e.g. and secure the progressive growth of other sources of financing (e.g. private or domestic)? How to increase the effectiveness of ODA, identifying the best and most innovative tools, policies and partnerships available? How could development partners design long-term support strategies that go beyond ODA? How can development partners provide support to avoid setbacks when ODA is no longer an option? What kinds of capacity building efforts (e.g. to allow trade and investment or domestic resource mobilisation), promotion of transfers of all kinds (from private investment to technologies or knowledge) could be fostered by ODA to smooth the transition? 


\section{Table of contents}

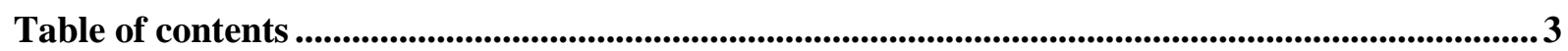

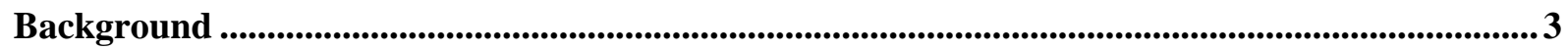

Executive summary...................................................................................................................................

Assessing: Where does Cabo Verde stand in the transition? ...................................................................10

1. Constraints to economic transition, beyond income, persist after LDC graduation..................... 10

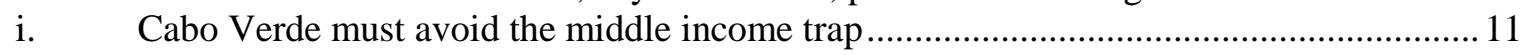

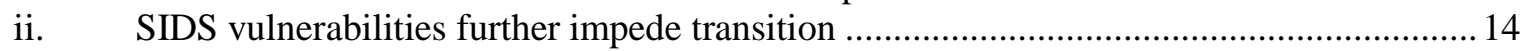

2. Addressing SDG financing needs and gaps remains challenging ......................................... 17

i. The Cabo Verdean national financing strategy must link to SDG financing needs and gaps 17

ii. Debt sustainability presents a key challenge to finance sustainable development.............20

3. Support for LDC graduation and transition was insufficient ...................................................22

i. $\quad$ Transition support groups lost steam following LDC graduation.......................................22

ii. New actors are phasing in while a few traditional providers are phasing out....................25

i. Although ODA increased following graduation, the terms and conditions of support

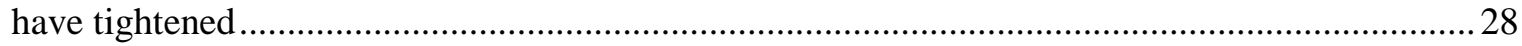

ii. Targeting of sectoral support is not fully aligned with country priorities...........................30

Benchmarking: How to compare Cabo Verde's transition finance with other peer groups and

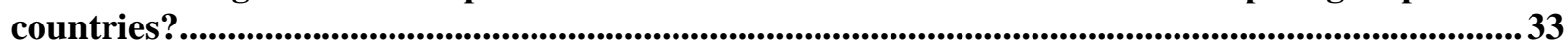

1. The transition finance mix after graduation presents new challenges.............................................. 33

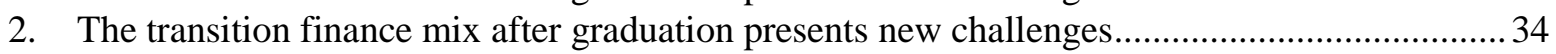

i. $\quad$ External resources are shifting quickly, yet ODA dependency remains a concern. ...........34

ii. Limited fiscal space presents new challenges for SDG expenditure ..................................38

3. Financing and capacity gaps are emerging across SDG-related sectors .....................................40

i. Social sector capacity and financing gaps are increasing (education, health, domestic

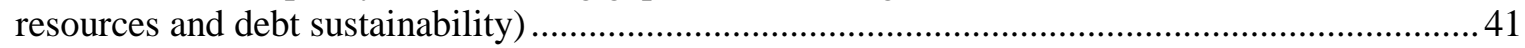

ii. Productive and service sectors are not attracting sufficient levels of OOF (trade,

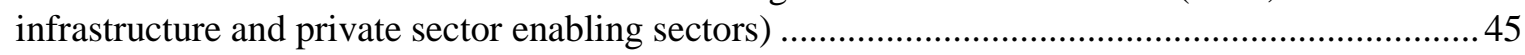

4. Opportunities to maximise financing, including and beyond ODF, must be seized ................... 48

i. Enabling the private sector for self-sustained financing for development ....................................5

ii. Harnessing blended finance to transform SIDS vulnerabilities into strengths ..........................51

iii. Promoting the contribution of diaspora communities and financial inclusion ..........................52

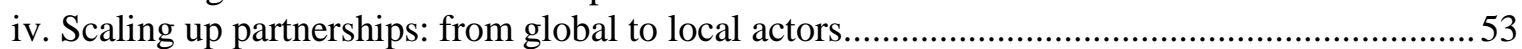

v. Leveraging Cabo Verde's leadership role in renewable energy to generate climate finance .....54

Counselling: Recommendations for the DAC and its partners: Promoting mixed transition

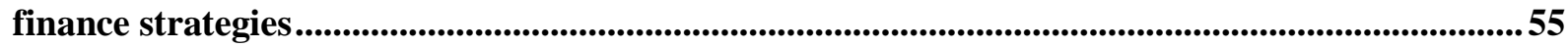

1. The co-operative strategy requires better support to manage debt, build resilience and to

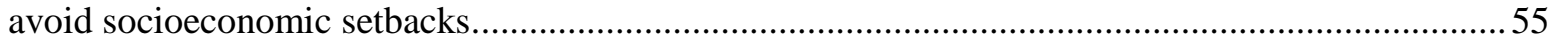

2. The competitive strategy calls for support to build capacities in productive and service

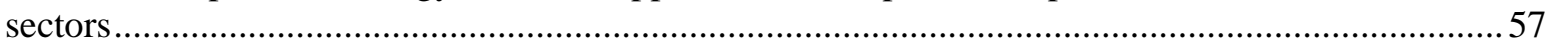

3. Bridging the divide between these strategies calls for a renewed partnership around

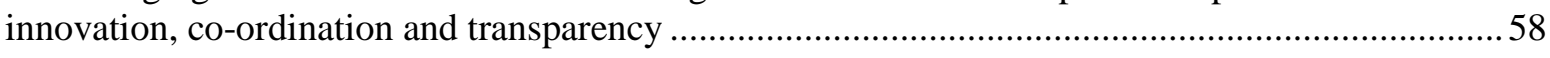




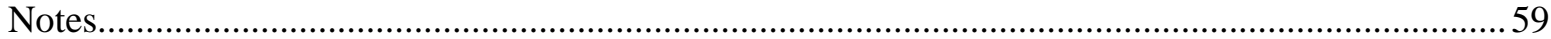

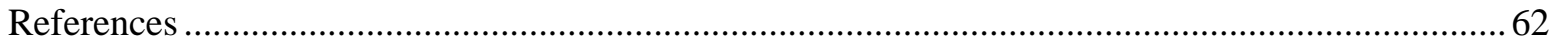

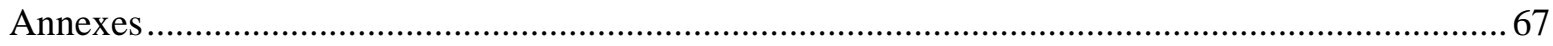

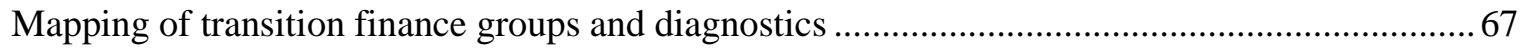

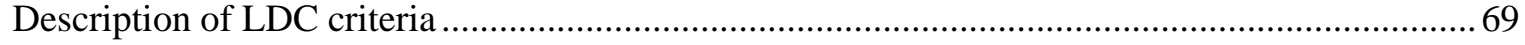




\section{Executive summary}

The Transition Finance pilot carried out with Cabo Verde applies a new (ABCs) approach to "Assess", "Benchmark" and "Counsel" actors within the transition landscape. Cabo Verde's economic transition has been characterised as a "success story". In 2007, the country was the second to graduate from the least developed country (LDC) category, and its progress to achieve the Millennium Development Goals (MDGs) has been exceptional. Yet, graduation from LDC to lower middle-income country (LMIC) has not guaranteed the country long-term sustainable development. On the contrary, the risk of potential setbacks has never been greater as the country enters the "MIC grey area" 2 . An $\mathrm{ABC}$ approach aims to provide a new way forward for better development co-operation and finance in support of national transition finance strategies and the 2030 Agenda.

The first component of the ABC approach, "Assessing", sheds light on the constraints to achieve the Sustainable Development Goals (SDGs). It demonstrates the risk of setbacks if adequate support is not provided.

- The European financial crisis coincided with LDC graduation and deeply impacted Cabo Verde's growth. For the first time, the country's income level declined - by USD 500 (2012-17). The country is now struggling to continue to finance its upward development trajectory as concessional finance is gradually replaced by nonconcessional finance (e.g. transitioning to the "Blend" window of MDBs). New socioeconomic challenges are also emerging. Rising inequalities across islands (rising Gini coefficient), informality (60\% of employment and majority women) and structural SIDS vulnerabilities (Economic Vulnerability Index criteria) all present major constraints.

- An immediate concern, the country is now classified at "high risk" of debt distress (134\% of GNI) by the IMF DSA (2016). Although loans initially tripled following graduation, the debt distress warning is now limiting the country's access to such financing. The question of how to achieve debt sustainability while financing sustainable development needs is particularly important to operationalise the new national strategy. To finance the new national sustainable development strategy (PEDS 2017-21), Cabo Verde is pivoting to new actors, particularly the People's Republic of China (PRC) and the private sector. Yet, a lack of transparency and coordination regarding the terms and conditions of financing has led to a call for renewed partnership.

- Although transition support groups were created to monitor LDC graduation, these have largely been ineffective. The "Groupe d'Appui à la Transition" (GAT), designed as the central co-ordination mechanism, was disbanded shortly after graduation and a growing number of ad hoc assessments by institutional stakeholders contribute to "report fatigue". Although budget support provides an important contribution, the transition period was insufficient. Tied aid is on the rise while funding to key SDG sectors like transportation and education have been phased out too quickly ( $-45 \%$ and $-30 \%$ respectively). Reversals across SDGs are emerging, including health (SDG3), work and economy (SDG8), industry and innovation (SDG9), reducing inequalities (SDG10), oceans (SDG14) and peace and justice (SDG16). A more thorough analysis of SDG financing gaps is crucially needed. 
To overcome these challenges, "Benchmarking" provides a comparative analysis of important shifts in the broader financing mix, identifying best practices among peer countries.

- Relative to other LMICs, Cabo Verde remains highly dependent on ODA despite LDC graduation ( $40 \%$ of external finance) and faces major challenges to attract other official flows (OOF) (e.g. achieving economies of scale and productivity barriers). Other sources of financing, such as foreign direct investment (FDI) and remittances, continue to contribute relatively large shares of external financing. Yet, their sustainable development footprint must be strengthened. Finally, due to relatively high domestic resources (20\% tax-to-GDP ratio), fiscal space is limited, putting pressure on domestic expenditure to ensure debt sustainability and finance the SDG gaps.

- OOF can be mobilised to support strengthening of the private sector enabling environment. Among LMICs, OOF provides a substitute, particularly in commercially viable productive and service sectors, i.e. banking, tourism, business, transportation, and trade policy. However, in Cabo Verde, OOF in support of infrastructure and private sector enabling environments are crucially missing to enhance competitiveness. Several peer countries provide best practices to successfully leverage OOF to strengthen private sector engagement, (e.g. upgrading tourism value chains and sustainable fisheries). In addition, OOF often does not fill the gaps in social sectors as ODA is reduced. ODA in the form of capacity building is currently lacking in these sectors.

- To mobilise sufficient resources, all sources of financing - FDI, remittances, and domestic resources - must contribute to fill SDG financing gaps. Benchmarking reveals a number of opportunities to enhance engagement with the private sector (e.g. strengthening bilateral development finance institution (DFI) engagement through regional integration), scale up blended finance (e.g. tap into capacity building for blue bonds and debt swaps), better harness the diaspora community (e.g. promote financial inclusion and microfinance), and further develop global, regional and local partnerships (e.g. South-South and triangular co-operation). Cabo Verde itself further provides an example for other SIDS seeking to successfully attract OOF in the energy sector.

Finally, the "Counselling" component delivers targeted recommendations for Cabo Verde's development partners to improve support for continued upward transition along the development continuum. In 2017, H.E. Mr. Jose Luis Rocha, Permanent Representative of Cabo Verde to the UN, called upon development partners to adopt a mixed strategy - "co-operative" and "competitive" - to support Cabo Verde's economic transition in line with the 2030 Agenda.

- The co-operative strategy requires better support to manage debt, build resilience and to avoid socioeconomic setbacks. Strengthening support for local institutional capacity building and domestic resource mobilisation will be crucial as ODA reduction is carried out (e.g. health and education) to tackle rising inequalities and ensure long-term sustainable development. Financing criteria among OECD DAC members must integrate economic and environmental vulnerabilities beyond income per capita levels as countries graduate. Strengthened monitoring of commitments to avoid tied aid is particularly important as countries graduate to reduce transaction costs and ensure country ownership. 
- The competitive strategy calls for support to build capacities in productive and service sectors. Cabo Verde's Doing Business ranking remains low (131/190 in 2018) and its competitiveness rank has fallen from 105 to 110 out of 135 countries (2017-18). Furthermore, efforts to promote coherent tax policies will be increasingly important as the country seeks to attract foreign investment (e.g. SEZ, off-shore banking, etc.). Already, Cabo Verde has made progress by recently accepting to join the OECD/G20 Inclusive Framework on Base Erosion and Profit Shifting (BEPS) Project. For Cabo Verde to achieve private sector-led growth and achieve debt sustainability, vulnerabilities as a small island developing state must be addressed. Strengthening the business environment, competition and tax policy and instruments in addition to enhanced support for infrastructure and trade capacities are needed.

- Bridging the divide between these strategies calls for a renewed partnership around innovation, co-ordination and transparency. A fusion of the co-operative and competitive strategies is needed to harness SIDS vulnerabilities as a strength. Addressing climate change requires leveraging Cabo Verde's strengths as a blue economy, including strengthened access to new and innovative instruments and forms of partnerships (e.g. GCF, diaspora bonds, blue bonds, debt swaps, etc.) As countries graduate from the LDC category, there is a need to better co-ordinate the responsibilities among actors and harmonise the approach to transition support among all development partners. 


\section{Assessing: Where does Cabo Verde stand in the transition?}

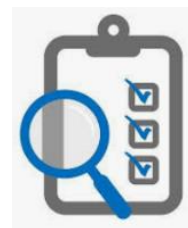

An "Assessment" provides an overview of the shifting transition finance landscape and prospects. Cabo Verde graduated from the LDC category in 2007, coinciding with the global financial crisis. The financial crisis severely limited economic growth (dropping from $+15 \%$ GDP/year 2008 to $-1 \%$ GDP/year 2009) (see Figure 1). Graduation from the LDC category further raised a new set of challenges to finance sustainable development. Countries that graduate from the LDC group are faced with reduction in concessional financing ${ }^{3}$ and withdrawal of preferential trade agreements. ${ }^{4}$

In the case of Cabo Verde, graduation has led to "high risk" of debt distress (reaching over $130 \%$ debt to GNI) ${ }^{5}$, hampering the country's ability to finance crucial SDG investments. In parallel, transition support groups led by development partners have dissipated and individual donors demonstrate a lack of co-ordination. Development finance is not effectively targeting country priorities which further risks development setbacks.

This section provides a diagnostic of the constraints and financing gaps impeding economic transition and achievement of the SDGs in Cabo Verde. It evaluates the support provided by development partners to overcome these limitations and to deliver Cabo Verde's new development strategy.

\section{This section assesses the following areas of Cabo Verde's transition:}

1. Economic constraints: The global financial crisis, coinciding with Cabo Verde's LDC graduation, upset European markets and produced negative spill-over effects in Cabo Verde. The country must overcome binding constraints to the business environment, including structural vulnerabilities as a SIDS;

2. Linking the national strategy to the SDGs: To achieve its 2018 national financing strategy and the 2030 Agenda, Cabo Verde must overcome mounting debt distress while reducing ODA dependency and leveraging private sector development. To continue an upward sustainable development trajectory, the SDG financing gaps must be identified and the new long-term financing strategy must be operationalised.

3. Transition support provided by development partners: Transition support provided by development partners during graduation did not deliver a long-term and systematic approach to prepare the country to efficiently manage shifting financial resources. The mismanagement of the transition has led to a growing gap in support for local institutional capacities, rising levels of tied aid, and a lack of co-ordination with actors beyond the OECD DAC, including the People's Republic of China and private sector actors;

\section{Constraints to economic transition, beyond income, persist after LDC graduation}

LDC graduation coincided with the global financial crisis, driving Cabo Verde into the middle income trap ${ }^{6}$, a constraint magnified by vulnerabilities as a SIDS. Cabo Verde's graduation from the LDC category was largely fuelled by strong European markets which contribute to both remittances and tourism in the country. With the onset of the crisis, the country's income per capita has stagnated and begun to drop off. This, in addition to growing regional inequalities, signals the importance of ensuring that growth is both sustainable and 
inclusive. In addition, Cabo Verde has yet to meet the Economic Vulnerability Indicator (EVI) threshold for LDC graduation, demonstrating the importance of SIDS structural economic and environmental constraints which continue to limit the country's development progress. This section is divided into $i$. assessing the middle income trap, and ii. assessing SIDS vulnerabilities.

\section{i. $\quad$ Cabo Verde must avoid the middle income trap}

The outbreak of the global financial crisis in Europe led to a number of negative spillover effects on economic growth in Cabo Verde. The crisis significantly impacted Cabo Verde's economic performance due to its strong ties to European markets. Figure 1 demonstrates that Cabo Verde's GDP growth is highly correlated with that of EU members (0.62). The EU is Cabo Verde's biggest trading partner (Spain and Portugal). The Escudo (local currency) is tied to the Euro which affected remittance volumes. Remittances from Europe make up more than $80 \%$ of total remittances. (World Bank Group, 2011 $1_{[6]}$ ) Foreign direct investment inflows (FDI) also dropped from $12.67 \%$ of GDP in 2007 to $7.36 \%$ of GDP in 2009, and these have remained low. While private sector credit growth was gaining momentum before the financial crisis, it declined significantly after 2007 and stagnated at zero growth between 2013 and 2016 (IMF, 2016 $\left.{ }_{[7]}\right)$.

Figure 1. Economic growth was severely impacted by the EU financial crisis

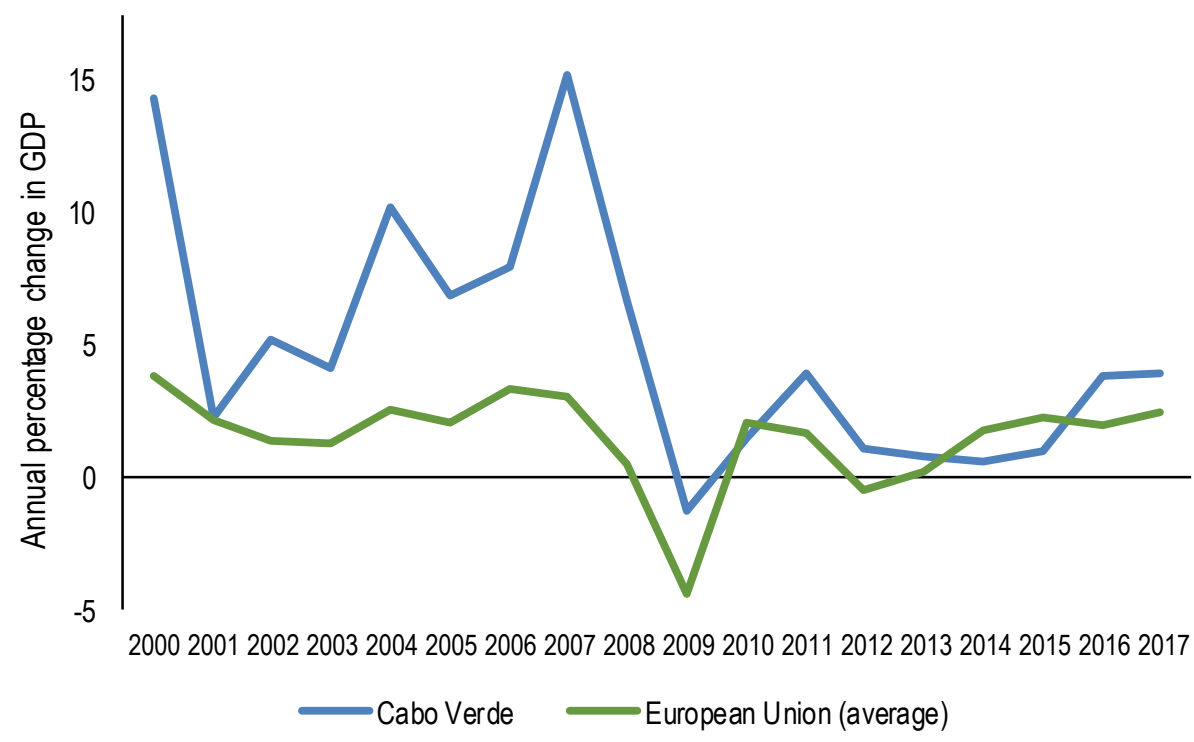

Source: Authors based on World Bank (2018[8]), "World Development Indicators" (WDI), https://datacatalog.worldbank.org/dataset/world-development-indicators

Following the financial crisis and LDC graduation, Cabo Verde's level of development as measured by GNI is declining. Figure 2 reveals that Cabo Verde's GNI per capita grew two-fold from USD 500 per capita to USD 1180 per capita in less than ten years (19821993). From 2002 to 2007, GNI levels again nearly doubled. The growth was supported by good governance, strong development co-operation and booming EU markets. Yet, 11 years after the financial crisis and LDC graduation, Cabo Verde remains in the LMIC group, and for the first time, national income has decreased - from USD 3500 to USD 3000 in only 5 
years. As presented in the following Benchmarking section, continued income growth requires an optimal mix of financing for sustainable development to converge towards the high-income level.

Figure 2. Following graduation, income per capita is declining

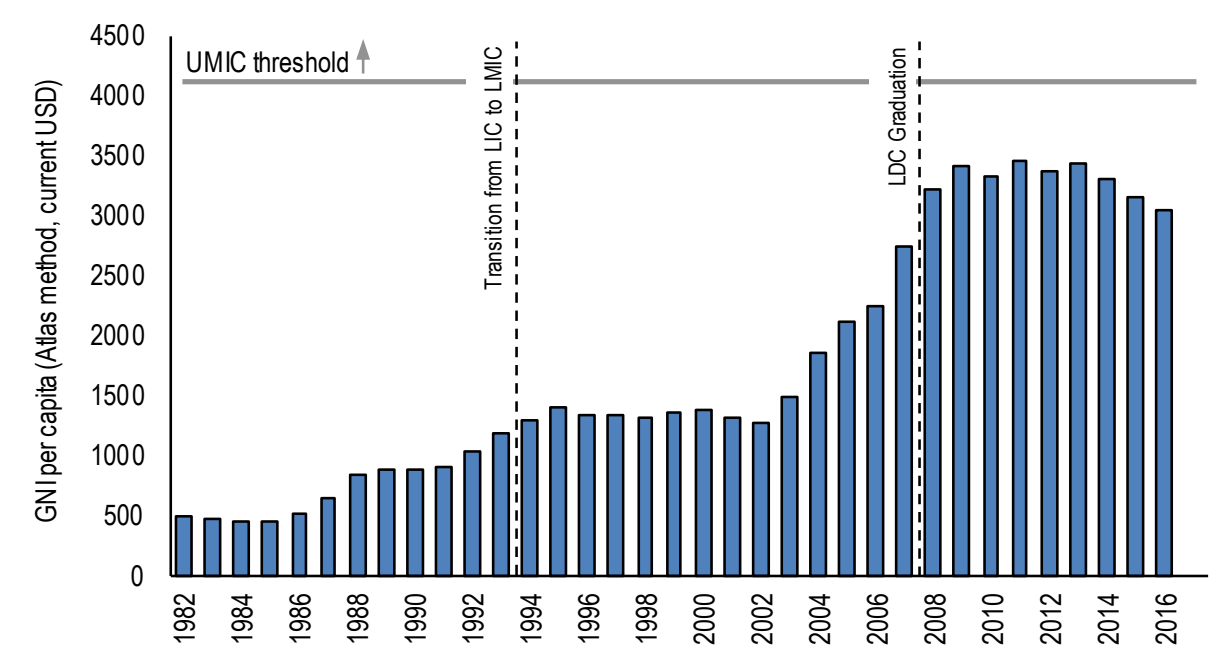

Note: GNI captures the welfare of nationals and is particularly important in the context of small states with high levels of foreign ownership in the economy (e.g. tourism, extractive industry, banking, etc.). Economic growth or GDP levels can be high in these contexts while income to nationals remains low. In 2016 and 2017 , Cabo Verde's GDP was growing at $3.8 \%$.

Source: Authors based on World Bank (2018[8]), World Development Indicators (WDI), https://datacatalog.worldbank.org/dataset/world-development-indicators

\footnotetext{
Human development in Cabo Verde has made great strides, but rising regional inequalities and poverty across islands demonstrate the importance of ensuring that growth is both sustainable and inclusive. Cabo Verde was the second country to graduate from the LDC category in 2007, following Botswana (1994). It has met most of its human development objectives under the MDGs, notably in health and education. The population living below the absolute poverty line of USD 1.90 a day dropped from $16 \%$ in 2001 to $8.1 \%$ in 2007. However, new socioeconomic challenges linked to rising inequalities are emerging. SDG 10 calls for countries to reduce the Gini coefficient measure of societal inequalities. Cabo Verde scores high for middle income countries at 50.1 in 2013, and its score has deteriorated from 2007 (47.2). (World Bank Group, 2007 [9]]), (UNDP, 2013 ${ }_{[10]}$ ) One of the major areas of inequalities is youth unemployment which was estimated at $50.8 \%$ in 2014 . $47.4 \%$ of the population are under 24 years old. (UNECA, 2016 $\left.6_{[11]}\right)$ The Box 0.1 demonstrates the challenge of rising inequalities across islands which threaten development setbacks.
} 
Box 0.1. Growing inequalities and poverty gaps across islands are on the rise

Inequalities between islands are linked to rapid growth in the tourism sector. By 2020, the government predicts that more than one million tourists will visit the archipelago, yet there is no strategy in place to spread the benefits of tourism across islands. The Figure 3 below shows that the most attractive tourist destinations - Boa Vista and Sal - also achieve the highest levels of income per capita. Tourism is concentrated (91\% of tourists) in two islands. Boa Vista accounts for $41 \%$ of night stays while Sal attracts 50\% of night stays. (Netherlands Enterprise Agency, $\left.2017_{[12]}\right)$ Yet, the two islands are the least populated, and the tourism sector does not create forward or backward linkages with the local economy. For example, little farming activity takes place on these islands and transportation connecting hotels with more fertile islands, which could promote local sourcing, remains poor. (World Bank Group, $\left.2013_{[13]}\right)$

Figure 3. Income per capita reflects growing inequalities between islands

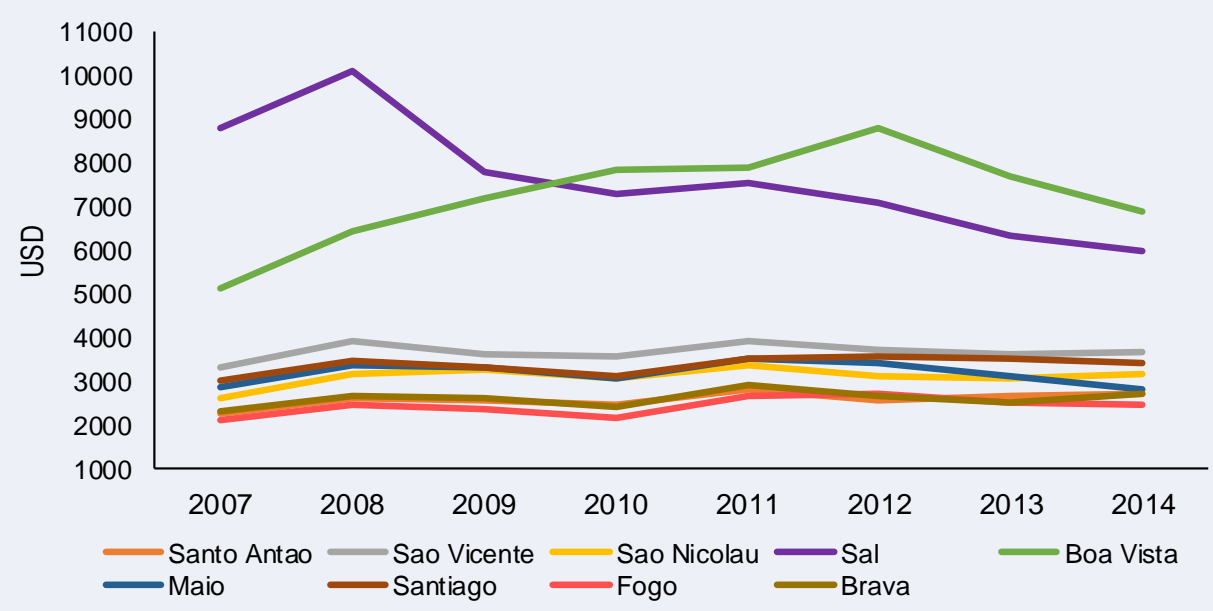

Source: Authors based on (Cabo Verde, 2017-2021 [14])

Tourism also risks exacerbating the urban-rural poverty divide if the benefits are not shared. Although the incidence of poverty is decreasing (-50\% in roughly a decade - 19902011), a large gap between urban (13.2\%) and rural areas (44.3\%) is emerging. (UNECA, 2016 $\left.{ }_{[11]}\right)$ Poverty remains prevalent in some of the most remote islands and rural areas, where more than $72 \%$ of the poor live in rural areas. (World Bank Group, 2013 ${ }_{[13]}$ )The high concentration of tourism in only two islands risks exacerbating regional inequalities (particularly in islands with the largest rural populations - Santiago, Santo Antão, and Fogo) if linkages with the other islands are not created. 


\section{ii. SIDS vulnerabilities further impede transition}

Additional economic and environmental vulnerabilities, beyond income per capita compound the challenges of economic transition. Many of these vulnerabilities are common to SIDS. Special consideration should be given to the Economic Vulnerability Index (EVI) criteria. Although the EVI is not sufficient on its own for LDC classification, the indicator demonstrates economic vulnerabilities and the persistent risk of development setbacks inherent in certain countries. The challenges faced by SIDS are well-known. The challenges presented below are specific to Cabo Verde (such as State Owned Enterprise (SOE) privatisation), yet many are also shared with other SIDS.

Although Cabo Verde graduated from the LDC category, it did not meet the economic vulnerability (EVI) criteria ${ }^{7}$. The Figure 4 below shows that the country met only two out of three LDC criteria established by the UN: i. GNI/cap and ii. human development $\left(\mathrm{HAI}^{8}\right)$ (Description of LDC criteria). The third criteria, the EVI captures many important SIDS vulnerabilities (e.g. population size, remoteness, extreme weather, export concentration, etc.). Cabo Verde's EVI ranking remains above the threshold for LDC EVI criteria (above 35 out of 100) and has stagnated more than a decade following graduation due mainly to agricultural instability and natural disasters. As demonstrated in the 2018 OECD SIDS Report "Making Development Co-operation work for Small Island Developing States", within the LDC group, SIDS struggle to meet the EVI criteria to structural economic vulnerabilities. (OECD, 2018 ${ }_{[15]}$ ) On average, SIDS score 5 percent lower than other LDCs according to the EVI criteria.

Figure 4. Cabo Verde meets only two out of three LDC graduation criteria

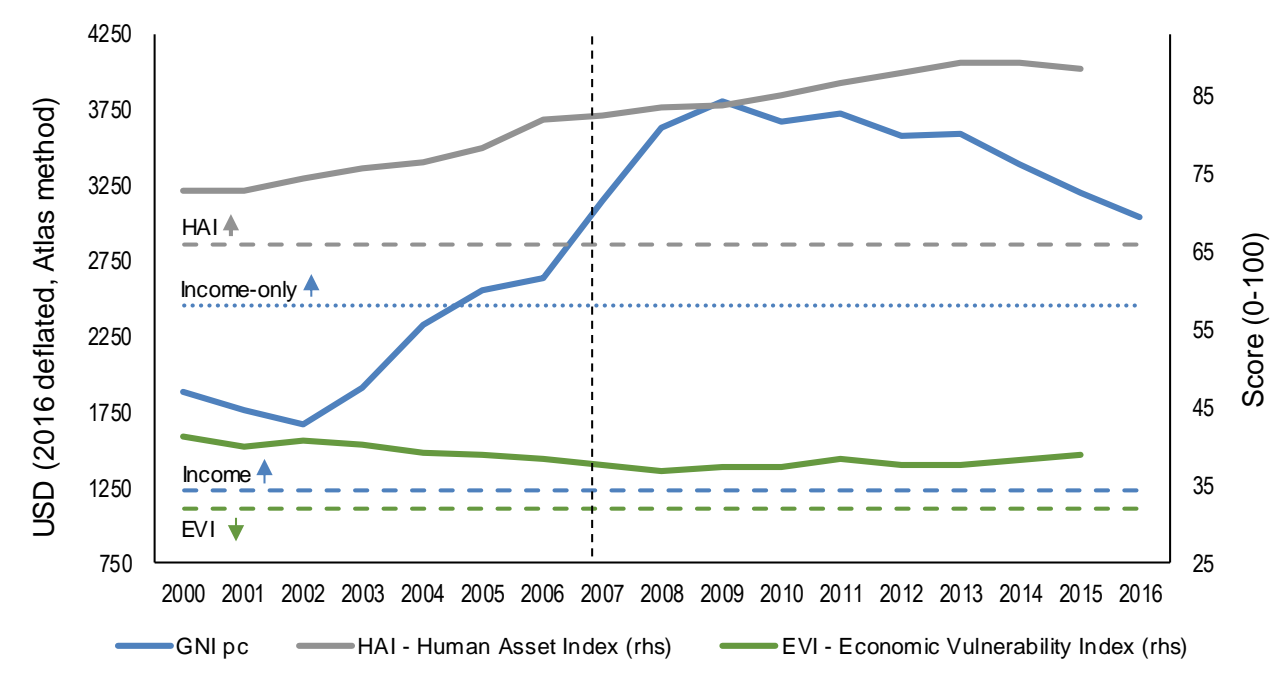

Note: GNI per capita is provided on the left axis; EVI and (Human Asset Index (HAI) scores are presented on the right axis. To graduate on an income only basis requires exceeding the 2460 USD level. To graduate meeting 2 out of 3 criteria, GNI per capita at USD 1230 is required in addition to either HAI at 66 or above or EVI at 32 or below ${ }^{9}$. EVI time series is based on retrospective calculations by FERDI based on updated index methodology in 2015 for the LDC Review by the United Nations.

Source: Authors based on World Bank (2018[8]), "World Development Indicators" (WDI), https://datacatalog.worldbank.org/dataset/world-development-indicators for GNI per capita; Ferdi (2015[16]), “A retrospective Economic Vulnerability Index", http://www.ferdi.fr/en/indicator/retrospective-economicvulnerability-index for EVI; Ferdi $\left(2016_{[17]}\right)$, "Human Assets Index retrospective series: 2016 update",

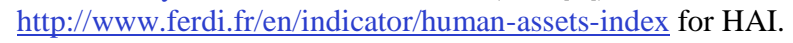


Cabo Verde struggles to achieve economies of scale and competitiveness due to its small market size, labour market inefficiency, and limited financial market development. Figure 5 below shows the World Economic Forum (WEF) World Competitiveness Index ranking of Cabo Verde compared to other sub-Sahara African (SSA) countries. Cabo Verde's score has declined from 105 to 110 out of 137 countries in 201718. (World Economic Forum, 2017 $7_{[18]}$ ) Cabo Verde is less competitive due mainly to its small market size (the largest gap, over 1 point below the SSA average). Limited size means the country cannot produce sufficient volume for its internal consumption needs (e.g. manufacturing). In addition, labour market inefficiency, business sophistication and limited financial market development present areas in which Cabo Verde scores lower than its peers. The privatisation of loss-making State Owned Enterprises (SOEs) represents a key challenge to private sector development and debt sustainability. ${ }^{10}$ The following section on the national financing strategy explores how the new Cabo Verdean government aims to address issues of competitiveness.

Figure 5. Several dimensions of competitiveness are lagging behind

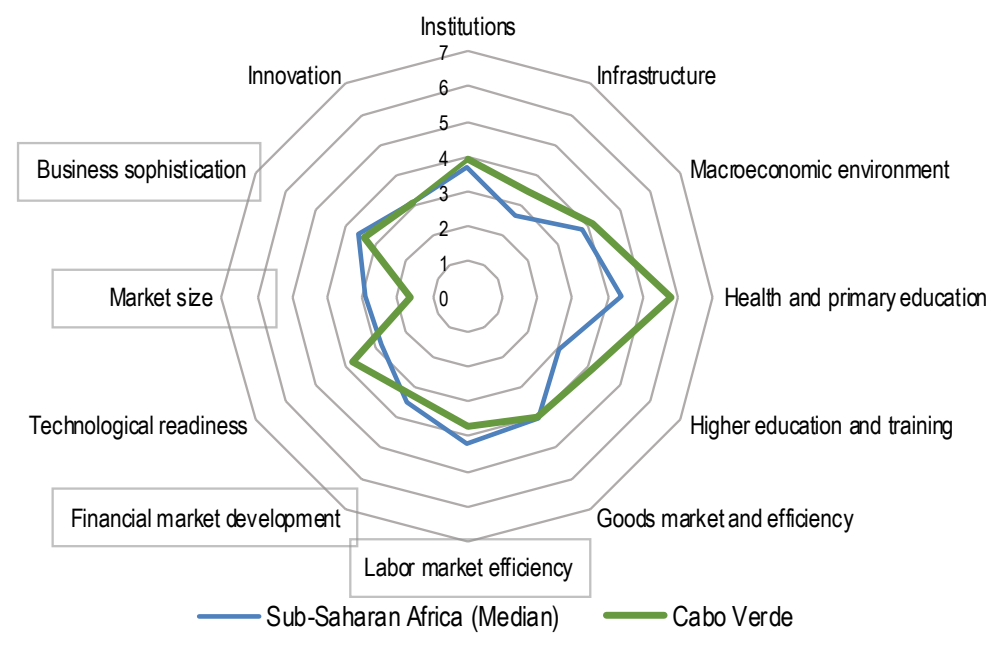

Source: Authors based on World Economic Forum (2017 $[18]$, The Global Competitiveness Report 2017-2018, www.weforum.org/gcr.

While the business enabling environment has improved, import dependency and a narrow export base (fisheries) persist. The country's World Bank Doing Business ranking has improved (from $147 / 190$ in 2008 to $131 / 190$ in 2018). While the country has made significant reforms to enable starting a business and registering property and taxes (e.g. Cabo Verde TradeInvest), access to credit continues to limit the ability of MSMEs to develop (e.g. the minimum threshold for personal loans was raised from 1,000 to 5,000 escudos). (World Bank Group, 2019 ${ }_{[19]}$ ) As demonstrated in Figure 6, Cabo Verde nonetheless struggles to overcome its narrow base for production and diversification. The EU (Portugal and Spain) accounts for more than $70 \%$ of imports to Cabo Verde and receives $85 \%$ of the country's exports. Its export basket contains four main product groups that account for over 80 percent of all export earnings. These include fresh fish, frozen and processed fish, footwear and accessories, apparel and accessories. In 2013, exports of fish and fishery products represented $84 \%$ of total merchandise trade and $4 \%$ of total working population are employed in the fisheries sector. (UNIDO , 2016 $\left.{ }_{[20]}\right)$ 
Figure 6. Cabo Verde must diversify beyond fisheries and upgrade its role in global value chains (total exports 2016)

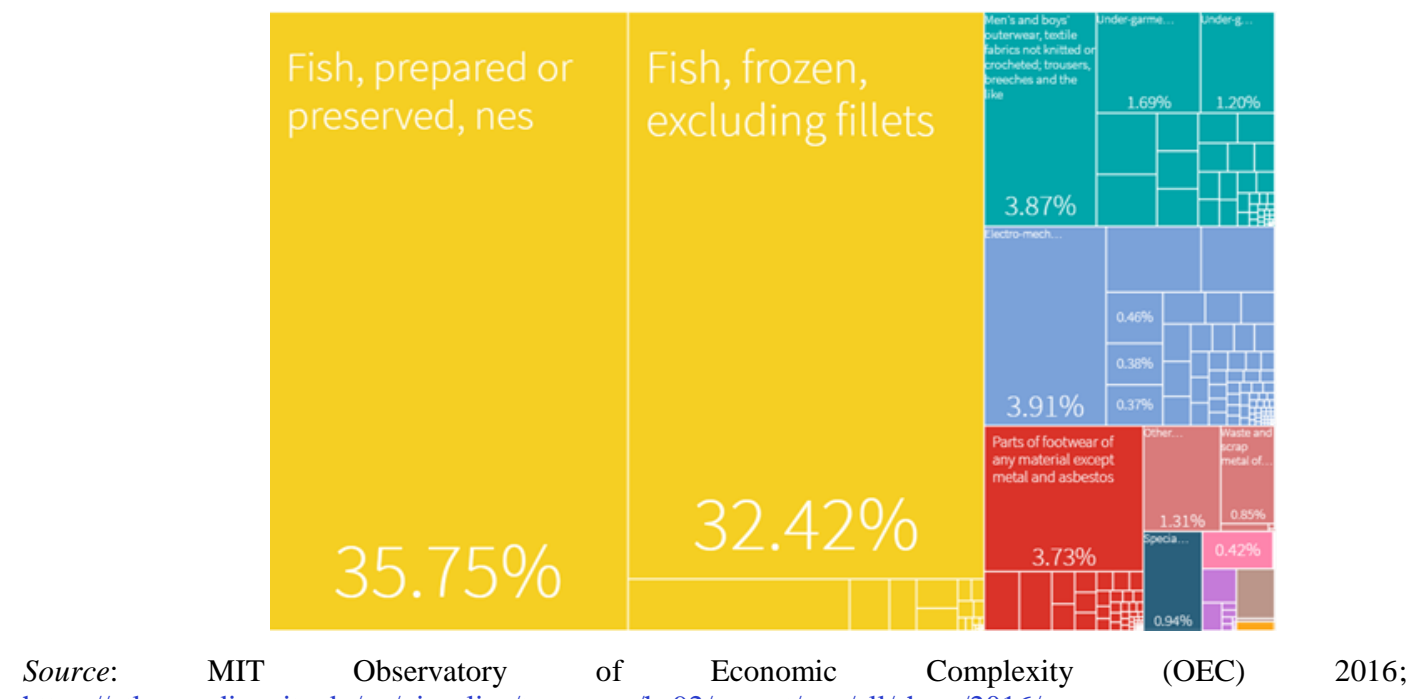

https://atlas.media.mit.edu/en/visualize/tree map/hs92/export/cpv/all/show/2016/.

Cabo Verde faces the challenge of geographic fragmentation which requires substantial infrastructure financing. SIDS face major infrastructure constraints including limited market access, high-energy costs and lack of inter-island transportation. (OECD, 2017 ${ }_{[21]}$ ) Cabo Verde has been referred to as a "fragmented micro-economy". (Enhanced Integrated Framework, $2013_{[22]}$ ) To ship a container from Praia to Lisbon (Portugal) is less expensive than to ship the same container from Praia to Mindelo (inter-island). Sustained investment to improve interisland transportation is critical to production and exports, including "internal" exports to key consumer markets such as the big cities and tourism islands. Each island requires separate infrastructure which results in multiplier effects on costs. Basics like energy, water, transportation and telecoms have a cost above the world average and must be duplicated nine times across each inhabited island. Cabo Verde's infrastructure is ranked is 94 out of 138 countries in the WEF's Global Competitiveness Index. The low ranking is due to in part to costly domestic and international transportation which have historically been handicaps to growth and development. Moreover, the national logistic system must be strengthened as the country lacks an interisland ferry and certain islands lack alternatives, including airports.

Water scarcity also presents a growing and costly challenge. Cabo Verde has the most expensive water tariffs in Africa at over USD 3/m3. (Kanwischer, 2012 [23]) Low water consumption per capita does not meet the recommended global standard (Growth and Poverty Reducing Reduction Strategy III, 2012-2016, draft). Water shortages, long-term drought, and poor soil create additional barriers for many of the Cabo Verde islands. Indeed, the scarcity of water resources has forced the country to rely on desalination for about 85 percent of water production. (Netherlands Enterprise Agency, 2017 $[12]$ ), (Kanwischer, 2012[23]) The cost of the energy-intensive desalination process is particularly high due to its dependence on power generation. With barely 10 percent of its surface as arable land and limited mineral resources, the country is also at a disadvantage for agricultural production.

Finally, Cabo Verde is particularly vulnerable to the impact of extreme weather events. Extreme weather events have a greater impact on SIDS due to their small scale. There is a need to ensure disaster and resilience financing is provided to avoid the risk of development 
reversals. As demonstrated in the Figure 7 below, droughts, volcanic activity, flooding and other forms of extreme weather have economic and social costs limit Cabo Verde's capacity to finance sustainable development. (EM-DAT , 2018 $[24])^{11}$ Climate change is expected to worsen natural hazards including tropical storms and hurricane activity. Cabo Verde faces significant challenges associated with climate change - especially rising sea levels and the greater frequency of severe weather patterns - which could increase the likelihood and severity of droughts and flooding.

Figure 7. Extreme weather events are costly and threaten development setbacks

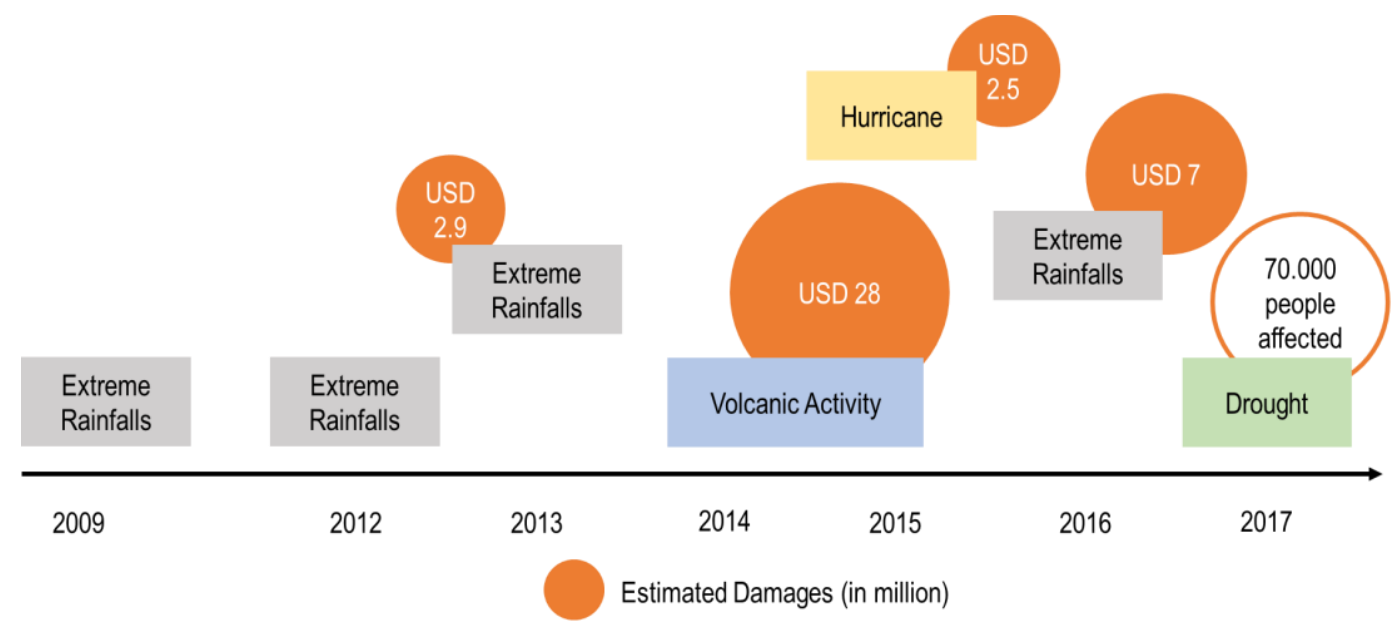

Note: The timeline is not fully comprehensive. Only extreme weather events captured in the source are represented.

Source: Authors based on World Bank (2018[25]),Cabo Verde Disaster Risk Management Development Policy Credit and Loan with Cat DDO (P160628) - Program Information Document (PID), http://documents.worldbank.org/curated/en/125621531480106694/pdf/Concept-Program-InformationDocument-PID-Cabo-Verde-Disaster-Risk-Management-Development-Policy-Credit-and-Loan-with-CatDDO-P160628.pdf.

\section{Addressing SDG financing needls and gaps remains challenging}

This section assesses the new Sustainable Development Strategic Plan, 2017-21 (PEDS) and how it seeks to finance the implementation of the 2030 Agenda. (Cabo Verde, 2017-2021 ${ }_{\text {[14] }}$ ) The PEDS breaks with previous national development strategies. Previous strategies were designed by UNDP and the Transition Fund, etc. This is the first national development strategy that is entirely driven by the Cabo Verde government. The section examines i) how the PEDS addresses SDG financing needs and gaps, and ii) the challenges to finance the strategy, particularly debt sustainability.

\section{i. $\quad$ The Cabo Verdean national financing strategy must link to SDG financing needs} and gaps

Cabo Verde's national financing strategy (2017-21) represents a crucial paradigm shift in the countries' transition to reduce ODA and achieve private sector-led growth. A new administration took office in April 2016. The administration launched the Sustainable Development Strategic Plan (PEDS) 2017-21 which translates the government's priorities in programmatic and operational terms. It prioritises domestic resource mobilisation to finance 
(89\%) of the development strategy. It further calls to achieve greater self-sustained financing, shifting from ODA dependency to the mobilisation of other sources of financing.

However, the strategy does not sufficiently link resource mobilisation to the 2030 Agenda or Addis Ababa Action Agenda (AAAA). The AAAA provides a comprehensive financing framework for the SDGs, yet the framework must be translated in to a coherent national strategy to mobilise and align all sources of financing (para 9). (United Nations, 2015 $5_{[4]}$ ) The Box 0.2 below highlights the emerging SDG financing gaps and needs in Cabo Verde. The PEDS lacks a mapping of SDG financing needs and gaps. Although the PEDS recognises that certain financing needs, for example, part of the infrastructure component, will require concessional loans, it does not provide a strategy to fill the financing gap across the SDGs, as concessional finance is phased out. The respective roles of different actors must be identified to ensure that the country is less dependent on ODA, while strengthening the mobilisation of internal resources and the attraction of private investment.

\section{Box 0.2. Cabo Verde's national financing strategy and the 2030 Agenda}

The new Sustainable Development Strategic Plan 2017-21 (PEDS) aims to transform Cabo Verde into a services and transport hub through increased private sector investments in key economic sectors. It seeks to promote value added beyond tourism by developing platforms in the areas of digital innovation, investment, finance, air support, maritime and commerce and industry. In addition, the country completed its first Voluntary National Review on the implementation of the SDGs in 2018. (Cabo Verde, 2018 ${ }_{[26]}$ ) Yet, these documents reveal the importance of ensuring the country has an adequate compass to link financing, the national development strategy and achievement of the 2030 Agenda.

How is Cabo Verde advancing to meet the SDGs?

Cabo Verde ranks $5^{\text {th }}$ out of 51 African countries, demonstrating strong progress to achieve

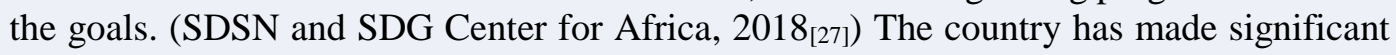
progress (Figure 8 indicated by upward arrows) to promote gender equality (SDG5), ensure clean energy (SDG7), consumption and production (SDG12), and to tackle climate change (SDG13).

However, progress across the SDGs is uneven and that certain goals risk reversal of progress (Figure 8 indicated by a downward arrow) including health (SDG3), work and economy (SDG8), industry and innovation (SDG9), reducing inequalities (SDG10), oceans (SDG14) and peace and justice (SDG16). In addition, the country has completed less than $50 \%$ of the progress needed to end hunger (SDG2), improve industry, innovation and infrastructure (SDG9), reduce inequalities (SDG10), and preserve life below water (SDG14).

Without a mapping of SDG financing needs according to progress, co-ordination of the different actors to fill emerging financing and capacity gaps will be challenging. For example, ODA in support of health and education has decreased rapidly following graduation, while progress to achieve SDG3 has reversed and SDG4 has begun to stagnate. Moreover, the share of domestic expenditure in these sectors is also decreasing. These challenges are explored further in the section on Benchmarking SDG financing gaps. 
Figure 8. SDG indicators reveal certain areas that must reverse course

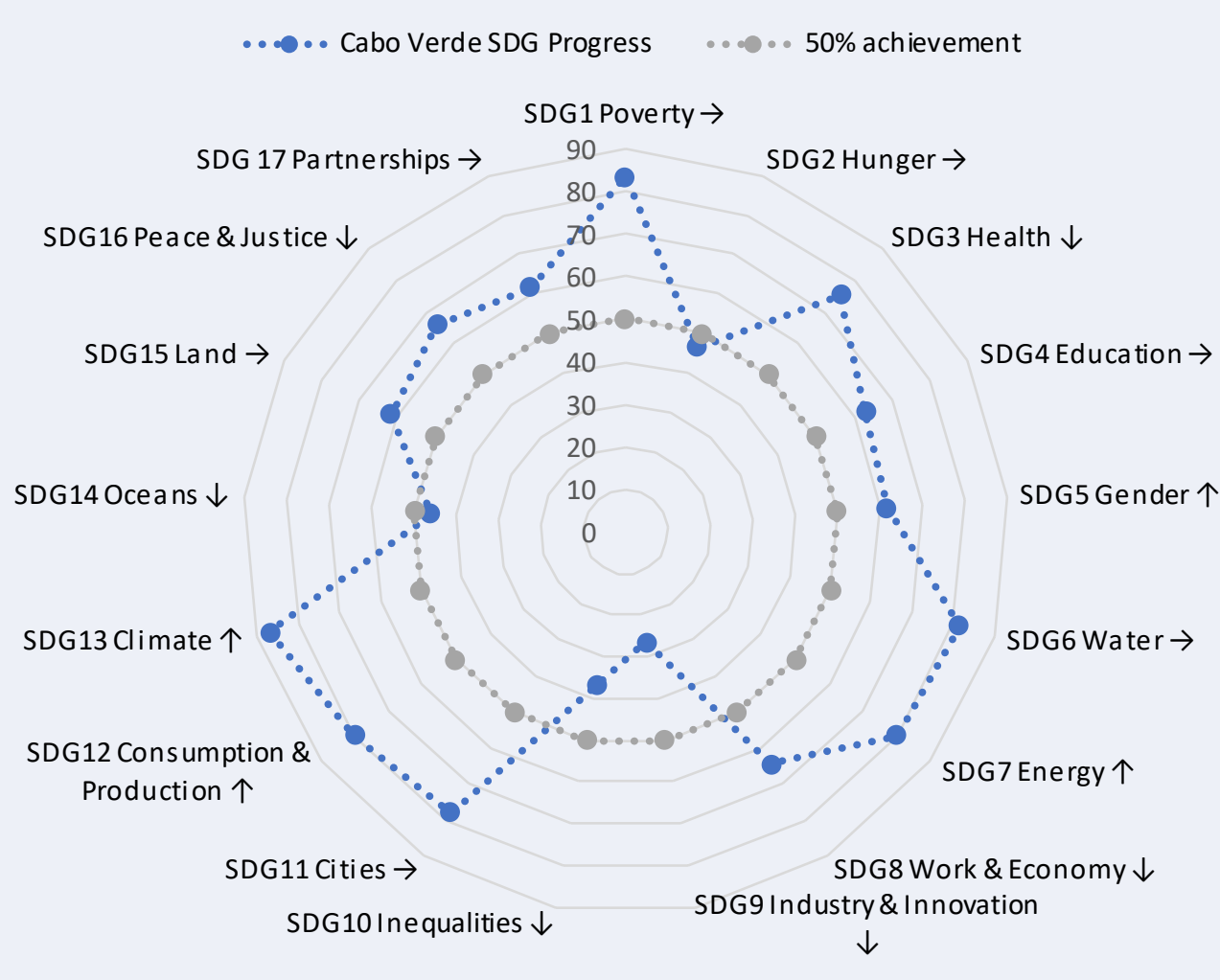

Note: The data is based on the methodology introduced by the UN SDSN SDG index. The index is intended to provide a percentage of achievement and represents the distance (from 100) remaining to achieve the goal. The arrows denote acceleration toward, maintained progress, or reversal from the goals (according to data availability (2000-2018).

Source: (SDSN and SDG Center for Africa, 2018 $\left.{ }_{[27]}\right)$

As ODA is reduced, how can SDG financing gaps be avoided?

The resource mobilisation strategy formulated in the PEDS does not link resources to the SDG targets and indicators framework. Instead, the PEDS outlines the following set of resources to be mobilised as a substitute for ODA:

- Climate finance: Green Climate Fund (Green Climate Fund - GCF) and the Global Fund for Environment (Global Environment Fund - GEF), other innovative facilities such as Blue Bonds, Debt Swaps/ capacity building to access these instruments,

- Development finance: South-South and triangular co-operation,

- DRM: Tax revenue through enlargement of the tax base, the reduction of informality, the modernisation of administrative machinery,

- Blended finance: PPPs through Cape Verde TradeInvest, and the Chambers Trade and Tourism for investment promotion,

- Remittances: Remittances for investment rather than consumption (through mutual funds, tax incentives for financial savings, facilitation of access to housing). 


\section{ii. Debt sustainability presents a key challenge to finance sustainable development}

Debt levels are now reaching a critical threshold due to SOE privatisation and nonconcessional public lending. ${ }^{12}$ External debt increased substantially after LDC graduation. In 2016, Cabo Verde was classified at "high risk" of debt distress for the first time by the IMF. Figure 9 shows that debt reached 129 (134) percent of GDP (GNI). Debt levels of public enterprises including Cabo Verde Airlines and social housing company IFH are close to $20 \%$ of GDP. ${ }^{13}$ Figure 10 demonstrates that private debt on commercial terms is the fastest growing source of external debt, increasing seven-fold since LDC graduation. It further shows that external multilateral debt provided on non-concessional terms represents the second fastest growing source. Bilateral lenders provide all financing on concessional terms. The largest share of the total debt composition (45\%) is provided by multilateral actors. The following section discusses the rise of non-concessional multilateral finance due to access to new "Blend" financing windows by MDBs.

\section{Figure 9. Government debt increased quickly following LDC graduation}

General government debt over time

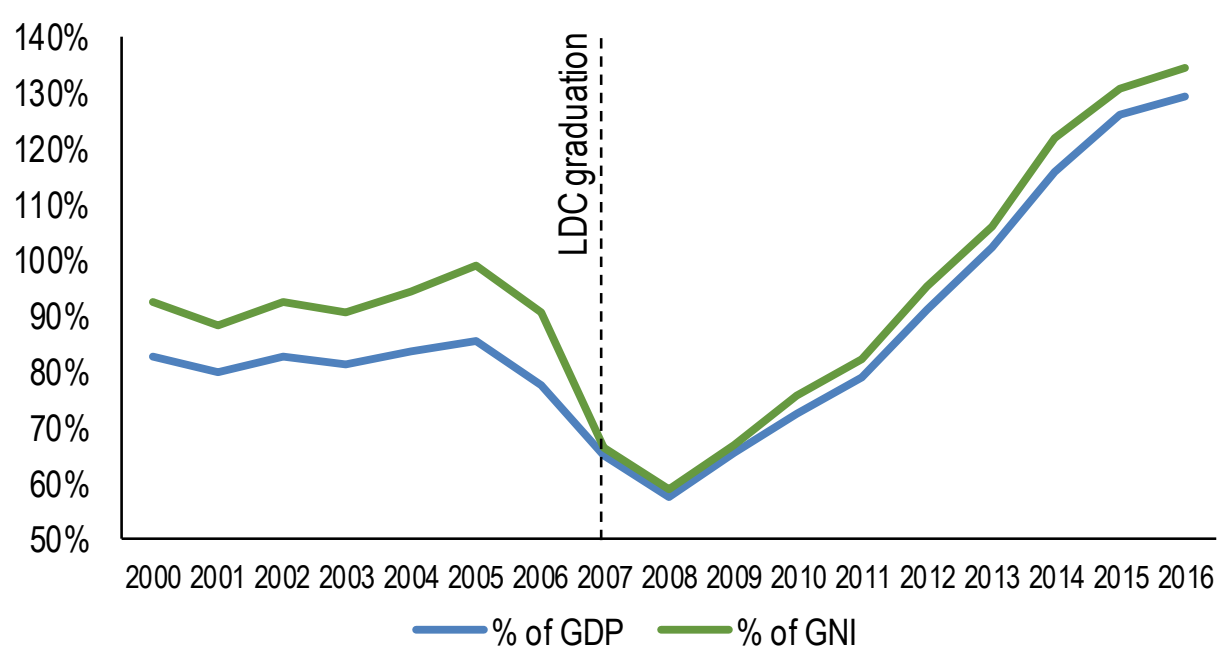

Note: Debt as percentage of GNI is calculated by the authors based on the data sources stated below. Source: Authors based on World Bank (2018[8]), World Development Indicators for GNI; IMF (IMF, 2018[28]), World Economic Outlook, https://www.imf.org/external/pubs/ft/weo/2018/01/weodata/index.aspx for government debt and GDP. 
Figure 10. External private debt is also growing fast while multilateral organisations represent the greatest share of total external debt

Growth rate of debtby provider

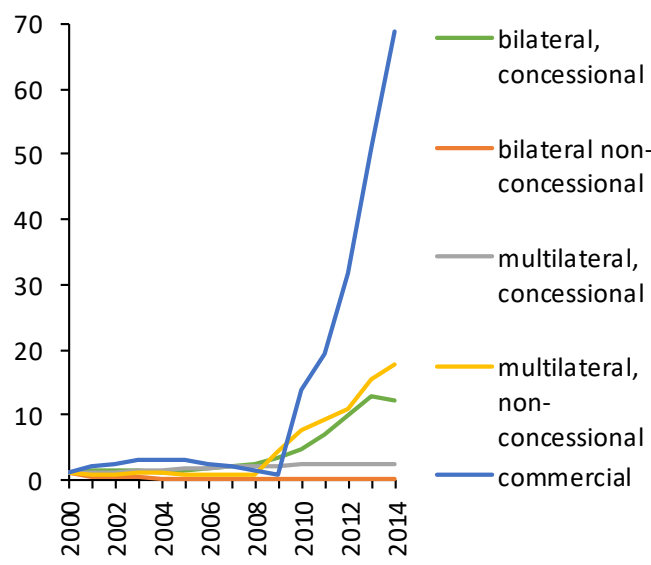

Composition of external debt in 2017

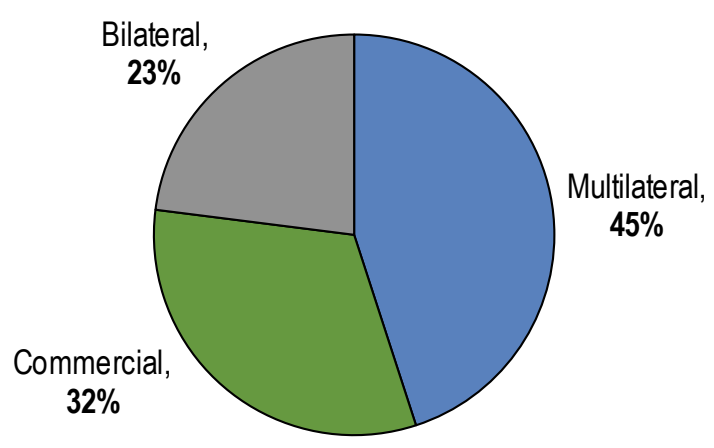

Note: Volumes in the lhs graph are indexed at year $2000(2000=1)$.

Source: Author's based IMF (2018[29]), Staff Report for the 2018 Article IV Consultation - Debt Sustainability Analysis, https://www.imf.org/external/pubs/ft/dsa/pdf/2018/dsacr18104.pdf

The 2016 IMF debt sustainability analysis classified Cabo Verde at "high risk" of debt distress and has resulted in limiting access to certain sources of external debt financing. Following the IMF debt distress classification, external debt, and particularly concessional loans are declining, while grants remain stable. The PEDS 2017-21 highlights that loans have decreased from 21.5 million escudos in 2013 to 5.8 million escudos in 2016. The debt sustainability of the country has been taken into account by lenders wishing to demonstrate financial prudence. (Cabo Verde, 2017-2021 ${ }_{[14]}$ ) Achieving debt sustainability cannot be achieved without adequate investments in key sectors. The question of how to attract the kind of investment required to increase government resources and reduce debt distress remains unanswered.

Achievement of the national development strategy will require ensuring debt sustainability of financing from new actors. To ensure development progress, Cabo Verde will require significant amounts of debt to finance key infrastructure - airports, ports, roads and other utilities - as well as other productive and service sectors to increase competitiveness. (Netherlands Enterprise Agency, 2017 [12] $)$ However, not all actors which provide these sources of financing have integrated the IMF's debt distress warning into lending practices. Different actors are playing by different rules. The section below raises the question of transparency of debt financing. For example, the People's Republic of China is extending loans as part of the "Belt and Road" Initiative. However, the terms and conditions of financing are opaque. Looking ahead, ensuring the predictability of financing will be crucial. The next section further explores what role development partners play to strengthen debt sustainability during LDC graduation in Cabo Verde. 


\section{Support for LDC graduation and transition was insufficient}

Given challenges and constraints presented above, the following section assesses the exante and ex-post support provided to Cabo Verde in the context of LDC graduation. The section examines how development co-operation and finance shifted following graduation, particularly in regard to the following key areas:

i. Transition support groups: What role have transition support groups played? (eg to ensure a "smooth transition")

ii. Development partners: Which partners are phasing in/out? (e.g. investors beyond the DAC)

iii. Terms and conditions: How have the terms and conditions of support changed? (e.g. Untying Aid Recommendation for LDCs and Highly Indebted Poor Countries)

iv. Sectoral targeting: How has the sectoral targeting of support changed? (e.g. social vs productive)

\section{i. $\quad$ Transition support groups lost steam following LDC graduation}

Several transition support groups were created to co-ordinate and monitor transition finance prior to LDC graduation. In 2005, the Budget Support Group (BSG) led by the Government of Cabo Verde, bilateral, and multilateral development partners was created to align and harmonise support around the country's Growth and Poverty Reduction Strategy. ${ }^{14}$ In addition, in 2006, Cape Verde created a consultative mechanism for transition support entitled, the "Groupe d'Appui à la Transition" (GAT) to support graduation from the LDC category. ${ }^{15}$ (GAT, 2007 $[30]$ ) These groups played a role in establishing the One Programme Cabo Verde, 2008-2011, under which the UN co-ordinated the implementation of a Transition Fund (USD 2.7 million per year) and the country's development strategy post-LDC graduation.

Before graduation, transition support groups helped Cabo Verde to access preferential trade agreements and to develop trade development strategies. Aid for Trade and preferential trade agreements have contributed to buffer against shocks and mobilise resources post-LDC graduation. The GAT supported Cabo Verde pre-graduation in accessing the Enhanced Integrated Framework (EIF) ${ }^{16}$ (i.e. aid for trade). (Enhanced Integrated Framework, $2013_{[22]}$ The country completed its accession to the WTO in 2008. The groups further helped Cabo Verde to successfully negotiate extended access to the EU's "Everything but Arms" (duty and quota free) programme, EU Special Partnership Agreement and EU GSP+. As a result, more than $90 \%$ of total Cabo Verdean exports to the EU benefit from the preferential GSP+ duties. (European Commission, 2018 ${ }_{[31]}$ ) Cabo Verde further benefits from the United States of America's African Growth Opportunity Act. As shown in Figure 11, the country's trade flows and exports demonstrated resilience to the financial crisis. The section below on "Benchmarking financing gaps" examines support needed for long-term financing and trade capacities. 
Figure 11. Cabo Verde's trade flows remained relatively stable after the outbreak of the financial crisis

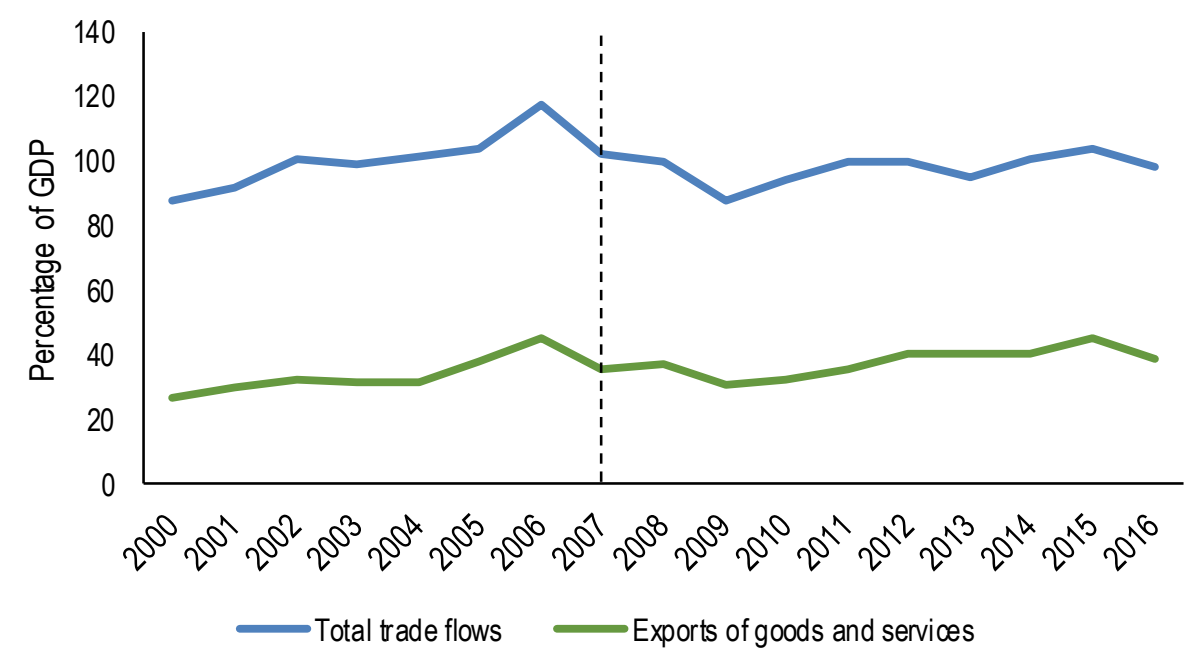

Note: The dashed line at 2007 indicates Cabo Verde's LDC graduation and the outbreak of the financial crisis. Source: Authors based on World Bank (2018 $8_{[8]}$ ), World Development Indicators (WDI), https://datacatalog.worldbank.org/dataset/world-development-indicators.

With the "small states exception", Cabo Verde was further able to access concessional and non-concessional finance from several multilateral actors. The predictability and gradual phase out of concessional finance provided by MDBs was strengthened by the small states exception. The exception recognises the unique economic vulnerabilities of small islands and thus provides exceptional access to concessional finance beyond the income per capita threshold. The "blend" window of several Multilateral Development Banks (MDBs), including the World Bank and the African Development Bank (AfDB), enables small states to access new forms of non-concessional financing. Total non-concessional or OOF levels have increased from USD 7.11 million before LDC graduation (2000-2007 average) to USD 279 million post-graduation (2008-2016 average). Figure 12 shows that the AfDB provides the majority share of OOF to Cabo Verde (73\%) while IBRD and OPEC provide (22.5\% and $4.5 \%$ respectively). OOF financing is provided mainly in the form of budget support as well as to support energy projects. In 2013, exceptional OOF was provided for communications and transportation/storage projects. MDBs providing OOF increasingly focus these funds to finance private sector-led growth. ${ }^{17}$ 
Figure 12. Small state exceptions allow Cabo Verde access to both concessional and nonconcessional multilateral finance

Sectoral allocation of OOF commitments 2009-2015 (lhs) and disbursements by provider since 2009 (rhs)
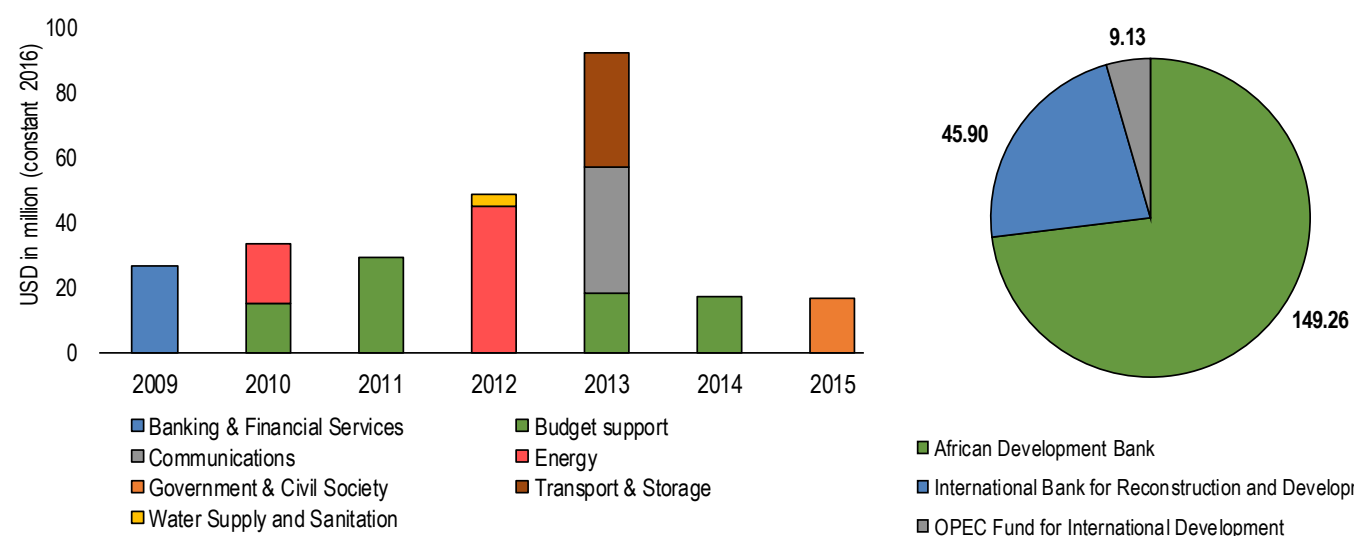

$\square$ African Development Bank

$\square$ International Bank for Reconstruction and Development

$\square$ OPEC Fund for International Development

Source: OECD (2018[32]), Creditor Reporting System, https://stats.oecd.org/Index.aspx?DataSetCode=crs1.

Following graduation, transition support groups have demonstrated a crucial lack of coordination and demonstrate the need for a revitalised partnership for LDC transition. Following LDC graduation, the production of reports and assessments by over 7 different agencies has contributed to some degree of report fatigue in the country. The vast range of recommendations provided by both bilateral and multilateral partners complicate implementation (see Mapping of transition finance groups). Assessments are often carried out on an ad-hoc basis. Without a central co-ordination mechanism, transition support groups have lost momentum and lack a clear strategy to align support for the country's national financing for sustainable development strategy. Box 0.3 provides an overview of international commitments to support LDC graduation. The Istanbul Programme of Action (IPoA) aims to enable over 20 additional countries to graduate by 2020 , demonstrating the need for a revitalised partnership in support of LDC graduation and transition. 


\section{Box 0.3. A revitalised partnership is needed in support LDC graduation and transition}

Although Cabo Verde benefited from transition support groups (e.g. GAT and BSG), these faced challenges to ensure adequate co-ordination of development partners over the longterm. International commitments on targeted transition support during and after LDC graduation must be improved.

Concrete and targeted support during and after LDC graduation is increasingly important to achieve the Istanbul Programme of Action (IPoA) objective of enabling half of the 47 LDCs to meet the criteria for graduation by 2020 . Only 5 countries have graduated from the LDC category to date (Botswana 1994, Cabo Verde 2007, Maldives 2011, Samoa 2014 and Equatorial Guinea 2017). In 2015, 14 LDCs met at least one criterion for graduation, while Vanuatu and Angola are scheduled to graduate from the LDC category. (UNOHRLLS, 2017 $\left.{ }_{[33]}\right)$ Partnership and co-ordination to implement commitments for LDC graduation must integrate post-graduation support as more countries graduate. Principles to guide LDC transition support following graduation are provided below:

- $\quad$ LDC support should be phased out in a "gradual and predictable" manner.

- $\quad$ LDC preferential market access should be extended for several years following graduation.

- Development partners should target support for national transition strategies.

- Development partners should take into account LDC indicators such as economic and environmental vulnerability in ODA allocation criteria.

ii. New actors are phasing in while a few traditional providers are phasing out.

A small group of mainly bilateral actors contributed to increasing total volume of ODA post-graduation $(+7 \%$ on average per year since 2008$)$. Figure 13 shows that the annual average ODA increase post-graduation was due mainly to exceptional financing by Portugal and Japan. Portugal represents 40 percent of total ODA to Cabo Verde between 2008 and 2016. The second largest increase in ODA was provided by Japan related to strengthening water supply systems and desalination plants (USD 31.9 million on average per year in 2008-16). In 2016 total ODA commitments to Cabo Verde reached USD 158.6 million. 
Figure 13. ODA provided by a smaller group of DAC members increased following LDC graduation

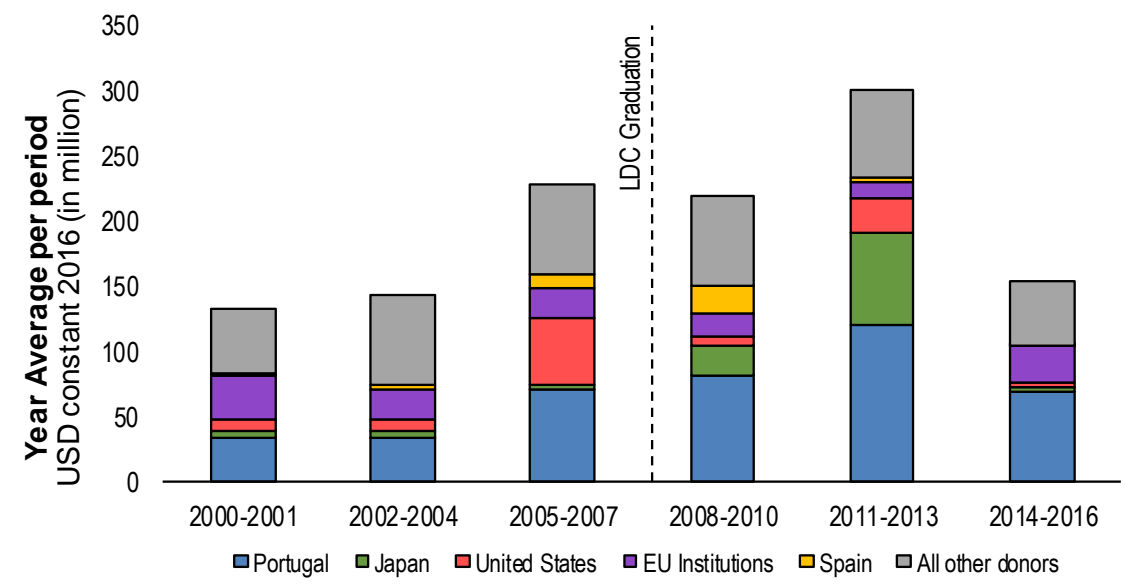

Note: The volume per time interval represents the yearly average within the respective interval. That is, flows are summed up per time interval and then divided by the number of years.

Source: Authors based on OECD (2018 $[32])$ Creditor Reporting System, https://stats.oecd.org/Index.aspx? DataSetCode=crs1.

However, several traditional bilateral donors are phasing out support following graduation. Figure 14 reveals that the United States, Netherlands and the European Union recorded the largest average decreases in ODA post-graduation. The US Millennium Challenge Corporation (MCC) programme is one of the main drivers of the phase out. The first five-year MCC phase amounting to USD 110 million started in 2005, and included several infrastructure projects and promotion of agricultural activities. The second MCC programme ended in 2017. It focussed on land management as well as water and sanitation projects and comprised a volume of USD 65.6 million. The MCC has not yet renewed its programme in Cabo Verde. In addition, support provided by the EU has decreased following graduation from USD 13.3 million 2000-07 to USD 9.7 million on average 2008-16. 
Figure 14. Actors beyond the DAC are increasing support while several traditional donors are gradually phasing out

Absolute difference in annual average pre/post LDC graduation

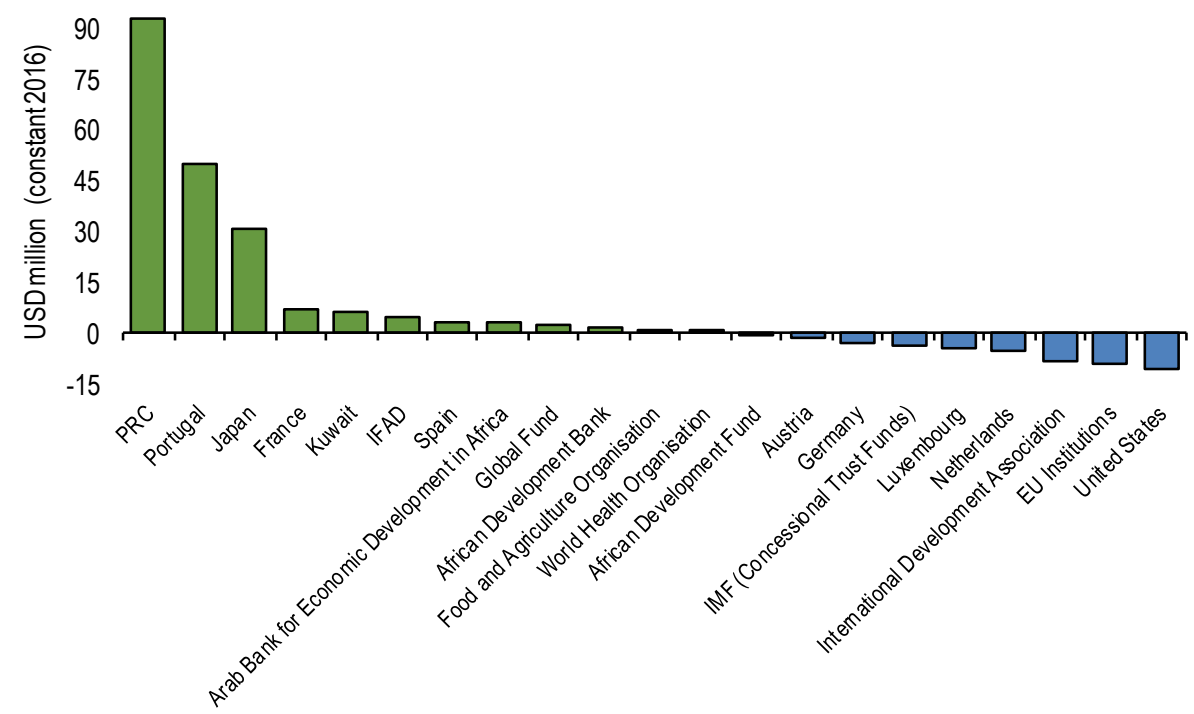

Note: The changes shown are the differences by donor in the average ODA provided to Cabo Verde per year before graduation (2000-2007) relative to after LDC graduation (2008-2016). Data from AidData was utilised to calculate the average annual change for the PRC.

Source: Authors based on OECD (2018 $\left.{ }_{[32]}\right)$ Creditor Reporting System, https://stats.oecd.org/Index.aspx?DataSetCode=crs1 and Authors based on AidData's Global Chinese Official Finance Dataset, https://www.aiddata.org/data/chinese-global-official-finance-dataset, (Dreher et al. (2017[34])); John Hopkins SAIS China-Africa Research Initiative (2018[35]), Chinese Loans to African Governments, http://www.sais-cari.org/data-chinese-loans-and-aid-to-africa.

Moreover, Cabo Verde is seeking investment from the People's Republic of China, particularly for social infrastructure. Figure 14 further shows that financing provided by the PRC has seen the largest increase (USD 93 million). The new financing provided by the PRC targets a wide range of social infrastructure-related areas, including the construction of rural schools and a national stadium as well as an electronic governance project in schools, public institutions, and hospitals. (Madeira, 2017 $[36]$ With the phasing out of certain traditional providers, Cabo Verde has intensified its relationship with PRC and is promoting the creation of a Special Economic Zone to promote the country's maritime economy. The relationship aims to transform Cabo Verde into a high value-added services platform.

The sustainable development contribution of certain projects raise concerns of a "hidden agenda". The field mission conducted in preparation for the pilot study revealed reservations from several members of the Budget Support Group in regard to certain dimensions of new projects. Notably, as an extension of PRC's "One Belt, One Road" initiative, the Macau Legend Development Ltd (Macau Legend) has begun constructing a USD 250 million casino complex on Santiago Island which does not appear in current data. In addition, a memorandum of understanding was signed between Cabo Verde and PRC to a Sino-Atlantic Bank, or credit institution to support the financial sector in Cabo Verde. (Madeira, 2017 ${ }_{[36]}$ ) 
A lack of transparency in regard to public and private debt financing risk further exacerbating debt distress. As noted previously, the PRC was a member of the initial transition support group or GAT established in 2006. However, the group was disbanded soon after. Today, transparency of information on debt financing remains a major challenge and is needed in order to assess the effectiveness of support. According to a recent study, Cabo Verde owes $1 \%$ of its external government debt to the PRC. (Jubilee Debt Campaign, 2018 ${ }_{[37]}$ ) Yet, only 4 years of data on PRC development finance are publicly available from Aiddata and 7 data points are available from SAIS CARI (Johns Hopkins University). In addition, 32\% of Cabo Verde's external debt is owed to private sector actors and represents the fasting growing source of external debt financing (see following section). However, little information about the terms and conditions of private financing is made publicly available.

\section{i. Although ODA increased following graduation, the terms and conditions of support have tightened}

Financing provided by the OECD DAC members shifted quickly from grants to concessional loans (tripling on average post-graduation). As highlighted in Figure 15, average loans per year have increased from an USD 41.9 million before graduation (2000-07) to USD 128.3 million post-graduation (2008-16). Bilateral actors provide the largest share of loans. Portugal provided $51.5 \%$ of loans on concessional terms following LDC graduation. The OECD DAC committed to target highly concessional resources and particularly grants in support of LDCs. The concessionality threshold required for ODA loans however changes as countries transition from LDC/LICs to LMICs. As a result, bilateral and multilateral actors must ensure that grants are gradually replaced by loans and that these are aligned to the absorptive capacity of beneficiaries.

Figure 15. Grant financing was quickly substituted by concessional loans following LDC graduation

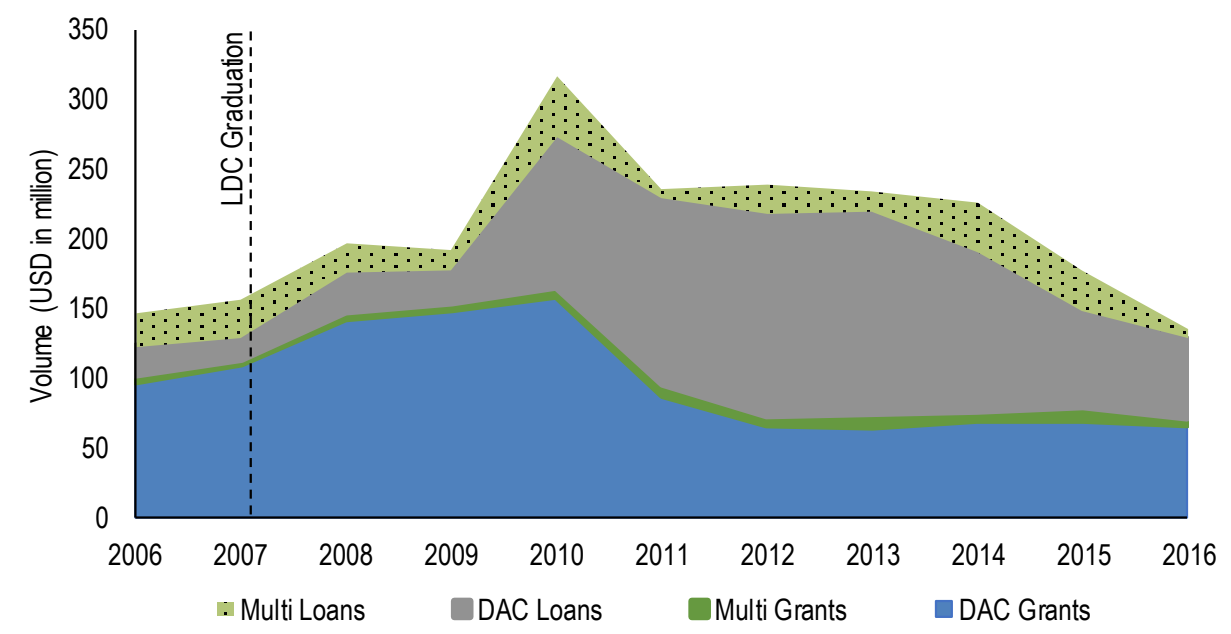

Note: The graph displays ODA commitment (USD constant, 2016).

Source: OECD $\left(2018_{[32]}\right)$, Creditor Reporting System, https://stats.oecd.org/Index.aspx?DataSetCode=crs1. 
In parallel, access to debt relief has declined. Cabo Verde is one of the most highly indebted SSA countries (in terms of gross public debt to GDP) ${ }^{18}$, yet access to debt relief is limited. Figure 16 shows that accessed UK MDRI funding from 2006 to 2012. The country does not qualify for Heavily Indebted Poor Country (HIPC) due to high income per capita level. ${ }^{19}$ Eligibility for HIPC is based on four main criteria: i. International Development Association (IDA) eligibility, ii. unsustainable debt burden, iii. track record of reform and sound policy, iv. developed a PSRP (Poverty Reduction Strategy Paper). (IMF, 2018 ${ }_{[38]}$ ) Cabo Verde also did not qualify for the Multilateral Debt Relief Initiative (MDRI) due to high income per capita level and the initiative was fully allocated in 2015. Eligibility for the MDRI was based on LIC status. (IMF, 2016 $\left.{ }_{[39]}\right)$

Figure 16. Debt relief has declined considerably following graduation

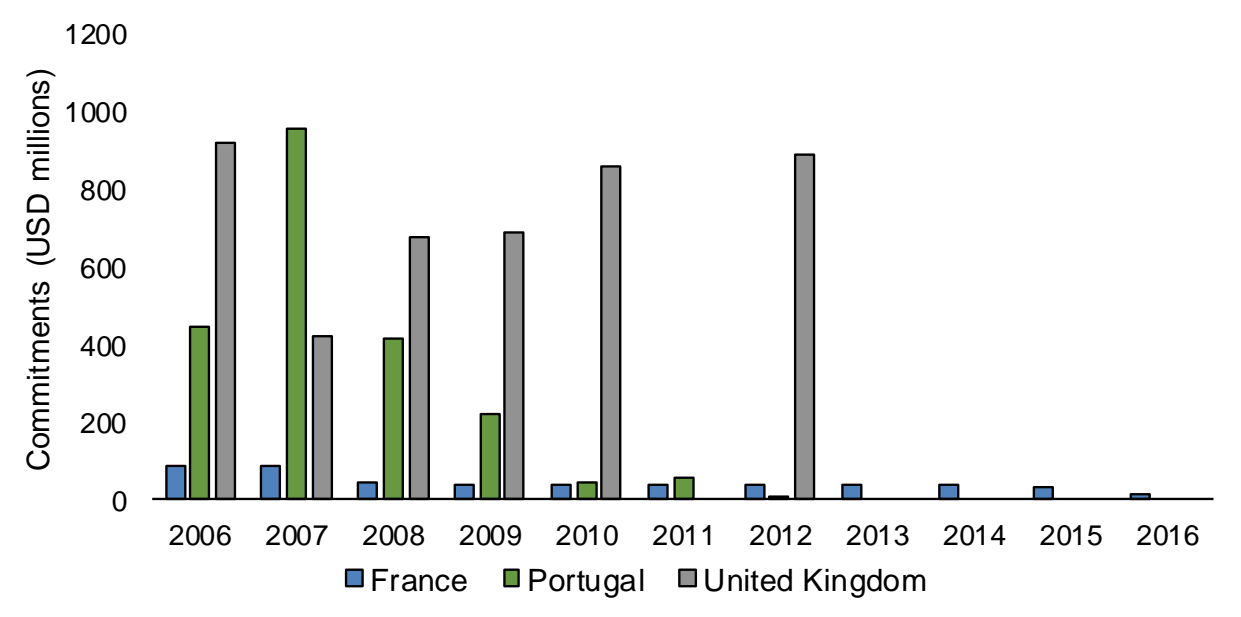

Source: OECD (2018[32]), Creditor Reporting System, https://stats.oecd.org/Index.aspx?DataSetCode=crs1.

Tied aid is also a growing concern which further risks intensifying debt distress. To benefit from the OECD DAC Recommendation on Untying ODA countries must either be classified as LDCs or as HIPCs ${ }^{20}$. As a result, Cabo Verde is faced with the challenge of an increase in legal and regulatory barriers which diminish competition for ODA-funded procurement. This presents a risk of higher transaction costs, reduced country ownership, and an additional public debt burden. $\left(\mathrm{OECD}, 2018_{[40]}\right)$ Figure 17 reveals that tied aid in Cabo Verde reached nearly 50\% total ODA commitments in 2011-13. 
Figure 17. Following LDC graduation, tied aid rose quickly in Cabo Verde

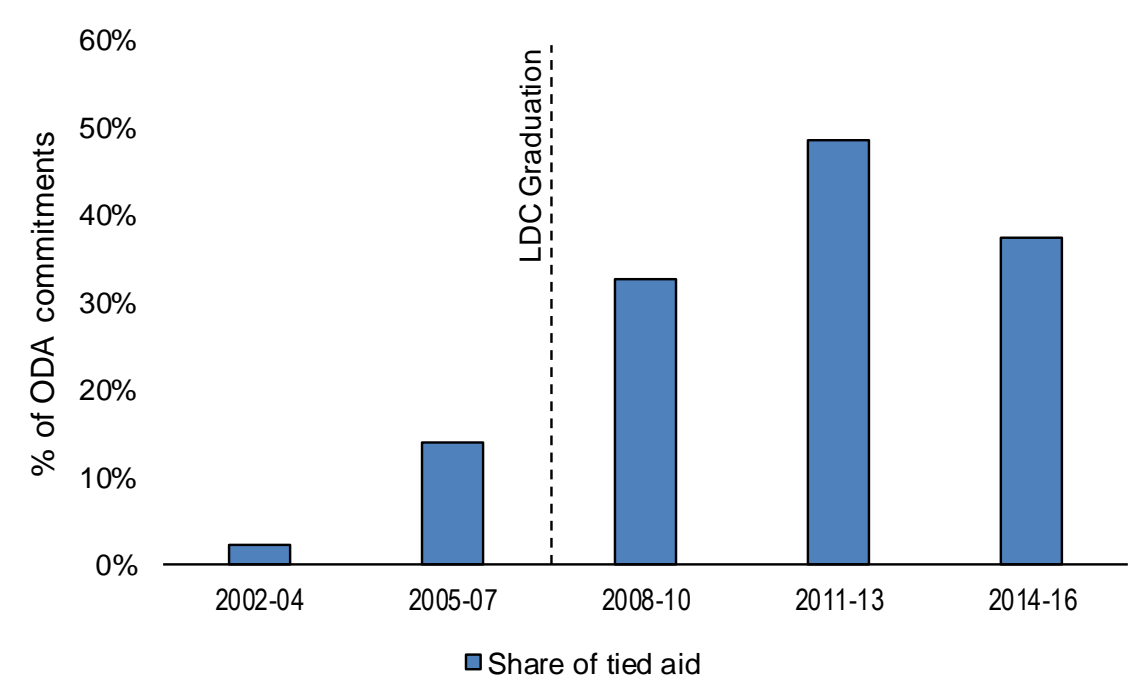

Note: Share of aid that tied in ODA commitments; excluding type of aid codes B02, H02 and G01 due to information on tying status.

Source: OECD (2018[32] $)$, Creditor Reporting System, https://stats.oecd.org/Index.aspx?DataSetCode=crs1.

Portugal represents $79.9 \%$ of tied aid provided to Cabo Verde. The high volumes of commodity assistance (USD 184 million, commitments) mentioned above created a credit line to a low-cost housing project implemented by IHF (2011-2016) ${ }^{21}$. The project led to significant contingent liabilities and raises the question of how to ensure the effectiveness of private sector development, in line with the Portuguese Memorandum of Understanding (MoU) with Cabo Verde 22 . (Portugal - Cabo Verde, 2017-2021 ${ }_{[41]}$ ) In the 2015 DAC Peer Review of Portugal, the issue of reducing tied aid to Cabo Verde, among other development partners, was raised as an important area for improvement in Portuguese development co-operation. (OECD, $\left.2015_{[42]}\right)$

\section{ii. Targeting of sectoral support is not fully aligned with country priorities}

Budget support remains a long-standing component of transition support, yet it does not address Cabo Verde's need for local capacity building. Since 2005, the EU, AfDB, The Netherlands, Austria, Spain and USA through the Millennium Challenge Account, prioritised ODA to Cabo Verde as direct budget support. (IPAD, 2007[43] $)$ Budget support is provided to Cabo Verde on both concessional and non-concessional terms. Volumes have increase from USD 17.5 million per year (2000-2007) to USD 27.1 million per year following graduation (2008-2016). Budget support and use of country systems is promoted by aid effectiveness principles. For example, Portugal's General Budget Support to Cabo Verde is linked to macroeconomic stability and effective implementation of public finance reforms. (OECD, $\left.2015_{[42]}\right)$ However, the Cabo Verdean government continues to face challenges to co-ordinate across ministries and to ensure the policy coherence. In its Budget Support assessment, the EU notes that a concern for institutional capacities of the Government, particularly "the lack of a proper monitoring and statistical system to accompany budget support." (European Commission, 2012 [44] 
A reduction of ODA to support education risks compounding growing regional inequalities. Figure 18 shows that the largest reductions in support have been carried out in the transportation and storage and education sectors (45\% and 30\% or USD 39.7 million to USD 25.6 million and USD 32.5 million to USD 22.7 million respectively). This trend is driven by the shift in ODA provide by Portugal towards "other commodity assistance" (import support for capital goods) and other social infrastructure (since 2010) as well as support by Portugal and Japan in energy and water and sanitation. The reduction of ODA to education comes during a critical stage as the country faces growing inequalities across islands and must seek to build local capacities for private sector led growth. The Section on Benchmarking below further addresses the issue of SDG/transition financing gaps across key sectors.

\section{Figure 18. ODA in support of transportation and education phased out quickly following graduation}

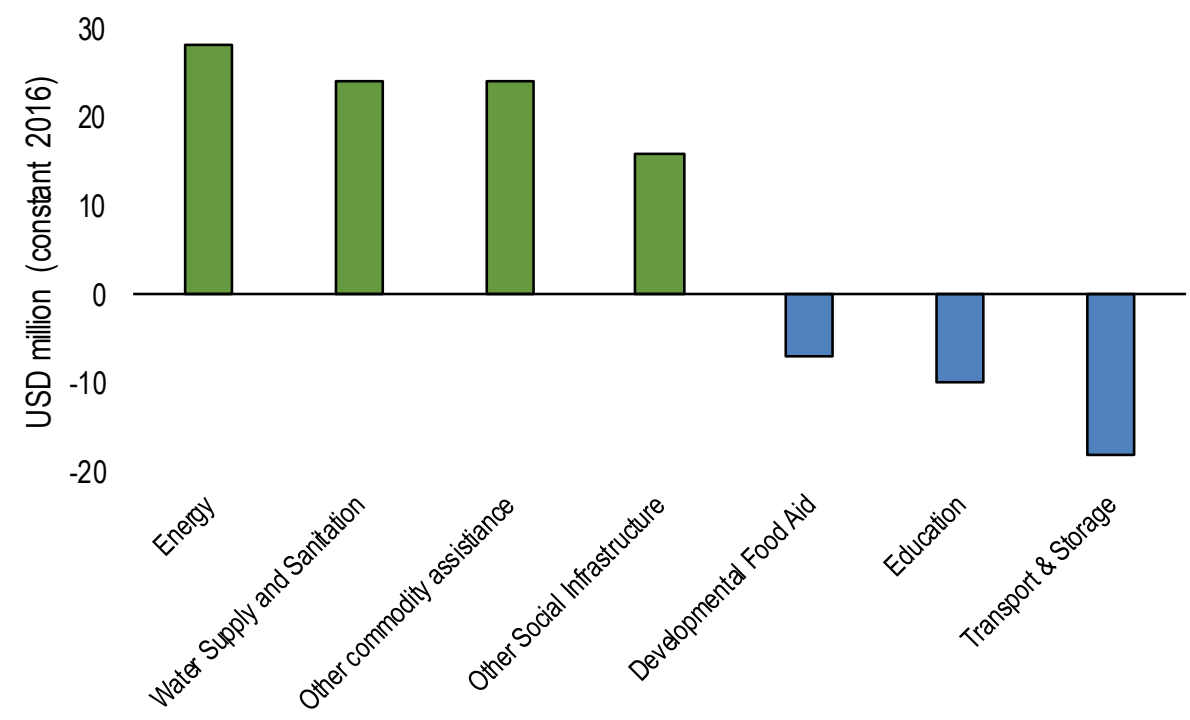

Note: The volumes displayed are ODA commitments while the change refers to the absolute difference of postgraduation year average (2008-2016) and pre-graduation average (2000-2007).

Source: OECD (2018[32]), Creditor Reporting System, https://stats.oecd.org/Index.aspx? DataSetCode=crs1.

In parallel, Cabo Verde receives increasing bilateral support for climate finance, mainly for water supply and sanitation and renewable energy. OECD DAC members committed to provide climate finance to LDCs and SIDS (e.g. in the SIDS Accelerated Modalities of Action (SAMOA) pathway in 2014). Figure 19 shows that Cabo Verde receives climate financing that is allocated primarily in support of water supply and sanitation (52\%) and energy generation (23\%). Between 2010 and 2016, USD 429.5 million was allocated to Cabo Verde for activities that principally targeted climate-change objectives. Of this, USD 327.67 million was committed as loans from Japan, Portugal and France for water supply and sanitation, and energy. Around 53\% (USD 228 million) of financing supported adaptation activities and $38.5 \%$ (USD 165.72 million) supported mitigation; the remaining amount (USD 35.76 million) targeted both objectives. Renewable energy production has been the fastest growing sector since graduation, reaching a total of USD 321.2 million (2008-2016). The largest contributors to this sector are Japan (electric power transmission/distribution and energy generation) and 
Portugal (renewable energy generation) with USD 100.9 million and USD 97.1 million since 2008 respectively.

Figure 19. Climate-related development finance provided to Cabo Verde is highly targeted to water supply and sanitation and mainly provided by Japan.
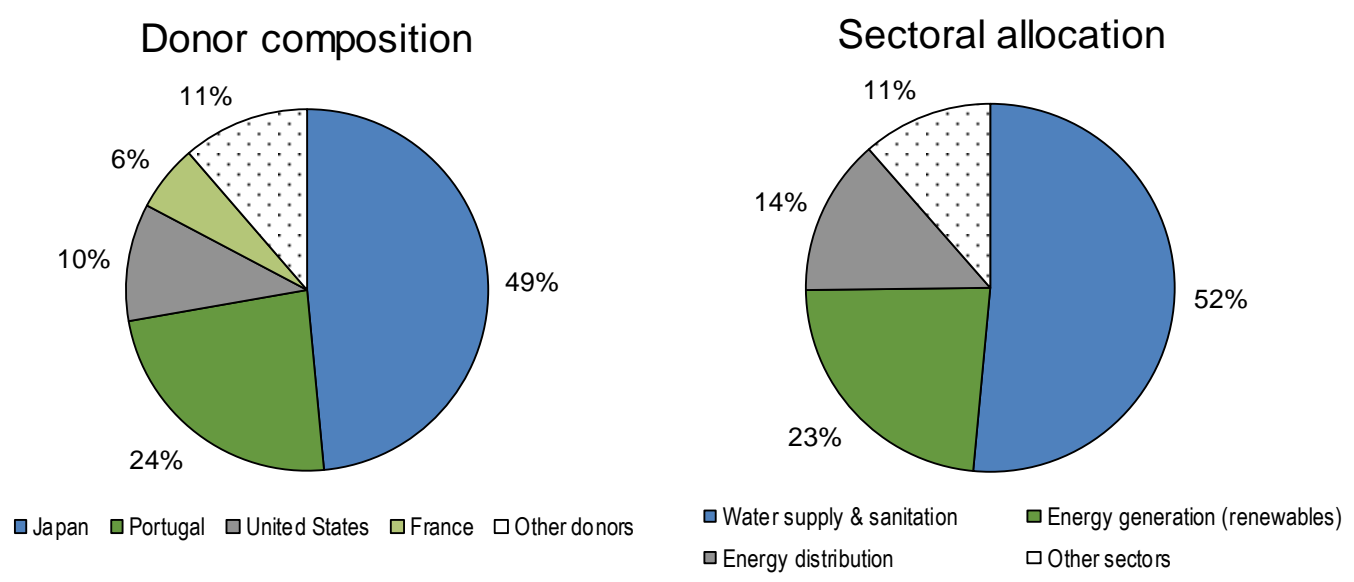

Note: Climate related refers to projects in the OECD Creditor Reporting System that are assigned with "1" or "2" for at least one of the markers on "climate adaptation" or "climate mitigation". The figures given represent the sum of flows between 2010 and 2016.

Source: OECD (2018[32]), Creditor Reporting System, https://stats.oecd.org/Index.aspx?DataSetCode=crs1.

The increase in climate finance was thanks largely to LDC support (e.g. via NAPA). However, graduation has limited Cabo Verde's access to global climate funds and risks setbacks as a SIDS. Identifying risks and needs in climate financing is more challenging following LDC graduation. Cabo Verde lost access to the National Adaptation Programmes of Action (NAPA) which helped to strengthen adaptation strategies and access to financing. ${ }^{23}$ As demonstrated above, the NAPA indicated the need to harmonise support for water supply and sanitation which translated directly to boosting levels of finance. Without NAPA support, many sources of climate financing such as the Green Climate Fund (GCF) require technical capacity and expertise that are challenging for SIDS with small administrations. SIDS also face challenges in identifying the risks and impacts of natural disasters and, consequently, in securing resources in their national budgets. High implementation charges further reduce the benefits received by SIDS through intermediary agencies. Cabo Verde has not yet accessed GCF financing due to these constraints, and amounts from the GEF remain small (USD 3.46 million in commitments 2000-2016 marked as climate related). 


\section{Benchmarking: How to compare Cabo Verde's transition finance with other peer groups and countries?}

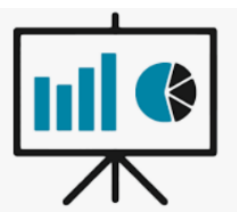

The following section on "Benchmarking" aims to apply a new holistic approach to identify the financing mix required to ensure the country's continued upward transition (see (OECD, 2018 $\left.8_{[3]}\right)$ ). Achieving the right financing mix needed to continue the upward trajectory requires co-ordinating the roles of a growing array of actors. Providers of ODA must increasingly consider how support can be targeted more effectively to maximise other forms of financing. Examination of the shift in Cabo Verde's access to other forms of financing (e.g. remittances, FDI, domestic resources, OOF) is essential to ensure that ODA reduction also supports adequate substitution of alternative sources of financing tailored to local absorptive capacity.

This section provides an analysis of the transition finance landscape before and after LDC graduation - ODA, OOF, private sector, domestic resources, and remittances. It compares the financing shifts to other peer groups (i.e. LMICs and SIDS) and peer countries/LDC graduates (e.g. Fiji, the Maldives, Mauritius, Seychelles, etc). The section addresses three main questions:

1. How has the transition finance mix shifted after graduation and what are the risks? This section examines the impact of ODA reduction on alternative sources of financing as Cabo Verde's income per capita level increased. The substitution of external and domestic sources of financing remains imperfect. How can the country overcome ODA dependency while mobilising other sources of financing?

2. What are the transition finance/SDG financing gaps? Rapid reduction of ODA across sectors can result in transition/SDG financing gaps, particularly if ODA is not substituted by other resources. This section identifies those SDG-related sectors in which OOF is not reaching optimal levels relative to peer countries at similar income levels. What are the reasons for gaps across social and productive sectors?

3. What are the opportunities to fill the gaps? This section addresses questions including: What role can the OECD DAC play to minimise the risks and help to correct market failures across SDG-related sectors? How can private sector actors be mobilised to create markets (e.g. in health and education)? How can Cabo Verde more effectively sequence and prioritise different resources to maximise the development impact?

\section{The transition finance mix after graduation presents new challenges}

Following graduation, Cabo Verde remains highly dependent on ODA at $40 \%$ of total external resources. Other sources of financing are not substituting at optimal rates ${ }^{24}$, and beyond the share of external financing, these flows also present new trade-offs to manage. Benchmarking peer countries sheds light on how resources can be strengthened in support of sustainable and inclusive development. The section presents the trends in substitution of i) external and ii) domestic resources before and after LDC graduation.

4. What are the transition finance/SDG financing gaps? Rapid reduction of ODA across sectors can result in transition/SDG financing gaps, particularly if ODA is not substituted by other resources. This section identifies those SDG-related sectors in which OOF is not 
reaching optimal levels relative to peer countries at similar income levels. What are the reasons for gaps across social and productive sectors?

5. What are the opportunities to fill the gaps? This section addresses questions including: What role can the OECD DAC play to minimise the risks and help to correct market failures across SDG-related sectors? How can private sector actors be mobilised to create markets (e.g. in health and education)? How can Cabo Verde more effectively sequence and prioritise different resources to maximise the development impact?

\section{The transition finance mix after graduation presents new challenges}

Following graduation, Cabo Verde remains highly dependent on ODA at $40 \%$ of total external resources. Other sources of financing are not substituting at optimal rates ${ }^{1}$, and beyond the share of external financing, these flows also present new trade-offs to manage. Benchmarking peer countries sheds light on how resources can be strengthened in support of sustainable and inclusive development. The section presents the trends in substitution of i) external and ii) domestic resources before and after LDC graduation.

\section{i. External resources are shifting quickly, yet ODA dependency remains a} concern.

A new approach to measuring the share of external financing can provide a tool for predicting the substitution of resources at a given level of income. Figure 20 below presents the financing mix in the Cabo Verde before and after LDC graduation. It illustrates the average share of sources of external finance as income levels increase and ODA is reduced. Examining the average share of external financing does not intend to indicate an "optimal" financing mix. A diversity of financing mixes can lead to higher levels of income. The methodology provides a tool for predicting and anticipating the substitution of resources at a given level of income.

Cabo Verde remains dependent on ODA and other sources of financing have not reached optimal levels of substitution. Dependency on ODA is characteristic of SIDS. Cabo Verde also faces challenges to effectively raise other resources to finance sustainable development. Figure 20 demonstrates that both before and after LDC graduation, ODA accounts for more than $40 \%$ of total external resources in Cabo Verde, placing it slightly above the curve for most developing countries. Each of the external resource flows (i.e. remittances, FDI and OOF) are further examined below.

- Levels of $\mathrm{OOF}^{25}$ have picked up following graduation. Yet, these flows remain low relative to other developing countries (at less than 10\%). Issues related to mobilisation of OOF are presented below.

- Before LDC graduation, the share of remittances in Cabo Verde was above the average for LMICs at nearly $30 \%{ }^{26}$ The share dropped below the LMIC average from nearly $30 \%$ to just under $20 \%$ of total external flows following graduation. The drop in the share of remittances is due to the depreciation of the Escudo (pegged to

\footnotetext{
${ }^{1}$ A diversity of financing mixes can achieve upward transition. The term "optimal" does not indicate that all countries should attempt to balance resources according to the distribution on average. Attracting levels of external private or domestic resources above the curve, does not indicate that these flows are suboptimal. Rather, the trend lines provide a proxy threshold for substituting sufficient levels of other resources as ODA is phased out.
} 
the Euro) to the dollar over the 2008-2013 period, due to the financial and economic crisis in European countries. ${ }^{27}$ (World Bank Group, 2011 $1_{[6]}$ )

- Finally, private flows have continued to grow after graduation. These resources must be leveraged to strengthen the sustainable development footprint. (OECD, $\left.2019_{[5]}\right)$

Figure 20. The mix of external transition finance resources in Cabo Verde is shifting.

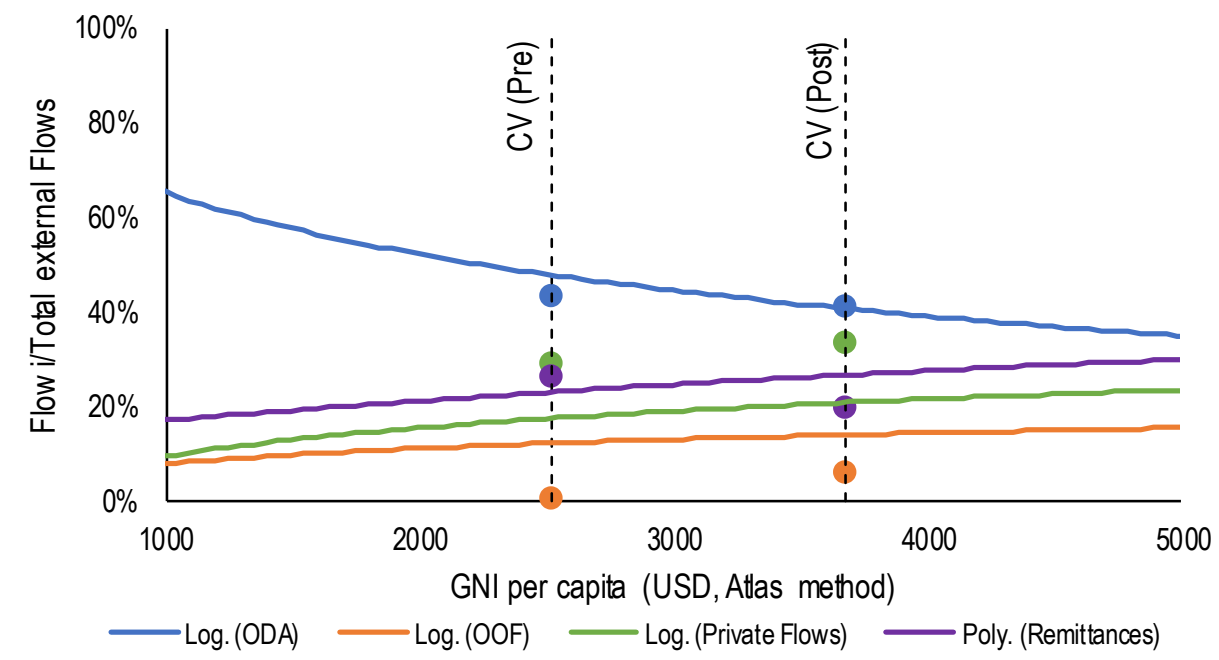

Note: The pre- and post-LDC graduation lines indicated above are 5 year averages before and after the 2007 graduation. The 2000 to 2016 time series is used in order to account for the impact of the global financial crisis on resources. The lines represent the predicted values from logarithmic and polynomial regressions using all ODA eligible countries. The total external flow is the sum of ODA, OOF, private flows and remittances.

Source: Authors based on OECD (2018[32]), Creditor Reporting System, https://stats.oecd.org/Index.aspx?DataSetCode=crs1 for ODA and OOF; DAC database for private flows; World Bank (2018[8]), World Development Indicators, https://datacatalog.worldbank.org/dataset/world-developmentindicators for remittances and GNI per capita.

\begin{abstract}
Although the share of OOF has increased slightly, Cabo Verde struggles to attract this resource across sectors - a trend common among SIDS due to small market size and low productivity. ${ }^{28}$ As demonstrated in Figure 21, OOF is expected to double from around 10 to $20 \%$ as a share of external financing in the LMIC income bracket. As discussed previously, SIDS benefit from the small island exception which allows multilateral providers to extend concessional flows at higher income levels, and thus, reduces the share of OOF financing in these countries. However, other barriers limit SIDS ability to attract OOF, particularly the capacity to engage bilateral DFIs due to small market size which affects productivity, limiting the achievement of economies of scale. For example, Papua New Guinea (PNG) achieves nearly $30 \%$ OOF as a share of external financing. The case of PNG is exceptional due to high revenues from mining, oil and gas resources. Overcoming this challenge among SIDS without natural resource endowments requires new approaches to regional and global market integration. The financing gaps section examines the emerging SDG financing and transition gaps according to OOF substitution sectors.
\end{abstract}


Figure 21. Cabo Verde and most other SIDS receive relatively low OOF (2000-16)

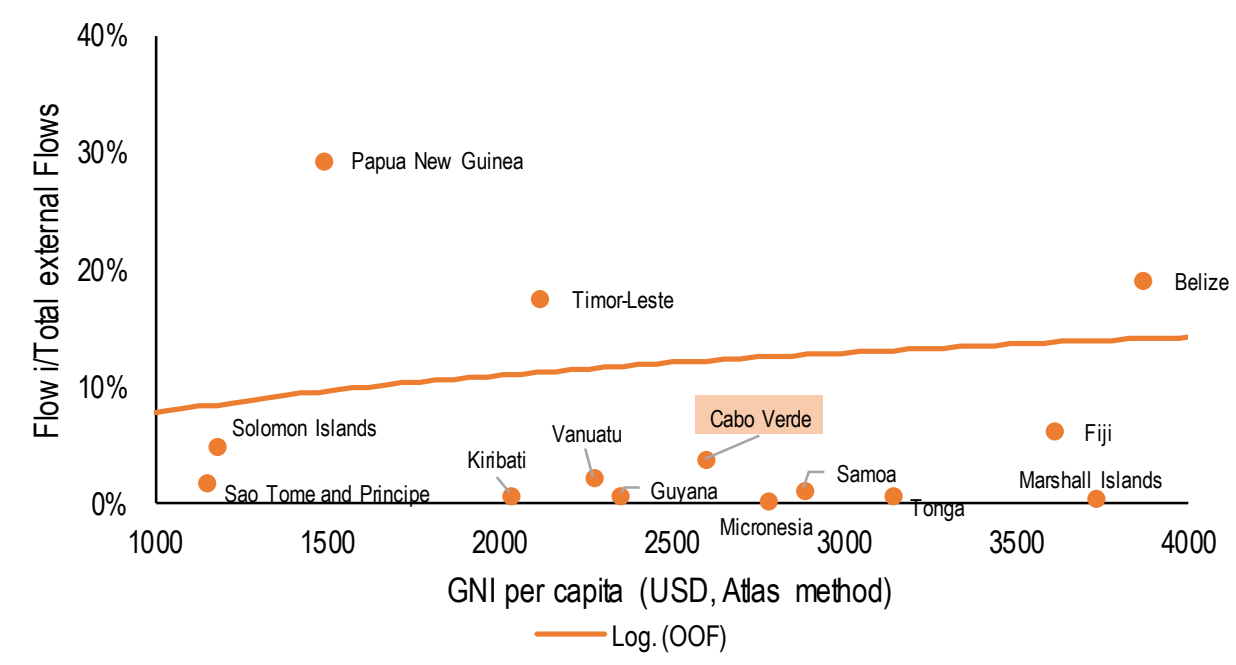

Note: The trend line for OOF flows is extracted from Figure 20; SIDS plotted are those eligible to ODA within the given income range.

Source: Authors based on OECD (2018 $\left.{ }_{[32]}\right)$, "Creditor Reporting System", https://stats.oecd.org/Index.aspx?DataSetCode=crs1 for ODA and OOF; DAC database for private flows; World Bank (2018 $\left.{ }_{[8]}\right)$, "World Development Indicators", https://datacatalog.worldbank.org/dataset/worlddevelopment-indicators for remittances and GNI per capita.

Cabo Verde receives higher relative remittances as a share of GDP, and these must be leveraged in support of sustainable development. Remittance inflows form an important revenue source in Cabo Verde, exceeding average shares of GDP in both SIDS and LMICs. ${ }^{29}$ Remittances inflows to Cabo Verde represent $11.2 \%$ of GDP (2012-16 averages) while remittances remained at just 7.6\% of GDP in other SIDS and 9.4\% in all LMICs. (Figure 22). However, Cabo Verde must further ensure that remittances contribute to inclusive growth. With more than 190000 Cabo Verdeans living abroad (36\% of the total population), there is significant potential to harness the diaspora community for sustainable development. With such a large diaspora community, several studies raise the importance of targeting exports to these groups. Others propose diaspora bonds as a means of channelling a greater share of remittances to productive investments for sustainable development. 
Figure 22. Remittance levels in Cabo Verde represent a higher share of GDP relative to other LMICs and SIDS

2000-2016

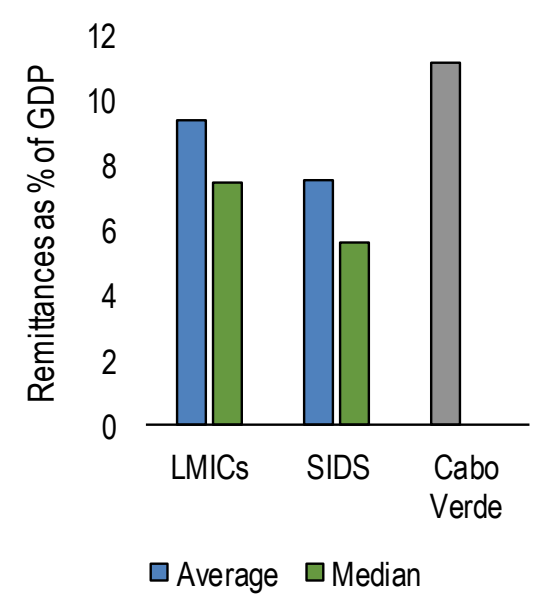

Source: Authors based on World Bank (2018 $\left.8_{[8]}\right)$, "World Development Indicators", https://datacatalog.worldbank.org/dataset/world-development-indicators.

High transaction costs are also limiting remittance mobilisation. In Cabo Verde, transaction costs were at $9.1 \%$ in 2016, higher than the SIDS average $(8.8 \%)$ and well above the internationally agreed target (3\%). Remittance costs in Cabo Verde are high due to the fees charged by money transfer operators (MTOs) who partner with local remittances providers. IMF Art IV 2018 encourages Cabo Verde to "reduce the high level of excess liquidity in the banking system" which has resulted in the loss of correspondent banking relationships. This loss represents a vulnerability, particularly to poorer segments of the population, given Cabo Verde's reliance on migrant remittances and deposits. (World Bank Group, 2011 $\left[1_{[6]}\right)$

Cabo Verde attracts higher FDI inflows relative to LMICs thanks mainly to tourism. Figure 23 shows that private market flows to the country are above the curve for LMICs, reaching $35 \%$ of external resources. The shares of private market flows in Cabo Verde are more than two times higher than the average in LMICs (at 15\% on average). The strong tourism sector drives FDI flows in Cabo Verde. The country is among the few SIDS, such as Samoa and the Maldives, whose LDC graduation was driven by FDI in the tourism sector. 
Figure 23. FDI inflows to Cabo Verde represent a higher relative share of external financing

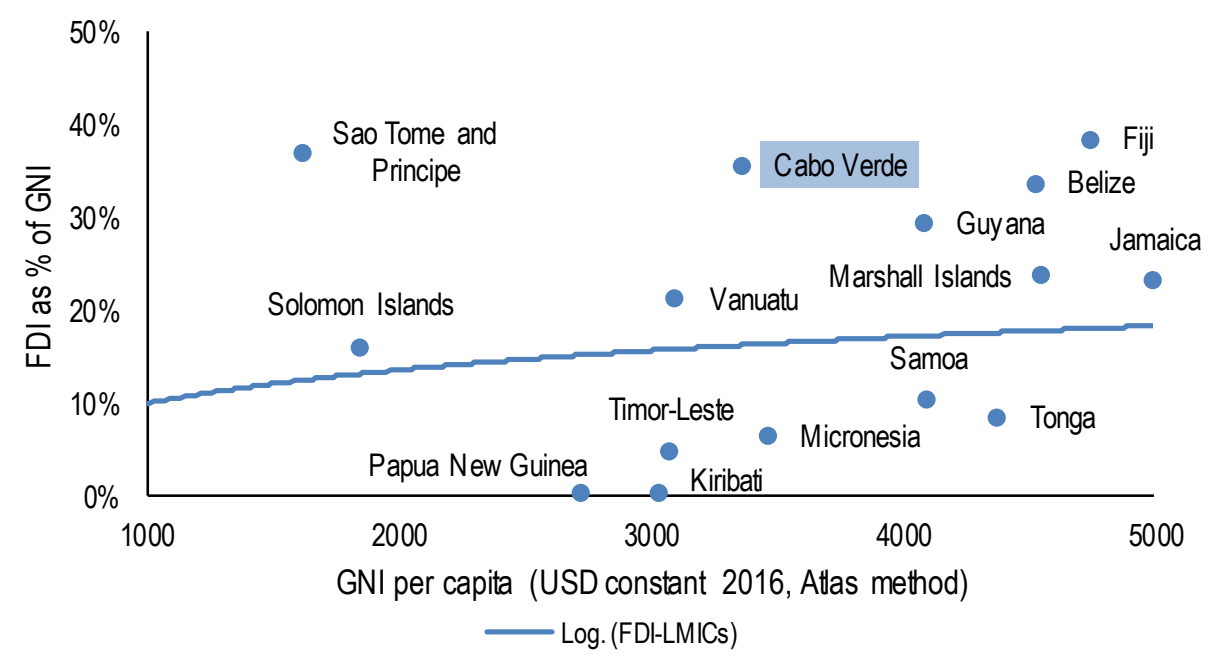

Source: Authors based on World Bank (2018[8]), World Development Indicators, https://datacatalog.worldbank.org/dataset/world-development-indicators.

However, the sustainable development footprint of foreign investment must be strengthened. The tourism sector alone accounts directly for 25\% of the GDP (over 18\% from the United Kingdom) but is not benefiting the local economy. (US Department of State, $\left.2018_{[45]}\right)$ Cabo Verdean operators have access to less than $10 \%$ of the total market. (Netherlands Enterprise Agency, 2017 ${ }_{[12]}$ ) Furthermore, processing of fish caught by foreign vessels comprises 15 percent of GDP. In 2014 the EU renewed its tuna fisheries agreement with Cabo Verde which allows EU vessels access to Cabo Verdean waters and extract resources in exchange for financial contribution. There is a risk of rent-seeking and increased prices if foreign investment does not create forward and backward linkages with the local economy. Furthermore, as noted previously, investments are not even across islands and risk increasing regional inequalities.

\section{ii. Limited fiscal space presents new challenges for SDG expenditure}

In terms of domestic financing, Cabo Verde's tax-to-GDP ratio before and after graduation is above average thanks to strong transparency and good governance. Despite its small size, the country's tax-to-GDP ratio remains at nearly $20 \%$ before and after graduation (see Figure 24). This ratio is above the average for the 16 African countries covered in OECD Revenue Statistics (19.1\% in 2015). High tax revenues in Cabo Verde are thanks largely to strong transparency and good governance, including effective fiscal policies. Cabo Verde ranks 48th according to the Transparency international index and 4th out of 54 in Africa according to the Mo Ibrahim Index of African Governance (IIAG). 
Figure 24. Domestic resource mobilisation remains above average before and after LDC graduation

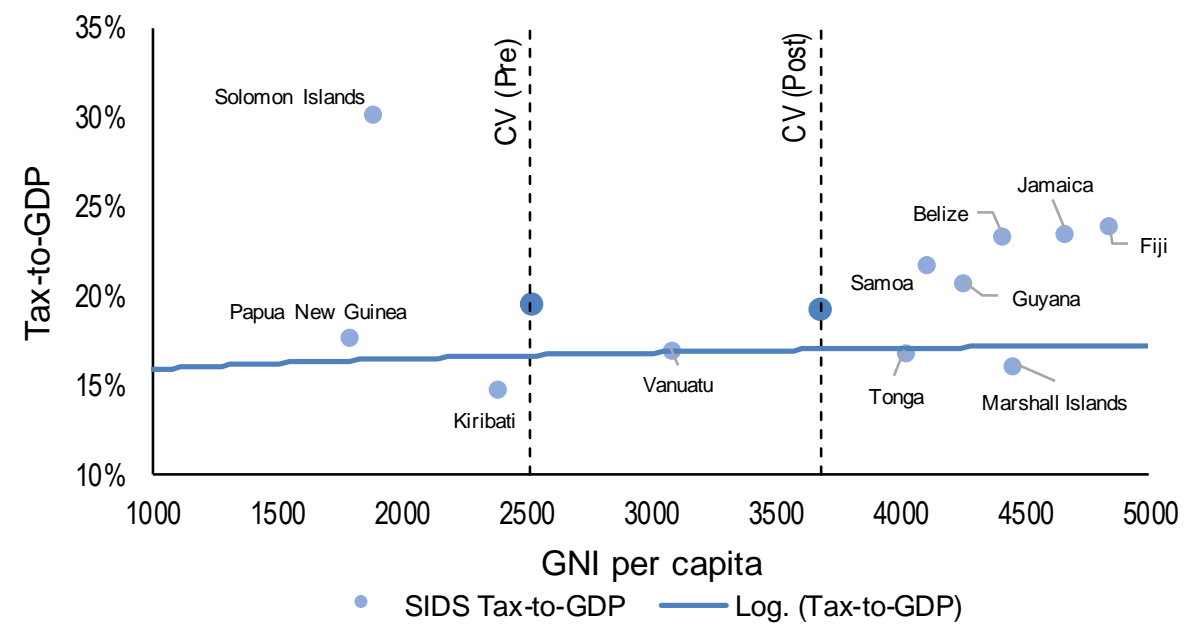

Note: Cabo Verde pre 5 year average 2003-2007 and post 5 year average 2008-2012; other countries based on 2012-2016 average; Cabo Verde in 2016: GNI pc 2970 and tax-to-gdp at 19.19\%

Source: Authors based on ICTD/UNU-WIDER (2018 $[46])$, Government Revenue Dataset, https://www.wider.unu.edu/project/government-revenue-dataset for tax-to-GDP; World Bank, World Development Indicators, https://datacatalog.worldbank.org/dataset/world-development-indicators for GNI per capita.

However, high domestic resources signal limited space for fiscal improvement and require strengthened efforts to ensure debt sustainability. Cabo Verde has already achieved high levels of domestic revenues. With total public-sector debt increasing from 68 percent of GDP in 2008 to approximately 126 percent of GDP in 2016, the country faces an increasing pressure to repay debts and strengthen public financial management. SOE privatisation has led to an increasing fiscal burden. As highlighted by Cabo Verde's Minister of Finance, surging debt (which more than tripled over 2008-17) also creates new constraints for public financial management. (Cabo Verde, 2015 [47]) Furthermore, financing that relies on increasingly nonconcessional private debt will require increased public revenues for continued investments in sustainable and inclusive development.

Informality remains challenging and presents a leakage in domestic resources. The informal sector in Cabo Verde is predominant and encompasses $60 \%$ of jobs and contributes to about $25 \%$ of GDP. In 2015, the business sector was comprised an estimated 33,000 informal firms providing close to 40,000 jobs. (Netherlands Enterprise Agency, 2017 ${ }_{[12]}$ ) Micro, small, and medium-sized enterprises (MSMEs) represent $98 \%$ of firms operating in Cabo Verde, providing more than 40 percent of jobs. (World Bank Group, 2017 ${ }_{[48]}$ ) Fisheries, for example, constitute a main driver of growth for private entrepreneurship, yet the limited level of processing of fish products and the lack of certification of products are a key impediments to thriving MSMEs in this sector. Due to its small market size, local MSMEs struggle to take advantage of market opportunities that require delivery of large stocks of standardised products and compliance with international standards. (UNIDO , 2016 [20]) 


\section{Financing and capacity gaps are emerging across SDG-related sectors}

As ODA is reduced following LDC graduation, adequate substitution of other resources is needed. The following section examines levels of OOF as a substitute for ODA across sectors. According to the SDG progress assessment presented previously, Cabo Verde demonstrates low-levels of progress and/or the risk of reversing course across SDGs. The transition finance gap methodology detailed below (i.e. examining the substitution of ODA and OOF across sectors - see OECD Transition Finance Methodology 2018, forthcoming) allows a forecasting of potential "at risk" sectors in need of a stronger approach to resource mobilisation.

i. Social sector gaps: As ODA is reduced in social sectors, the capacity building component is lacking, particularly in Health and Education (SDG3 and SDG4). Domestic resources are needed to finance these areas and reduce growing inequalities (SDG10). However, leakages in domestic resource mobilisation are emerging due to loss making SOEs in addition to increasing levels of informality and youth unemployment (SDG8).

ii. Productive and service sector gaps: Cabo Verde, as a SIDS, must address challenges to strengthen competitiveness of small markets and improve its Doing Business ranking. Financing gaps are emerging in support of trade, infrastructure, tourism and private sector development (SDG8, SDG9, and SDG17).

ODA reduction risks the emergence of financing gaps across SDG-related sectors. New work on transition finance seeks to identify the potential gaps and surpluses in financing across sectors (OECD Transition Finance Methodological Paper, forthcoming). Figure 25 demonstrates that a substitution between ODA and OOF can occur across certain sectors. Transition gaps emerge in sectors where market creation is more challenging. A natural convergence is often achieved in sectors where markets exist for private sector investment (such as the banking, business, or infrastructure sectors). In many commercially viable sectors, ODA decreases at roughly the same rate that OOF increases, leading to a substitution of flows as income levels rise. The same figure shows that in the health sector, for example, ODA phases out quickly while OOF does not phase in fast enough to fill the remaining gap. In these cases, other resources including public expenditure must be mobilised to provide sufficient support for public goods. 
Figure 25. Substitution of ODA and OOF across sectors reveals potential financing gaps
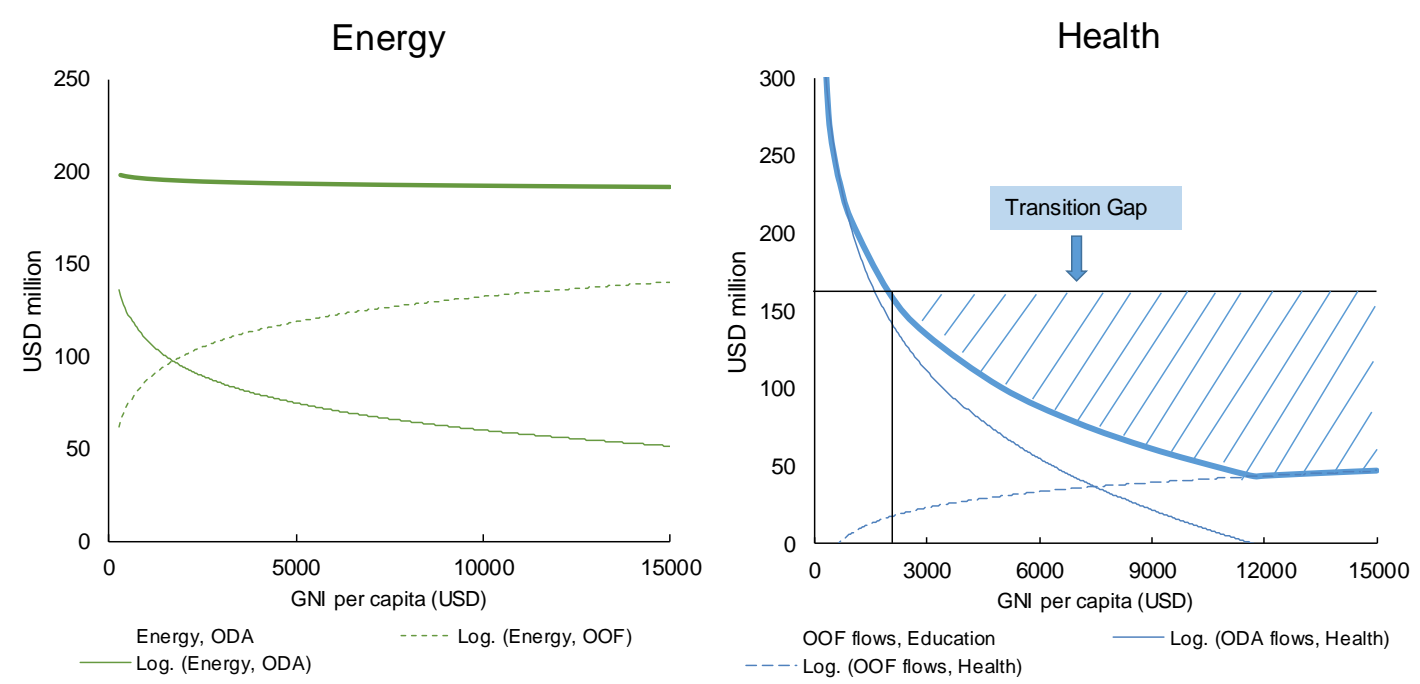

Source: OECD (forthcoming), "Transition Finance: Methodology and main findings" OECD Working Papers.

\section{i. Social sector capacity and financing gaps are increasing (education, health, domestic resources and debt sustainability)}

With ODA reduction, gaps are emerging both in terms of financing and capacities. The health (SDG3) and education (SDG4) sectors present the greatest risk, linked to rising inequalities (SDG10). The share of Cape Verdean government spending in support of health and education has declined (-1.5\% in education and $-0.4 \%$ in health over the $2012-16$ period) (World Bank development indicators). Inequalities are also on the rise. The country's Gini coefficient has increased to 51 in 2013 from 45 in 2007. Poverty reduction across the islands is uneven. While Sal has benefited from the reduction of the incidence of poverty from 25 to $10 \%$ (2000-2007), the incidence of poverty in Fogo remains high at $40 \%$, decreasing by only $2 \%$ in seven years. (World Bank , 2014[49]) Support to ensure adequate capacities to finance and design effective health and education systems is crucial as ODA to these sectors is phased out.

Support for capacity building in education (SDG4) is declining rapidly and represents an important capacity gap. Figure 26 shows that Cabo Verde receives ODA in support of education on par with other SIDS, yet OOF is not projected to substitute the future decrease in ODA. In addition, as mentioned previously, ODA to this sector has decreased most quickly by 30 percent since graduation. Although the literacy rate in Cabo Verde is the highest of West Africa south of the Sahara (75-80\%), the country requires continued support to formulate education policy and build institutional capacity to effectively implement policy, for example, to address rising inequalities. 
Figure 26. Cabo Verde demonstrates an important OOF gap in the education sector

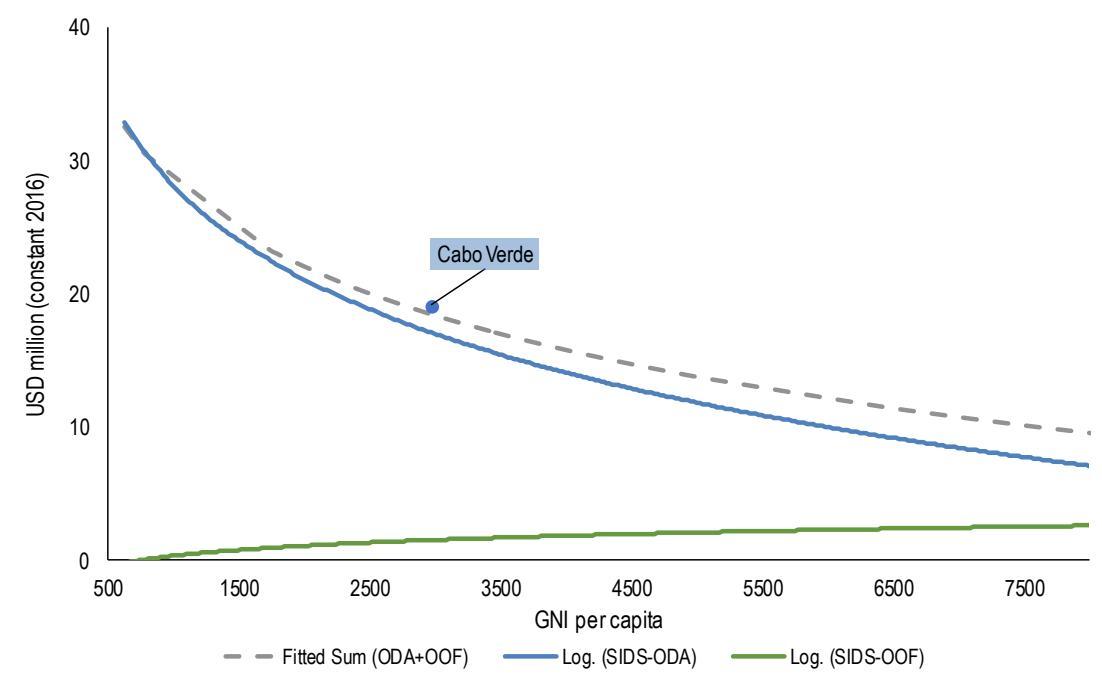

Note: The trend lines show predicted values of logarithmic regressions using ODA and OOF flows to ODA eligible SIDS; ODA and OOF to education includes the sector codes 110,111, 112, 113, and 114.

Source: Authors based on OECD (2018[32]), Creditor Reporting System, https://stats.oecd.org/Index.aspx?DataSetCode=crs1 for ODA and OOF; World Bank (2018[8]), World Development Indicators, https://datacatalog.worldbank.org/dataset/world-development-indicators.

In regard to the health sector (SDG3), another major financing gap is emerging. Figure 27 below reveals that Cabo Verde receives less ODA in support of health relative to other SIDS in the LMIC category and that furthermore, OOF in this sector is not substituting the loss in ODA. Cabo Verde remains highly reliant on external support for health spending (13.7\% of GDP in 2013) ${ }^{30}$. Furthermore, the cost of health services is rising. Cabo Verde's 2018 National Policy Review (NPV) indicates that dengue and zika epidemics as well as malaria present new health challenges. (Cabo Verde, 2018 ${ }_{[26]}$ ) As a result, the World Health Organisation (WHO) highlights that ODA reduction must be accompanied by efforts "to set up a performant mechanism to monitor the implementation of policies and plan at the regional and service delivery levels based on a robust health information system." ${ }^{31}$ This reflects a crucial need for expertise in health project management. 
Figure 27. A financing gap is also a concern in the health sector

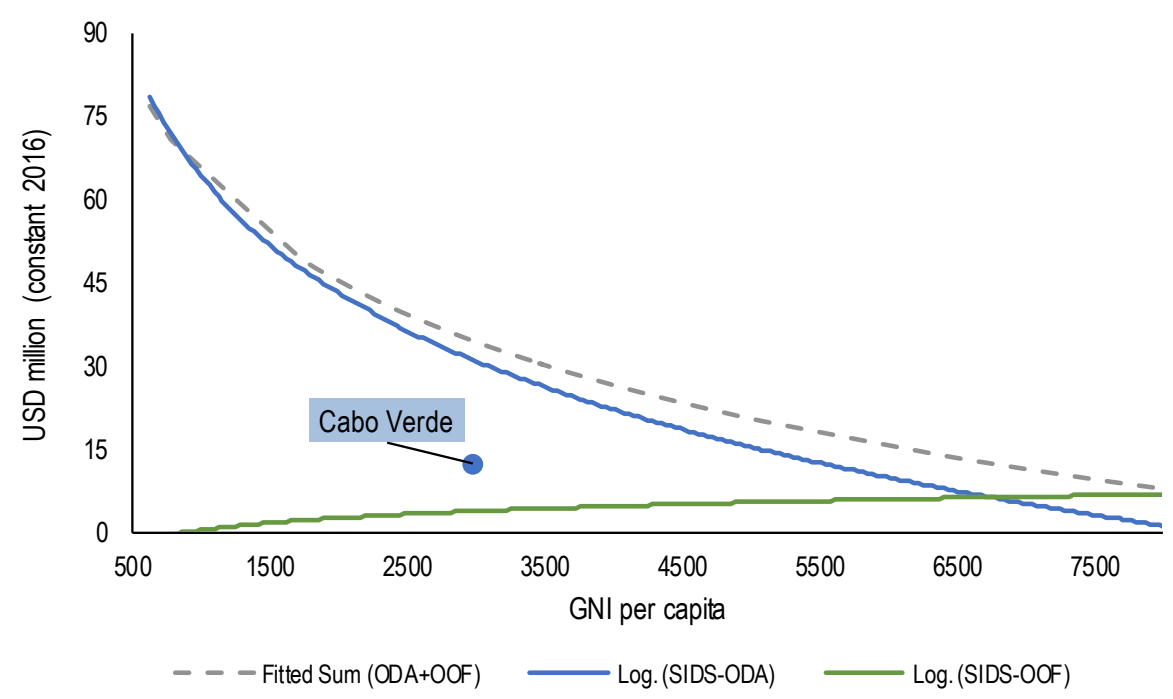

Note: The trendlines show predicted values of logarithmic regressions using ODA and OOF flows to ODA eligible SIDS; ODA and OOF to health includes the sector codes 120, 121, 122, and 130.

Source: Authors based on OECD (2018[32]), Creditor Reporting System, https://stats.oecd.org/Index.aspx?DataSetCode=crs1 for ODA and OOF; World Bank (2018[8]), World Development Indicators, https://datacatalog.worldbank.org/dataset/world-development-indicators.

Strains on domestic resources (SDG17) are magnified by debt distress and mismanagement of SOE privatisation. The PEDS recognises the importance of domestic resource mobilisation to finance priorities in areas such as health and education. To avoid the loss of domestic resources, more efficient governance and public sector reform is needed. Coordination between agencies is a key challenge that is raised across diagnostics. Cabo Verde's SOE privatisation process demonstrates the cost of public sector inefficiency. These costs will squeeze available expenditure across key SDG sectors.

Growing youth unemployment and informality (SDG8) have further resulted in low social security contributions, an emerging gap for domestic resources. Youth unemployment is contributing to a growing gap in the social security system. While national unemployment rates have decreased (from 11.5\% in 2000 to 10.3\% in 2017. In 2017 (World Bank Development Indicators WB dev indicators), youth unemployment is high at $32.4 \%$ (percentage labour force age 15-24) in 2017, up from 28.6\% in 2015. Informality is growing and leads to financing leakages. For example, Cabo Verde's geostrategic location represents the risk of growing illicit activities such as money laundering. Compared to other African countries, Cabo Verde's tax structure is missing social security contributions indicated in yellow in Figure 28 and is highly reliant on taxes on goods and services, indicated in blue. High youth unemployment and informality contribute to this gap. 
Figure 28. Social security contributions reflect a gap in Cabo Verde's domestic revenues

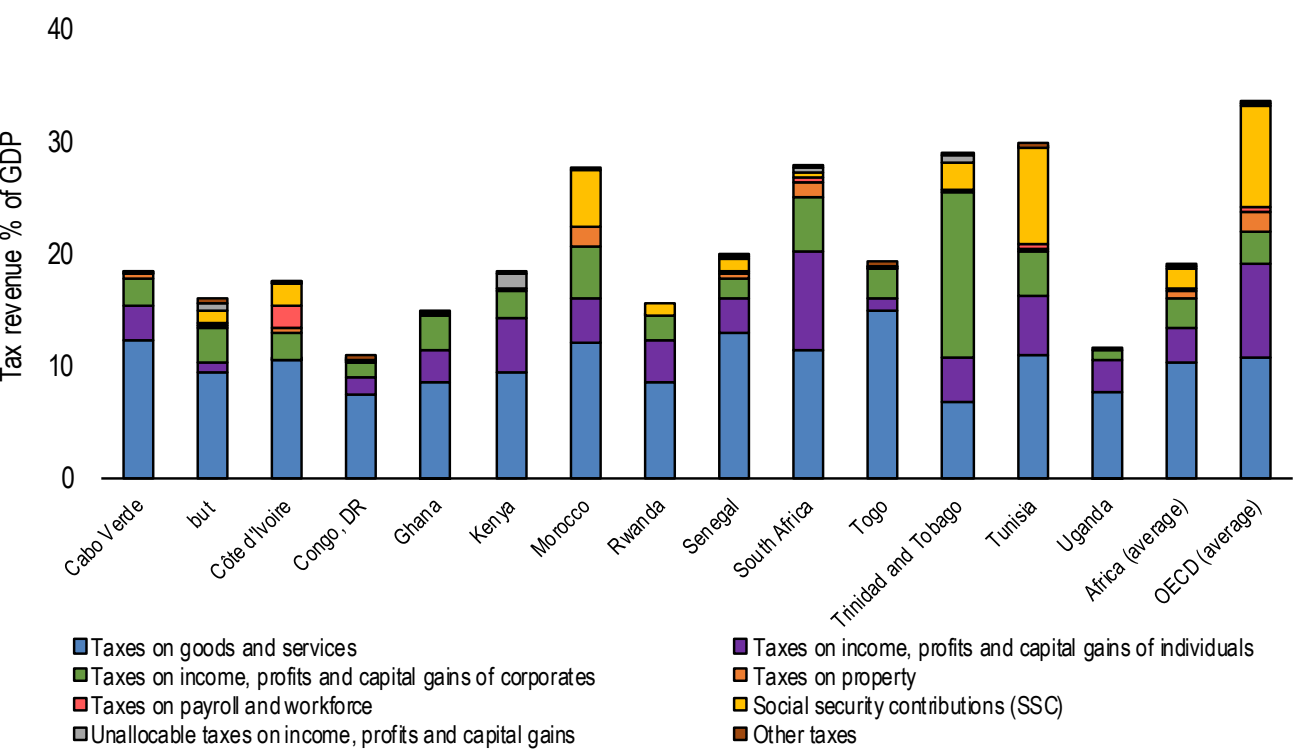

Source: OECD (2017 $[50])$, Global Revenue Statistics Database, http://www.oecd.org/tax/tax-policy/globalrevenue-statistics-database.htm.

Despite these challenges, Cabo Verde does not receive external support for more effective domestic resource mobilisation and receives only small amounts to address public financial management. Cabo Verde receives General Budget Support and technical assistance from the IMF for reform of public investment and management of infrastructure. However, support for domestic resource mobilisation is non-existent ${ }^{32}$. As shown in Figure 29, support for more effective domestic resource mobilisation and public financial management represents a very small share of ODA and OOF financing across SIDS. Yet, several SIDS have succeeded in mobilising such support. For example, the Solomon Islands receives support for DRM from Australia and New Zealand. 
Figure 29. Cabo Verde does not receive support for domestic resource mobilisation and only small amounts for public financial management.

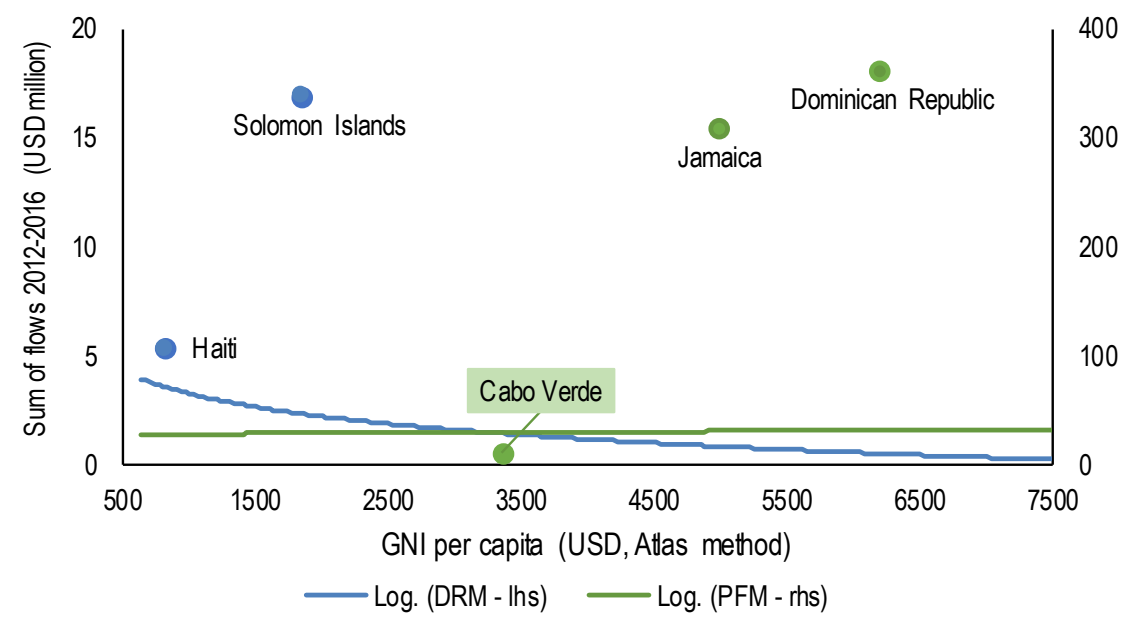

Note: ODA to PFM is covered by purpose code 15111; ODA to DRM is covered by purpose code 15114.

Source: Authors based on OECD (2018[32]), Creditor Reporting System, https://stats.oecd.org/Index.aspx?DataSetCode=crs1 for ODA; World Bank (2018[8]), World Development Indicators, https://datacatalog.worldbank.org/dataset/world-development-indicators for GNI per capita.

To avoid further avoid domestic financing gaps, Cabo Verde is taking steps to monitor the reform of investment and tax regimes. There is a risk of a dual economy and adverse effects due to selection of investors. Significant issues persist around the challenges of building tax systems in SIDS. Across SIDS, a disproportionate number have sought to bolster DRM through the tax haven/financial services model. Incentives policies were introduced in Cabo Verde in the 1990s to attract FDI which included tax exemptions on profits, repatriation, property, and imports of capital goods. Although the policies have contributed to a booming tourism sector, today with the country's limited fiscal space, there is a question of how to ensure the fiscal sustainability of such policies, i.e. to avoid inefficient loss of domestic revenues. Recently, Cabo Verde has made progress by accepting to join the OECD/G20 Inclusive Framework on Base Erosion and Profit Shifting (BEPS) Project.

\section{ii. Productive and service sectors are not attracting sufficient levels of $\mathrm{OOF}$ (trade, infrastructure and private sector enabling sectors)}

Important gaps also exist in Cabo Verde's key productive sectors, due mainly to insufficient commercial viability of small markets, weak business enabling environment and the high cost of infrastructure (i.e. multiplier effect). Cabo Verde's Doing Business ranking remains low (131/190 in 2018) and its competitiveness rank has fallen from 105 to 110 out of 135 countries $(2017-18)^{33}$. These studies raise the importance of increasing the international reach of MSMEs. Infrastructure financing should be strengthened to ensure commercially viability (e.g. domestic travel, logistics, connectivity). The transition period in Cabo Verde was too short, and the necessary infrastructure is not yet in place to attract the private sector and to ensure a return on investment to repay growing debt.

Despite pre-graduation support for trade, today the country receives little external support to improve trade policies and regulations and struggles to reach its goal of establishing itself as a player in the global trade system. The Figure 30 below shows that 
in SIDS the substitution of ODA and OOF occurs at approximately USD 1800 GNI per capita, early than in most LMICs (at approximately USD 2,900 income per capita). However, Cabo Verde has not yet generated OOF in this sector. Certain SIDS, such as Dominican Republic, Mauritius and Seychelles, receive significant volumes of OOF in support of trade which could provide guidance in future work. The DTIS report carried out by the EIF emphasises that diversifying exports and building competitiveness in Cabo Verde will rely on overcoming production constraints. According to the study, "the main barrier to Cabo Verde's exports are non-tariff barriers including, including licensing procedures, technical barriers to trade (TBTs) and sanitary and phytosanitary measures (SPS)."

Figure 30. In the trade policies and regulations sector, OOF can substitute ODA, yet Cabo Verde has not achieve this substitution

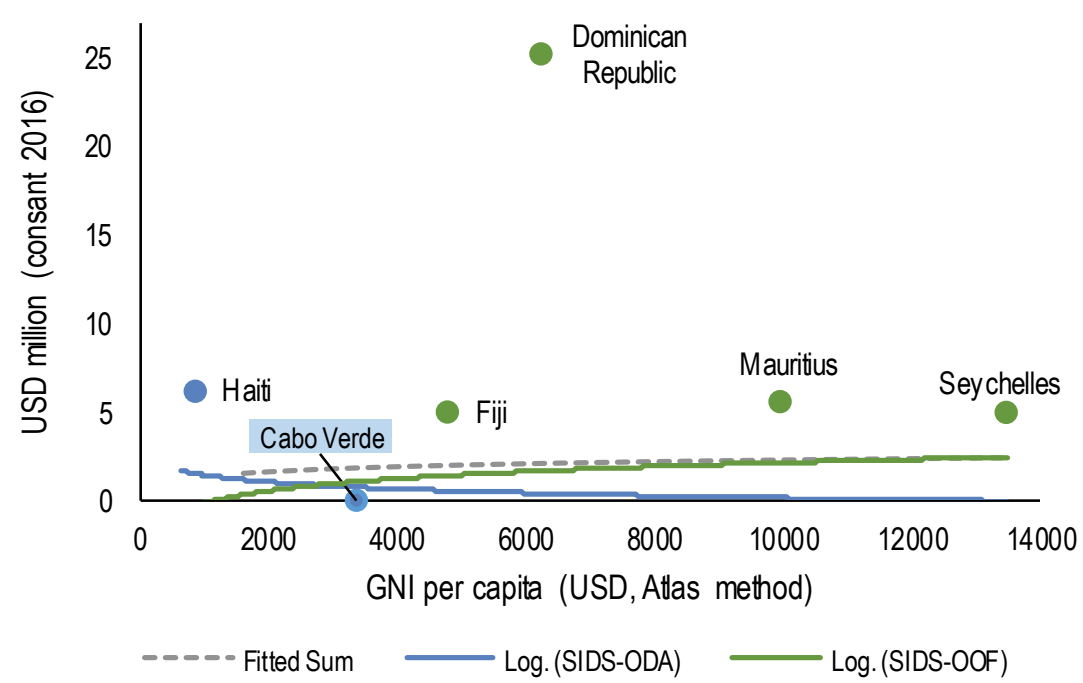

Note: The trendlines show predicted values of logarithmic regressions using ODA and OOF flows to ODA eligible SIDS; ODA and OOF to trade policies and regulations includes the sector code 331.

Source: Authors based on OECD (2018 $\left.{ }_{[32]}\right)$, Creditor Reporting System, https://stats.oecd.org/Index.aspx?DataSetCode=crs1 for ODA and OOF; World Bank (2018[8]), World Development Indicators, https://datacatalog.worldbank.org/dataset/world-development-indicators.

The transportation and storage sector represents another major financing gap, particularly as a key enabler for productive capacity and trade diversification. The Figure 31 reveals that OOF also tends to phase out alongside ODA levels. Cabo Verde has yet to attract $\mathrm{OOF}$ in support of transportation and storage. In addition ODA support to the transportation and storage sector saw the largest decrease of all sectors following graduation. In the figure below, Dominica, Fiji and Kiribati provide potential examples of how SIDS can better attract OOF in this sector. 
Figure 31. The transport and storage sector gap is growing

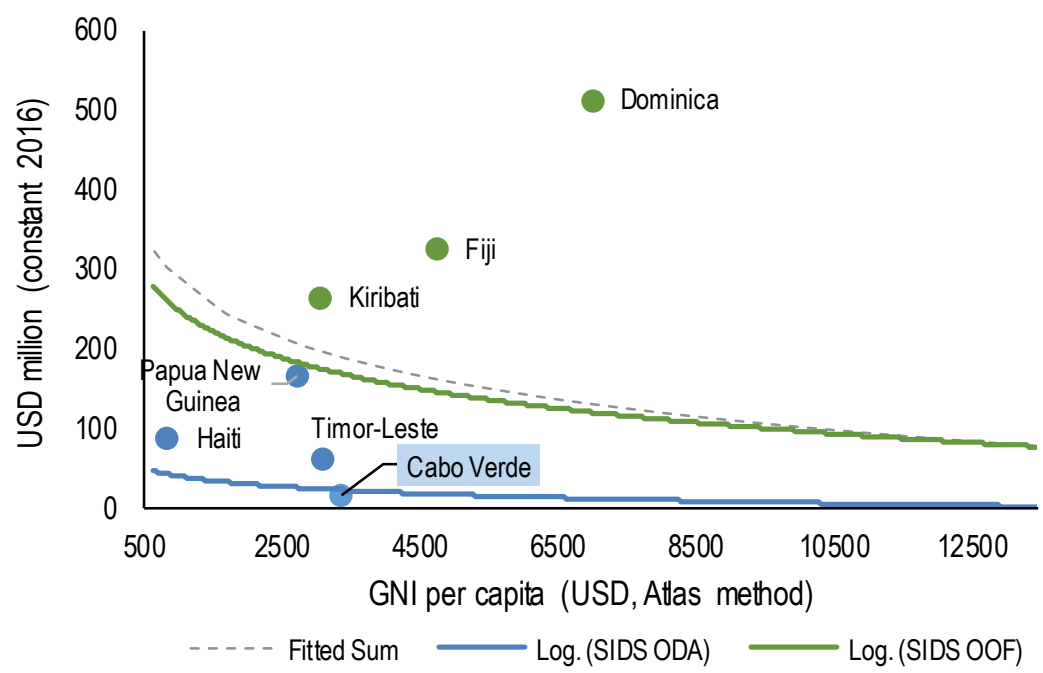

Note: The trendlines show predicted values of logarithmic regressions using ODA and OOF flows to ODA eligible SIDS; ODA and OOF to transport and storage includes the sectorcode 210.

Source: Authors based on OECD (2018[32]), Creditor Reporting System, https://stats.oecd.org/Index.aspx?DataSetCode $=$ crs1 for ODA and OOF; World Bank $\left(2018_{[8]}\right)$, World Development Indicators, https://datacatalog.worldbank.org/dataset/world-development-indicators.

Cabo Verde further lacks OOF to address the growing financing gaps in the service sectors, e.g. tourism, business and banking, crucial for private sector engagement. Given the importance of the services sectors to build local private sector capacities and ensure services can finance growing debt distress, it is crucial that these gaps in financing be addressed. Figure 32 reveals that OOF in support of the tourism sector is very low among SIDS, at less than USD 4 million and should not be expected to substitute ODA. OOF in support of tourism is only attracted by a handful of SIDS, particularly the Dominican Republic, although these countries are often highly reliant on this sector. Other sectors, such as the business and services or banking sectors, can be expected to attract OOF as a substitute for ODA (i.e. achieve commercial viability). However, Cabo Verde has weak financial markets and support to strengthen the banking sector, for example, is currently missing. 
Figure 32. OOF can substitute ODA to support the private sector enabling environment
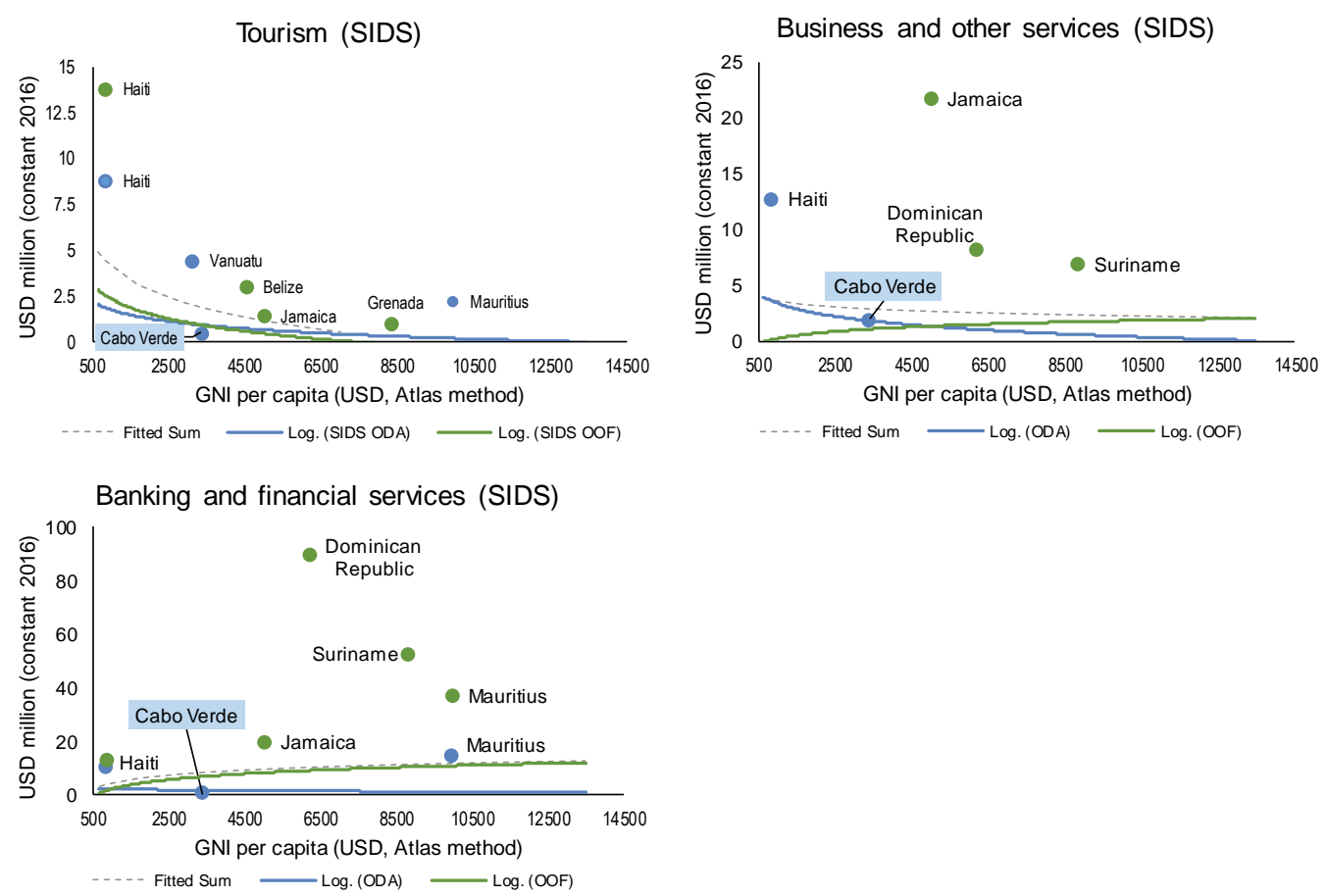

Note: The trendlines show predicted values of logarithmic regressions using ODA and OOF flows to ODA eligible SIDS; ODA and OOF to tourism includes the sector code 332, banking and financial services the sector code 240 , and business and other services the sector code 250 .

Source: Authors based on OECD (2018[32]), Creditor Reporting System, https://stats.oecd.org/Index.aspx?DataSetCode=crs1 for ODA and OOF; World Bank (2018[8] $)$, World Development Indicators, https://datacatalog.worldbank.org/dataset/world-development-indicators.

This section has demonstrated that OOF cannot substitute ODA across all sectors. The ability to attract OOF has significant repercussions for resource mobilisation across SDG-related sectors. In most social and several productive and service sectors, resources beyond OOF must be mobilised. In order for resources to be invested where needs are greatest, policies must be devised to ensure proper functioning of markets. The following section provides an array of policy tools and best practices to strengthen broader resource mobilisation.

4. Opportunities to maximise financing, including and beyond ODF, must be seized

This section identifies opportunities to maximise all available public, private, domestic and international resources to avoid financing and capacity gaps, in line with the Addis Ababa and 2030 Agendas. Ultimately, narrowing transition/SDG financing gaps will rely on the ability of governments to more effectively raise all available resources, including and beyond ODA and OOF, or ODF, across sectors. For example, the Cascade Approach developed by the World Bank aims to create markets across sectors, including in health care services and education through better sequencing of public and private financing, tailored to the local investment and regulatory environment, governance and institutional capacity, and development needs. 
Peer countries provide strategies to fill the gaps left by ODA reduction by harnessing new sources of financing. Figure 33 demonstrates the heterogeneity of financing mixes in other SIDS that have graduated from the LDC category or are scheduled to graduate (Samoa in 2014 and Maldives in 2011, Vanuatu scheduled in 2020) as well as other aspirational "peer countries" such as Mauritius and Seychelles. The different financing mixes in countries with similar characteristics (i.e. SIDS vulnerabilities, and LDC graduation) provide some insight into alternative strategies to address ODA reduction while maximising other available resources. For example, the graph demonstrates that the Maldives, an LDC graduate reliant on tourism, has been successful in harnessing private flows and OOF to improve income per capita levels. Furthermore, Fiji collects very high relative shares of remittances (4.6\% GDP), demonstrating for example, the importance of the Australian and New Zealand banking programs aimed at lowering transfer fees.

Figure 33. SIDS LDC graduates reveal a heterogeneity of possible financing mixes

Average net disbursements 2012-16

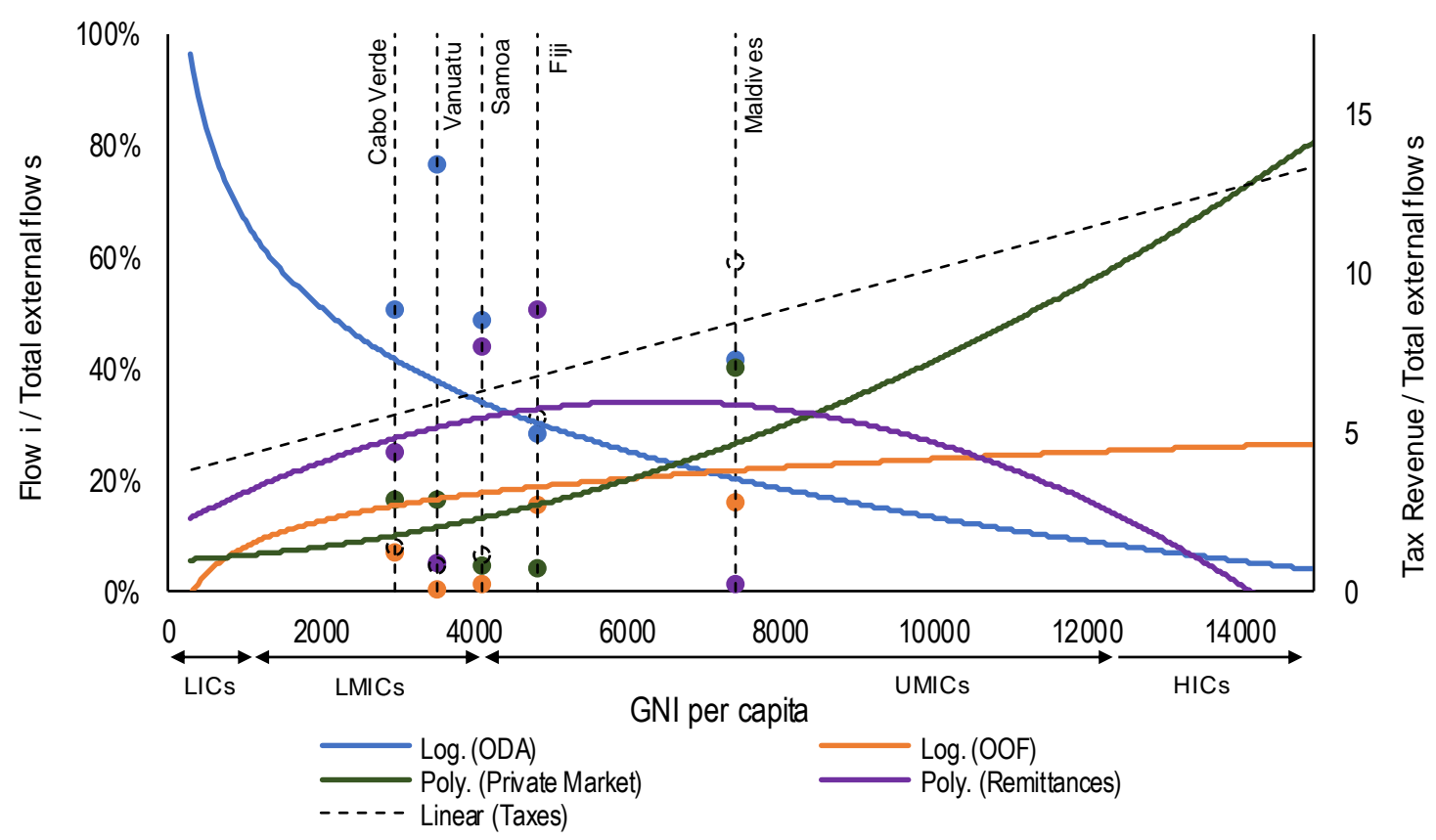

Note: Seychelles and Mauritius will be included in future iterations of this graph pending data availability.

Source: Authors based on OECD (2018[32]), Creditor Reporting System, https://stats.oecd.org/Index.aspx? DataSetCode=crs1 for ODA and OOF; DAC database for private flows; World Bank (2018[8]), World Development Indicators, https://datacatalog.worldbank.org/dataset/worlddevelopment-indicators for remittances and GNI per capita; ICTD/UNU-WIDER (2018[46]), Government Revenue Dataset, https://www.wider.unu.edu/project/government-revenue-dataset for tax revenue.

The following section presents opportunities and best practices such as these based on the experience of peer countries, such as the Maldives and others, tailored to support Cabo Verde's transition context. The case of Cabo Verde as a best practice for attracting financing for renewable energy is further provided to share lessons learned with other SIDS soon to graduate (e.g. Vanuatu). The key financing opportunities are grouped according to: i. Private sector, ii. Blended finance, iii. Diaspora communities, iv. From global to local actors, and v. Renewable energy. 


\section{i. Enabling the private sector for self-sustained financing for development}

High levels of FDI in the tourism sector must promote positive spillovers and local sourcing. Cabo Verde's graduation from the LDC category was largely driven by the tourism sector. Developing forward and backward linkages will be crucial to ensure that foreign investments contributes to tackling rather than increasing regional inequalities. Tourism accounts for $90 \%$ of Cabo Verde's FDI. (Netherlands Enterprise Agency, $2017_{[12]}$ FDI in the tourism sector is provided mainly by the United Kingdom, Spain and Portugal for all-inclusive hotel resorts on the islands of Santiago and Sal. In a recent interview, the President of Cabo Verde further noted that FDI should be better mobilised along key clusters "maritime, shipyard, or airline industries". Upgrading tourism value chains is a promising avenue for development. Cabo Verde ranks 86 out of 141 countries on the WEF Travel and Tourism Competitiveness Index 2015. The sector could be transformed to remove barriers for local entrants (e.g. MSMEs) and promote value capture by niche markets (e.g. "Made in Cabo Verde" products such as wine, grogue, cheese and coffee) (Chatham House: The Royal Institute of International Affairs, 2015 [51]).

Cabo Verde must further diversify beyond tourism with opportunities notably in fisheries. For Cabo Verde as in other SIDS, fisheries are a vital component of the local private sector accounting 200 million jobs and the means of subsistence for over 880 million people, nearly $12 \%$ of the world population. Exporting of fish and fishery products valued at USD 58.4 million in 2012 which is equivalent to $84 \%$ of total merchandise trade. Maximising fishery exports requires sufficient refrigeration and logistics for fish preparation. International trade of fish also requires skills to carry out international quality certification processes. Investment in resource management, harvest and post-harvest technology can further help local fisheries to become competitive. (UNIDO , 2016 ${ }_{[20]}$ ) In addition, from a conservation perspective it is important to ensure local resources are exploited in a sustainable manner.

Several diagnostics raise the transformational potential of Cabo Verde to achieve economic transition as an international hub/platform for production and services. The PEDS recognises the country's strategic position as a SIDS (located in the middle Atlantic connecting Europe, Africa and the US) and its potential as an international hub/platform for services. In Cabo Verde, Trade Invest was created in 2013 in order to provide investment services and promotion. According to the DTIS 2013, TradeInvest must seek targeting beyond tourism, and must explore other areas for investment, notably ICT enabled Business Process Outsourcing (BPO) and off-shore financial services.

Maldives presents a best practice in policy design to enable private resources following LDC graduation, notably by upgrading fishery value chains. Figure 34 demonstrates the role of increased fish exports to increase private market resources in the Maldives. Contrary to Cabo Verde, Maldives lost duty-free quota-free access to the European Union and Japan as well as the GSP following graduation. Despite loss of preferential treatment and higher tariffs, the Maldives was able to diversify export countries (beyond EU, Thailand and US), enter new markets and work toward higher value-added activities (positioning Maldivian fish as a niche product). In addition, Maldives is incentivising environmentally sustainable fishing value chains. Through the use of ecolabels or Marine Stewardship Council (MSC) certification, the country has created a price premium for local fishermen and the possibility for consumers to make more informed choices. As a result, private market resources now represent a higher percent of total external resources and ODA dependency has been reduced. 
Figure 34. The Maldives provides a best practice in generating private market flows following LDC graduation

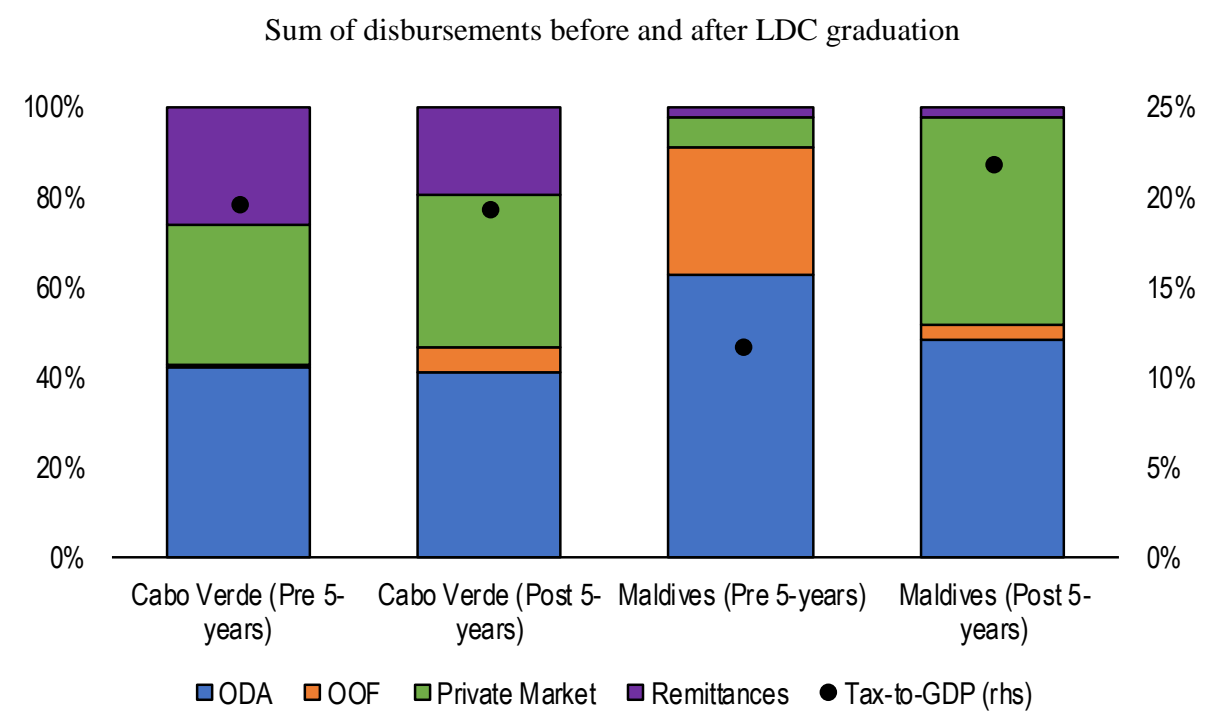

Note: +/- 5 years; Maldives successfully marshalled OOF pre-graduation while generating additional private resources and DRM following graduation.

Source: Authors based on OECD (2018[32]), Creditor Reporting System, https://stats.oecd.org/Index.aspx?DataSetCode=crs1 for ODA and OOF; DAC database for private flows; World Bank (2018[8]), World Development Indicators, https://datacatalog.worldbank.org/dataset/world-developmentindicators for remittances and GNI per capita; ICTD/UNU-WIDER (2018[46]), Government Revenue Dataset, https://www.wider.unu.edu/project/government-revenue-dataset for tax revenue.

\section{ii. Harnessing blended finance to transform SIDS vulnerabilities into strengths}

Seychelles demonstrates opportunities to transform SIDS vulnerability into a strength through blended finance ${ }^{34}$ in support of the Blue Economy. Cabo Verde faces challenges to attract external financing due to growing debt distress and limited capacity to structure complex financing modalities. However, new opportunities are emerging that allow the country to marshal financing that minimises debt distress while promoting the value-added of the Blue Economy. ${ }^{35}$ Debt write-offs in exchange for preservation of marine life (SDG14) are becoming a viable option. Box 0.1 provides a closer look at how the Seychelles is leveraging the Blue Economy and gaining access to Blue Bonds and Debt Swaps. These financial instruments have allowed the country to mobilise resources by exchanging sovereign debt for marine conservation. 


\section{Box 0.1.Seychelles: Leveraging the Blue Economy through Blue Bonds and Debt Swaps}

The World Bank offers many opportunities for training on the use of new and innovative financing modalities in support of the Blue Economy and tailored to SIDS economies. The first example is the Seychelles Blue Bond with an envelope at USD 10.5 million. The Blue Bond is implemented by the World Bank/GEF Third South West Indian Ocean Fisheries Governance and Shared Growth Project (SWIOFish3) and aimed at conservation and fisheries management planning, capacity build and in institutional strengthening.

Seychelles defaulted in 2008 and has an outstanding USD 152 million Eurobond due in 2026. Debt sustainability puts pressure on the country's ability to research and regulate tourism while prohibiting damaging activities like oil and gas exploration and dredging. To ensure that Seychelles has the resources necessary to continue marine conservation, a debt swap was prepared and carried out in 2016 for USD 20 million. The debt swap was led by the Nature Conservancy which freed USD 6 million in funding for conservation and is set to increase protected areas from $1 \%$ to $30 \%$.

\section{iii. Promoting the contribution of diaspora communities and financial inclusion}

Promotion of financial inclusion of the Diaspora community also presents new opportunities to raise resources in support of SDG investments. Remittances are not always channelled to the poorest segments of the population. The poorest segments of the population often face the greatest challenges to achieve financial inclusion. Linking remittances to other financing products (savings, insurance, bonds, loans, etc.) can help to increase financial inclusion and allow government to leverage remittances for investment. The example of Mauritius (see Box 0.2) provides insights to ensure that migrants have access to the financial knowledge and services necessary for inclusive growth. Other initiatives such as diaspora bonds for impact investment aim to promote remittances in support of entrepreneurship and investment rather than consumption. (UNDP, 2017 [52])

\section{Box 0.2. Best Practice: Mauritius capitalises on the contribution of Migrants and Financial Inclusion}

Mauritius is a middle-income country that has been successful in capitalising on migration as a tool for economic transition. The Mauritian government has responded to increased migration with a comprehensive and circular strategy. Although use of remittances in Mauritius is low (6\% of all financially included adults), the new strategy seeks to improve opportunities for migrants to invest, develop small and medium enterprises, and use their newly acquired skills from abroad. As a result, the country was ranked highest within the Southern African Development Community (SADC) in terms of financial inclusion. $90 \%$ of adults have access to financial services.

Support for the microfinance sector and institutions further presents an alternative means to strengthen inclusive access to financing. MSMEs account for 90 percent of firms, yet they receive only 58 percent of the number of bank loans. (World Bank Group, 2017 [48]) The Central Bank of Cabo Verde recognises the important role that microfinance (e.g. microloans, micro-insurance, money transfers) can play to promote entrepreneurship 
and job creation. In 2007, Cabo Verde passed a law that promotes the transparency and sustainable development of banking in the microfinance sector. As a result, the Banco Cabo Verde has created a Microfinance Office. In support of this initiative, LuxDev facilitates and increases access to inclusive and quality financial services in Cabo Verde. At the microlevel the project focuses on capacity building to ensure compliance of micro finance institutions with new regulatory framework and instil best practices.

\section{iv. Scaling up partnerships: from global to local actors}

To scale up its potential as an international hub/platform, Cabo Verde must integrate regional and global markets. As stated previously, Cabo Verde does not attract OOF from bilateral DFIs. Although Portugal's DFI, SOFID, has the capacity to structure small loans, there are no projects in the pipeline in Cabo Verde. ${ }^{36}$ In order for Cabo Verde and other SIDS to be competitive, they must serve a broader global or regional market. There is untapped potential for regional integration (mainly services for health and offshore services) and strategic positioning with Europe (e.g. ECOWAS chair). An example of support for regional integration, the European Commission's current Multiannual Financial Framework for 2014-2020 contains approximately EUR 2 billion for private sector development, including targeted work in SIDS. The EC's programming has contributed to the launch of a new regional co-operation initiative with GIZ and ECOWAS aimed at strengthening the transition to renewable energy. Box 0.3 demonstrates how Cabo Verde can leverage the opportunity to scale-up partnership between SIDS and DFIs/other investors through regional co-operation. Other opportunities for regional integration include networks such as the Portuguese-speaking African Countries (PALOP).

\section{Box 0.3. Regional co-operation for transition to renewable energy in West Africa - ECOWAS, GIZ and EU}

In August 2018, the ECOWAS Centre for Renewable Energy and Energy Efficiency (ECREEE) in co-operation with Deutsche Gesellschaft für Internationale Zusammenarbeit (GIZ) launched a project aiming at improving the governance of the renewable energy and energy efficiency sector in West Africa. ECREEE acts as a vehicle for ensuring equal and accelerated progress as well as harmonisation of donor activities. The project is funded by the European Union and the German Co-operation (GIZ).

The project further resulted in the adoption of national regional renewable energy, energy efficiency and energy access targets by 2030 and works to promote partnership with DFIs and investors, targeting new opportunities for sustainable energy investments.

At the local level, South-South and Triangular Co-operation can help to localise the SDGs and tackle growing inequalities (particularly in health and education). Cabo Verde has long benefited from the strong role played by CSOs. Yet, these actors could be better empowered to implement national policies, including those related to health and education. ${ }^{37}$ For example, UCLG promotes city-to-city co-operation alongside south-south and triangular co-operation to strengthen capacities and technical assistance including in SIDS. Currently, Cabo Verde benefits from triangular co-operation in support of technical assistance on nutrition in partnership with the FAO and the People's Republic of China. 


\section{v. Leveraging Cabo Verde's leadership role in renewable energy to generate climate finance}

Finally, Cabo Verde is a leader in attracting OOF in support of renewable energy (SDG7), an example that can be replicated in other SIDS. Currently, about $27 \%$ of the energy consumed in Cabo Verde comes from renewable sources. The government's goal is to increase this number to 50 percent by 2020 , which presents additional investment opportunities for companies in this sector. With high dependence on imported fossil fuels and high costs of energy production (energy production is estimated at $70 \%$ higher than EU average (REEP, 2012), support for renewable energy is essential in Cabo Verde. Figure 35 below shows that Cabo Verde attracts very high levels of ODA and OOF in support of the energy sector compared to its peers. Development partners, particularly Portugal and Japan, are providing support aligned to Cabo Verde government priority to shift energy production toward renewables (see INDC), particularly solar and wind which have high potential. The current strategy has been successful thanks to opening energy markets to private sector investment and government supported projects, including "adequate taxation, tariffs and financial mechanisms in favour of RE" and guarantees for investment and intellectual property rights (REEP, 2012).

Figure 35. Cabo Verde succeeds in attracting ODA and OOF to the energy sector

Financing gaps in the energy sector in SIDS

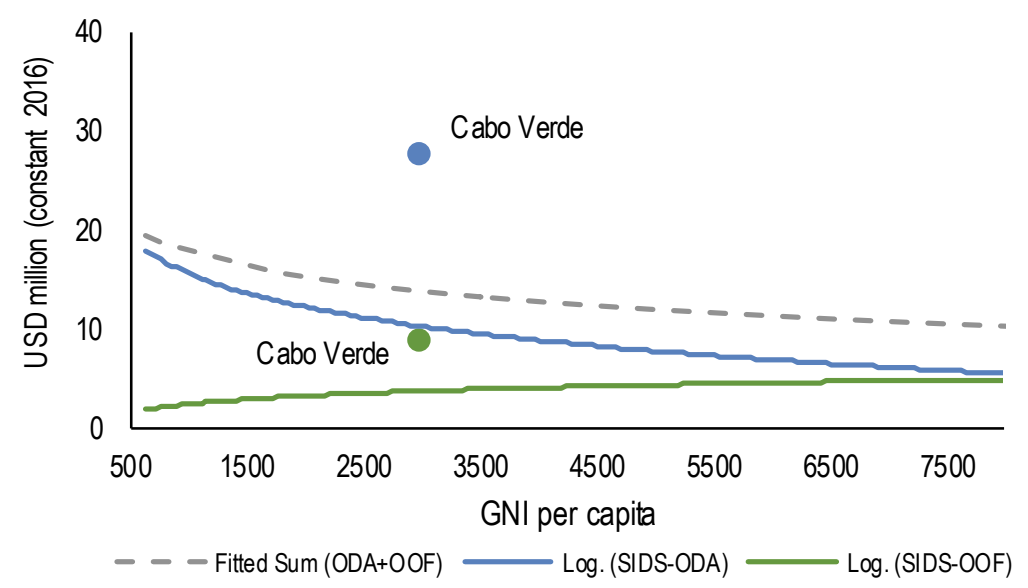

Note: The trendlines show predicted values of logarithmic regressions using ODA and OOF flows to ODA eligible SIDS; ODA and OOF to the energy sector includes the sector codes 230, 231, 232, 233, 234, 235, and 236.

Source: Authors based on OECD (2018[32]), Creditor Reporting System, https://stats.oecd.org/Index.aspx?DataSetCode=crs1 for ODA and OOF; World Bank (2018[8]), World Development Indicators, https://datacatalog.worldbank.org/dataset/world-development-indicators. 


\section{Counselling: Recommendations for the DAC and its partners: Promoting mixed transition finance strategies}

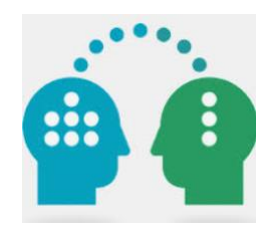

Cabo Verde's new national financing strategy (PEDS) will require OECD DAC support that combines mixed strategies for transition financing. In 2017, H.E. Mr. Jose Luis Rocha, Ambassador of Cabo Verde to the UN, called upon development partners to adopt a mixed strategy to support Cabo Verde's economic transition in line with the 2030 Agenda. All sources of finance should contribute to the implementation of the national strategy for sustainable development. As noted in the "Assessing" and "Benchmarking" sections, Cabo Verde's national strategy will rely primarily on domestic resource mobilisation (89\%). Yet, there remains a crucial gap to link external resource mobilisation to the 2030 Agenda. A fusion of the co-operative and competitive strategies presented below is needed to transform SIDS vulnerabilities such as tackling climate change into leveraging these as strengthens, e.g. the Blue Economy. The mixed strategy to achieve economic transition requires a combination of support along the following three dimensions:

1. Co-operative strategy: Development partners must support mobilisation of domestic resource mobilisation, debt restructuring, and ensure that ODA reduction contributes to strengthening capacities and resilience in health and education systems and other social issues such as environment and climate change, etc. to avoid socioeconomic risks.

2. Competitive strategy: In parallel, development partners must step-up support for the enablers of self-sustained financing, i.e. trade, investment, industrialisation, and private sector participation in infrastructure and productive sectors

3. Renewed partnership: Finally, greater harmonisation of support by development partners is needed to operationalise a mixed approach to transition finance strategies. Operationalising the strategies will require better co-ordination in addition to the promotion of innovation and enhanced transparency.

1. The co-operative strategy requires better support to manage debt, build resilience and to avoid socioeconomic setbacks.

There is a continuous need for public sector intervention and Official Development Finance (ODF) throughout graduation and transition. Economic transition driven by income per capita has led to the withdrawal of certain donors, some more gradually than others. Other development criteria, beyond income, such as economic and environmental vulnerabilities, should drive withdrawal decisions. Moreover, as demonstrated in the Benchmarking section, ODA provided by development partners is phasing out quickly in key SDG-related sectors while OOF does not always provide a reliable substitute. While budget support remained consistent, risks of both financing and capacity gaps (e.g. expertise in health and education project management) are emerging. Strengthening support for local institutional capacity building will be crucial as ODA reduction is carried out.

Financing must be better targeted to address economic and environmental vulnerabilities even after LDC graduation and beyond income per capita levels. SIDS in particular require support to address the specific challenges of small market size, import dependency, narrow export base, spatial dispersion of islands, remoteness, climate-related disasters, etc. Following 
LDC graduation, Cabo Verde continues to require targeted support to build capacities to design national adaptation strategies and to enable access to new sources of climate finance.

Infrastructure financing remains a key challenge in Cabo Verde particularly to strengthen transportation, water security, and electricity. OECD DAC members must target investments in line with national financing for sustainable development strategies and priorities. To reduce transaction costs and ensure country ownership, OECD DAC members must adhere to their commitment to avoid tied aid. As demonstrated in the Assessment and Benchmarking sections, the terms and conditions of ODA shifted quickly following graduation, leaving a short window for transition. The priorities set for ODA financing were not aligned to country needs (e.g. social housing). With the growing debt burden, well targeted infrastructure financing is crucial to attracting private sector engagement and repay debt service.

OECD DAC members must provide support for the SOE privatisation process and assess potential social impacts (e.g. inequalities). With the high concentration of foreign investment in Cabo Verde, there are risks of private rent capture and negative impact on prices. OECD DAC members can play a role to help monitor reforms of the investment and tax regimes. Investment regimes and tax policies must be designed in support of sustainable and inclusive development. In Cabo Verde, there is a need to better monitor tax incentives and Special Economic Zone (SEZ). OECD DAC members should align with strategy of partners and reinforce efforts to improve tax co-operation. Furthermore, there is a risk of the emergence of a dual economy if investors are not selected prudently. With growing foreign investments, efforts are needed to fight rising inequalities (e.g. geographical - across islands, rural/urban, unemployment, gender, youth).

Addressing the risk of debt distress is a precondition for achieving the SDGs. Urgent action is required to transform the current, unsustainable model (130\% debt to GNI) which, as indicated by the IMF classification, has led the country to present a "high risk" of debt distress. Investments are needed to enhance commercial viability and to deliver returns on infrastructure financing (e.g. logistics and connectivity). While the People's Republic of China represents $1 \%$ of the current debt portfolio in Cabo Verde, its role and the role of other private investors is growing and lending continues on less concessional terms. OECD DAC members should consider how to leverage the missed opportunities to support the transformation agenda in Cabo Verde.

To address debt sustainability, dialogue with a broader set of public and private sector actors is crucially needed. As a result of LDC graduation, grants declined rapidly while concessional and non-concessional loans increased. Transition support groups disbanded and currently do not represent all major actors. In parallel, access to debt relief phased out. There is a need to strengthen global and national co-ordination mechanisms with multilateral organisations (IMF Debt Sustainability Assessments), non-Paris Club actors and private sector actors to monitor external private debt to ensure adequate terms and conditions of debt finance following LDC graduation. Moreover, the criteria for accessing debt relief programmes and untied aid recommendations should be reconsidered in the case of high debt distress.

Support to strengthen domestic resource mobilisation (e.g. tackling informality) is essential to mitigate the impact of debt distress. Cabo Verde struggles to overcome high informality which puts strain on social security contributions and other forms of domestic resource mobilisation. Illicit flows also present a risk to financing leakages as migration from 
West Africa grows. Migration presents a security risk as well as new challenges to successfully finance health and education. Alternative sources of financing (e.g. LuxDev and microfinance) must be further explored and scaled up to address informality and to ensure that no one is left behind.

Domestic resource mobilisation is the central pillar of financing required to avoid transition gaps as ODA is reduced. Support must be targeted to help countries identify, model, and implement the tax policies needed to increase expenditure, particularly in key social sectors (e.g. health and education). In order to reduce aid dependency, OECD DAC members must provide investments that secure long-term sustainable development. Understanding how to better target domestic resource mobilisation and public financial management will be essential to balance country ownership and long-term strategic interests.

2. The competitive strategy calls for support to build capacities in productive and service sectors

For Cabo Verde to achieve its national ambition to implement a private sector-led development growth strategy, constraints to competitiveness as a small island developing state must be addressed. As demonstrated in the Assessing and Benchmarking sections, Cabo Verde's faces many challenges to strengthen competitiveness due to its small market size. Seeking integration with broader global or regional markets will be crucial. Opportunities for regional integration remain untapped, services potential for health, offshore services, etc. and strategic positioning with Europe (e.g. via ECOWAS) could be further scaled up. The trade potential of Cabo Verde could further be strengthened, particularly through consolidation of MSMEs and strengthening financial inclusion. Moreover, regional and global integration are needed to leverage the potential of Cabo Verde as a "start-up economy", particularly in relation to engagement with bilateral DFIs.

Strengthening the business environment, competition and tax policy will require continued support. As mentioned, Cabo Verde's Doing Business ranking has declined and continued commitment to improving the business environment is critical. Reduction of tied aid will be essential to ensure competitiveness of the local markets and to encourage local entrepreneurship. Furthermore, efforts to promote tax co-operation will be increasingly important as the country seeks to attract foreign investment (e.g. SEZ, off-shore banking, etc.). Cabo Verde has made progress by recently accepting to join the OECD/G20 Inclusive Framework on Base Erosion and Profit Shifting (BEPS) Project. As mentioned previously, infrastructure financing is crucial to ensure competitiveness (e.g. transportation and electricity costs). Priority to fill in the infrastructure gap, and/or improve logistics and connectivity (e.g. dams and agriculture). Finally, OECD DAC must support domestic entrepreneurship and promote SME development (consolidation).

Cabo Verde further requires enhanced support for investment and trade capacities. Cabo Verde must achieve economic diversification to reduce vulnerabilities and ensure continued economic growth. The transformation agenda calls for promoting the "Made in Cabo Verde" brand and establishing the country as a logistics/maritime platform including existing exports and agricultural niches while increasing domestic value and backward and forward linkages (BPO, tourism, fisheries). Additionally, the country can leverage FDI and fishing agreements to maximise the sustainable development footprint of these resources in support of the maritime/logistics platforms. OECD DAC members must strive to better leverage the local value-added via the "Blue Economy" and the provision of targeted support for SDG14 "safeguard healthy oceans, and make fish trade sustainable". Improving 
integration in global value chains and focusing on SME development will be essential and also rely on enhanced capacity building.

\section{Bridging the divide between these strategies calls for a renewed partnership around innovation, co-ordination and transparency}

There is a need to bridge the divide between co-operative and competitive strategies. A mix of both strategies is needed to achieve a holistic approach to financing for sustainable development in Cabo Verde. A fusion is needed to harness SIDS vulnerabilities, for example due to climate change, and leverage these as a strength (e.g. the Blue Economy). A triptych of transparency, innovation and co-ordination must be implemented to bring the two strategies together coherently and ensure continued upward economic transition.

In regard to transparency, the question of debt sustainability requires a renewed effort to restore trust among all development partners. In light of the growing role of the People's Republic of China to finance the transformation agenda in Cabo Verde, there is a need to strengthen the transparency of financing and dispel concerns of a "hidden agenda" (e.g. off-shore financial centre). Transition support groups should be inclusive of all development partners and private sector actors. Private external government debt represents $32 \%$ of Cabo Verde's debt portfolio. Private investors should be engaged in discussions on debt sustainability to ensure a smooth transition from concessional to non-concessional financing. The Cascade approach (creating markets in health, education, etc.) could help to secure win-win partnership with private sector actors.

Development partners can help to deliver innovative solutions to maximise financing for sustainable development in Cabo Verde. New instruments and forms of partnerships must be leveraged. Remittances provide a significant source of financing yet these could be better leveraged in support of productive sustainable development investments. Diaspora bonds provide one opportunity. Other opportunities should be explored, including the potential to target exports to the diaspora community and improving financial literacy and inclusion of migrants. Other types of innovative finance: blue, green, impact bonds can further be developed. However, there is a need to identify partners and build local capacities (e.g. accessing the Green Climate Fund). The example of the Seychelles provides one best practice, particularly in the area of debt swaps. Finally, engagement with DFIs requires additional capacity building and integrating regional and global markets. OECD DAC members must promote instruments and modalities adapted to local context.

Finally, OECD DAC members have a key role to play in strengthening co-ordination among all development partners, particularly in the context of LDC graduation. LDC graduation resulted in a multiplication of reports and assessments addressing transition issues. The numerous institutional agencies involved in LDC graduation require better coordination to avoid duplication of efforts and "report fatigue". Co-ordination with the private sector also needs to be reinforced. Within Cabo Verde's administration there is also a need to strengthen inter-ministerial capacities and structure co-ordination to address new challenges, including the fusion of competitive and cooperative approaches (climate, blue economy). Limited knowledge sharing and expertise (e.g. agriculture/green) as well as lack of capacity to structure innovative instruments must also be addressed. Finally, co-operation from the global to the local level must be strengthened. The participation of civil society and south-south and triangular co-operation can help to build capacities and localise the SDGs and tackle growing inequalities. 
As countries graduate from the LDC category, there is a need to assess the responsibilities among actors. How to understand the roles of the different actors (e.g. OECD DAC, non-traditional providers, multilateral organisations, private sector actors, NGOs, etc)? How to account for the dichotomy between the DAC and other actors, particularly in terms of commitments to countries most in need (eg LDCs, SIDS, LLDCs, fragile and conflict-affected countries)? Currently, different actors play by different rules. How can the DAC seize opportunities to raise the level of accountability?

An opportunity is emerging to strengthen support for the creation of "integrated national financing frameworks" (INFFs) as called for by the Addis Ababa Action Agenda (para 9). OECD DAC members can support, alongside other institutional stakeholders, a new coordination mechanism aligned to the PEDS and extended to all actors in order to better identify the roles of public, private, domestic and external actors in support of financing for the SDGs at country-level.

${ }^{1}$ A recent Inter-Agency Task Force (IATF) on Financing for Development meeting emphasised the importance of ensuring the coherence of a financing strategies and frameworks. For more information see: https://developmentfinance.un.org/sites/developmentfinance.un.org/files/ Opening\%20presentation_FSDO.pdf

${ }^{2}$ A "MIC grey area" represents the stage at which developing countries attain the middle-income per capita threshold at which they no longer benefit from certain international commitments and agreements, particularly the allocation of concessional financing and preferential trade agreements. Yet, vulnerabilities beyond income persist among middle income countries and require continued targeted support.

${ }^{3}$ LDCs benefit from OECD DAC member pledges to target highly concessional ODA loans (2014 OECD DAC HLM agreement to establish the grant element threshold of $45 \%$ for LDCs as from 2018), and the EU, Ireland, Portugal, United Kingdom committed to targeting greater volumes of ODA to LDCs: $0.15-0.2 \%$ ODA/GNI to LDCs. (OECD DAC, 2016[54])

${ }^{4}$ LDCs benefit from preferential trade agreements. These include: the Generalised System of Preferences (GSP) with duty and quota free access to LDCs, for example the EU "Everything But Arms" agreement, and the US African Growth Opportunity Act (AGOA), Canada Least Developed Country Tariff, certain emerging economies are providing trade preferences to LDCs, and others provide trade preferences to LDCs via regional trade agreements. (United Nations Committee for Development Policy, 2016 $[55]$ )

${ }^{5}$ The IMF DSA 2016 notes that the risk of external debt distress has increased with growing publicly guaranteed debt, although on highly concessional terms. Contingent liabilities due to restructuring of SOEs present another risk. The DSA recommends strengthening public investment management and management of SOE contingent liabilities.

\footnotetext{
${ }^{6}$ Several empirical studies suggest that while growth does not stagnate at the middle-income level, economic factors associated with growth differ between middle income and other countries. The ADB shows that variables such as banking/currency crises, government debt as a share of GDP, and capital flows beyond FDI become more important for continued economic growth among middle income countries. Avoiding a middle income trap, as a result, requires operationalising a new growth

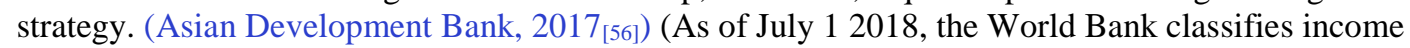


categories as follows: low income <995, Lower middle income 996-3895, upper middle income: 3,896-12,055 and high income: $>12,055$.).

${ }^{7}$ EVI measures structural economic vulnerability resulting from natural or external shocks.

${ }^{8} \mathrm{HAI}$ measures basic social indicators related mainly to health and education.

${ }^{9}$ The graduation threshold is set at $10 \%$ below the inclusion threshold which is at 36 (UN Economc Analysis \& Policy Division, 2018 [53])

10 The total debt stock for the three largest SOEs reached 32\% of GDP in 2016 (USD 550 million), with the largest debt held by Imobiliária, Fundiária e Habitat (IFH) (USD 225 million), followed by ELECTRA (USD 192 million) and Transportes Aéreos de Cabo Verde (TACV) (USD 134 million) (World Bank, 2018 [57])

${ }^{11}$ Drought in 2002 with 30,000 people affected, Drought in 1998 with 10,000 people affected, Volcanic activity in 2014 (1995) with 2500 (6306) people affected, Flood in 2009 with 150 people affected, Storm in 2015 with economic costs of USD 1.1 million.

${ }^{12}$ Concessional debt is defined as loans with an original grant element of 25 percent or more.

${ }^{13}$ Concessional and debt service indicators suggest that Cabo Verde can service its debt obligations OECD 2016.

${ }^{14}$ The BSG is made up of the African Development Bank, the European Union, Luxembourg, Portugal and the World Bank. The BSG set-up a joint process for monitoring and evaluating Cabo Verde's performance across a number of policy areas, as the basis for disbursing pledged budget support funding. The joint review missions take place twice a year and brings together some development partners providing sectoral or general budget support to Cabo Verde.

${ }^{15}$ The GAT included the Government of Cabo Verde, multilateral institutions (African Development Bank, World Bank, European Union and the UN System) as well as bilateral actors (Austria, People's Republic of China, Spain, USA, France, Netherlands, Luxemburg and Portugal).

${ }^{16}$ The EIF is a multi-donor trust fund, which provides co-ordinated financial and technical support to build trade capacity in 48 LDCs and three graduated countries. The EIF is an Aid for Trade programme designed for the LDCs. The EIF is recognised under Goal 8a of the Sustainable Development Goals.

${ }^{17}$ Cabo Verde graduated to AfDB non-concessional finance (ordinary capital) in 2009 (based on income per capita, debt profile low or moderate risk, debt sustainability analysis). The country continues to receive concessional finance extended by the ADF on an exceptional basis, although it was set to exit in 2015. In addition, Cabo Verde is a "blend" country accessing both IDA and IBRD with the Small State Exception. This exception recognises vulnerabilities beyond income, including high transportation costs, fewer opportunities to pursue economies of scale and severe human capital constraints because of their small populations.

${ }^{18}$ The Heavily Indebted Poor Countries Initiative and Multilateral Debt Relief Initiative, contributed to a two-thirds reduction of debt in sub-Saharan Africa by 2008

${ }^{19}$ The HIPC and related Multilateral Debt Relief Initiative (MDRI) programmes have relieved 36 participating countries of USD99 billion in debt.

${ }^{20}$ Kosovo, Kyrgyzstan, the Maldives, Marshall Islands, Micronesia, Samoa, Syria, Tajikistan, Tonga, and Zimbabwe have been added to the list of countries that benefit from the OECD DAC Recommendation on Untying ODA. These countries were included based on exceptionally high levels of indebtedness.

${ }^{21}$ A public-private consortium was established with Cabo Verdian and Portuguese actors to oversee the housing project "Casa para Todos". The Public-Private Partnership has led to contingent liabilities. 
${ }^{22}$ A Memorandum of Understanding was signed by Portugal and Cape Verde with the objective of starting negotiations for the conclusion of a new Strategic Co-operation Programme (SCP) from 2017-2021.

${ }^{23}$ Following graduation from the LDC category, Cabo Verde no longer accesses the NAPA whose main objective is "identification of the urgent and immediate needs and concerns of the least developed countries (LDCs), relating to adaptation to the adverse effects of climate change". The last 2007 NAPA exercise in Cabo Verde highlighted water scarcity as one of the main challenges facing the country. It further emphasised the need for investment to protect and prevent degradation of coastal zones caused by both climate aggressions and the tourism sector. Lastly, it stressed the need to develop the adaptability of agro-silvo-pastoral production systems to ensure and improve national food production.

${ }^{24}$ A diversity of financing mixes can achieve upward transition. The term "optimal" does not indicate that all countries should attempt to balance resources according to the distribution on average. Attracting levels of external private or domestic resources above the curve, does not indicate that these flows are suboptimal. Rather, the trend lines provide a proxy threshold for substituting sufficient levels of other resources as ODA is phased out.

25 Other Official Flows (OOF) are official flows provided by OECD DAC members that either do not meet the concessionality requirements of ODA and/or are commercially-oriented. For more information on the sectoral characteristics of this form of financing, see: "Official Development Finance in the SDG-era: A sectoral overview" (DCD/DAC(2018)24)

${ }^{26}$ Cabo Verde does not demonstrate signs of the "Dutch disease" mainly because most of the tradable sector wages are concentrated in the tourism sector.

${ }^{27}$ Portugal and France accounts for $30.4 \%$ and $22.2 \%$ of remittance inflows respectively.

${ }^{28}$ Multilateral concessional lending through the small states exception has played a role to reduce the need for OOF financing in middle income SIDS.

${ }^{29}$ The highest remittance share of GDP among SIDS is found in Haiti (29.6\%), Comoros (21.2\%) and Tonga (19.9\%). While certain Upper Middle-Income Countries (UMICs), such as Mauritius, benefit from volumes of remittances that are similar to levels in Cabo Verde, these volumes represent a much smaller share of GDP (less than $1 \%$ in Mauritius).

${ }^{30}$ Cabo Verde receives a majority of technical assistance from multilateral organisations such as WHO, Global Fund, FAO, West Africa Health Organisation, etc.

${ }^{31}$ The EU-LUX-WHO programme supports the national strategy for universal healthcare coverage.

32 Despite high-level of tax-to-GDP, the country's level of debt distress remains high due to government debt which requires further support to more effectively raise resources and ensure debt sustainability.

${ }^{33}$ Cabo Verde is ranked 127 out of 190 countries according to the WB Doing Business index due to low scores in the categories: getting electricity (145), protecting minority investors (164), and resolving insolvency (168).

34 The OECD defines "blended finance" as "the strategic use of development finance for the mobilisation of additional finance towards sustainable development in developing countries". For more information see: $\quad$ http://www.oecd.org/development/financing-sustainabledevelopment/development-finance-topics/blended-finance.htm

${ }^{35}$ Cabo Verde signed the Blue Growth Charter in 2012, signalling efforts "to minimise environmental degradation, biodiversity loss, and the nondurable use of marine resources, and to maximise the economic and social benefits to the population".

${ }^{36}$ Loans provided by SOFID require a minimum of USD 250 thousand up to 10 years while the average ODA project size in Cabo Verde was USD 400 thousand in 2016-17. 
${ }^{37}$ Cabo Verde created a network connecting NGOs, national police, health centres and community law centres, which is considered to be effective according to the $2018 \mathrm{GSP}+$ report.

\section{References}

Asian Development Bank (2017), The Landscape of Economic Growth: Do Middle-Income Countries Differ?, https://www.adb.org/publications/landscape-economic-growth-middleincome-countries.

Cabo Verde (2018), Voluntary National Report of the Implementation of the 2030 Agenda for Sustainable Development, https://sustainabledevelopment.un.org/content/documents/19580Cabo Verde VNR SDG Ca bo Verde 2018 ING final NU 280618.pdf.

Cabo Verde (2015), Managing Sovereign External Debt to Serve Development: The Case of Cabo Verde, https://unctad.org/meetings/en/Presentation/tdb62_Item2_CaboVerde_en.pdf.

Cabo Verde (2017-2021), Bases para o Plano Estratégico de Desenvolvimento Sustentável (PEDS), http://www.mf.gov.cv/index.php/legislacao-new/cat view/55-documentos/128direccao-nacional-do-planeamento-dnp.

Chatham House: The Royal Institute of International Affairs (2015), Institutional Stability and Economic Success in Africa: Lessons from Cabo Verde, https://www.chathamhouse.org/sites/default/files/field/field document/15\%2003\%2009\%20C abo\%20Verde\%20Duarte_kl\%20(edited).pdf.

Dreher, A. (2017), “Aid, China and Growth: Evidence from a New Global Development Finance Dataset", AidData Working Paper Nr. 46, https://www.aiddata.org/data/chinese-globalofficial-finance-dataset.

EM-DAT (2018), The International Disaster Database, Centre for Research on the Epidemiology of Disasters (CRED), https://www.emdat.be/.

Enhanced Integrated Framework (2013), Diagnostic Trade Interation Study Update, https://www.enhancedif.org/en/country-profile/cabo-verde.

European Commission (2018), The EU Special Incentive Arrangement for Sustainable Development and Good Governance ('GSP+') assessment of Cabo Verde covering the period 2016 - 2017, http://trade.ec.europa.eu/doclib/docs/2018/january/tradoc_156540.pdf.

European Commission (2012), Good governance and development contract and support to the Special Partnership Cape Verde-EU, https://ec.europa.eu/europeaid/sites/devco/files/aapgovernance-economic-growth-cape-verde-af-2012_en.pdf.

Ferdi (2016), "Human Assets Index retrospective series: 2016 update", Ferdi Working paper P179, http://www.ferdi.fr/en/indicator/human-assets-index. 
Ferdi (2015), A retrospective Economic Vulnerability Index, http://www.ferdi.fr/en/indicator/retrospective-economic-vulnerability-index.

GAT (2007), Déclaration sur la sortie effective et durable du Cap Vert du Gropue des Pays les Moins Avancés adoptée par le Gouvernement du Cap-Vert et le Groupe d'Appui à la Tranition (GAT), http://www.oecd.org/fr/pays/caboverde/38889374.pdf.

ICTD/UNU-WIDER (2018), "Government Revenue Dataset", https://www.wider.unu.edu/project/government-revenue-dataset.

IMF (2018), Debt Relief Under the Heavily Indebted Poor Countires (HIPC) Initiative, https://www.imf.org/en/About/Factsheets/Sheets/2016/08/01/16/11/Debt-Relief-Under-theHeavily-Indebted-Poor-Countries-Initiative.

IMF (2018), Staff Report for the 2018 Article IV Consultation - Debt Sustainability Analysis, https://www.imf.org/external/pubs/ft/dsa/pdf/2018/dsacr18104.pdf.

IMF (2018), World Economic Outlook Database 2018, https://www.imf.org/external/pubs/ft/weo/2018/01/weodata/index.aspx.

IMF (2016), IMF Country Report: Cabo Verde, https://www.imf.org/external/pubs/ft/scr/2016/cr16367.pdf.

IMF (2016), The Multilateral Debt Relief Initiative, https://www.imf.org/external/np/exr/facts/pdf/mdri.pdf.

IPAD (2007), COUNTRY EVALUATION, http://www.oecd.org/countries/caboverde/40982951.pdf.

John Hopkins SAIS China-Africa Research Initiative (2018), "Chinese Loans to African Governments, Version 1.1 September 2018”, http://www.sais-cari.org/data-chinese-loans-andaid-to-africa.

Jubilee Debt Campaign (2018), Africa's growing debt crisis: Who is the debt owed to?, https://jubileedebt.org.uk/wp/wp-content/uploads/2018/09/Briefing_09.18.pdf.

Kanwischer, P. (2012), WaterPricing in Cape Verde, Goethe-Universität Frankfurt am Main, https://wocatpedia.net/images/4/49/Irmler\%2C_Li_2012_Water_Pricing_in_Cape_Verde.pdf.

Madeira, J. (2017), The Dragon Embraces Africa: Cape Verde-China Relations, Brazilian Journal of Strategy and International Relations, https://seer.ufrgs.br/austral/article/viewFile/76262/47682.

Netherlands Enterprise Agency (2017), Cabo Verde: Multi-sector market study focused on tourism value chain development, https://www.rvo.nl/sites/default/files/2017/08/Cape\%20Verde\%20MultiSector\%20Market\%20Report_Focus\%20Tourism_pub.pdf.

OECD (2019), Global Outlook on Financing for Sustainable Development 2019: Time to Face the Challenge, OECD Publishing, https://doi.org/10.1787/9789264307995-en.. 
OECD (2018), 2018 Report on the DAC Untying Recommendation, https://www.oecd.org/dac/financing-sustainable-development/development-financestandards/DCD-DAC(2018)12-REV2.en.pdf.

OECD (2018), Creditor Reporting System (database), OECD, Paris, https://stats.oecd.org/Index.aspx?DataSetCode=crs1.

OECD (2018), Making Development Co-operation Work for Small Island Developing States, OECD Publishing, Paris, https://dx.doi.org/10.1787/9789264287648-en.

OECD (2018), Transition finance: update on ongoing discussions and work, https://one.oecd.org/document/DCD/DAC(2018)4/en/pdf.

OECD (2017), African Economic Outlook 2017, https://doi.org/10.1787/aeo-2017-en.

OECD (2017), "Global Revenue Statistics Database”, http://www.oecd.org/tax/tax-policy/globalrevenue-statistics-database.htm.

OECD (2017), SUMMARY RECORD OF THE 1027TH DAC MEETING, https://one.oecd.org/document/DCD/DAC/M(2017)4/FINAL/en/pdf.

OECD (2017), SUPPORTING COUNTRIES DEVELOPMENT PATHWAYS IN THE SDG ERA: UPDATE AND EMERGING ISSUES, OECD, https://one.oecd.org/document/DCD/DAC(2017)17/en/pdf.

OECD (2015), OECD Development Co-operation Peer Reviews: Portugal 2016, OECD Development Co-operation Peer Reviews, OECD Publishing, Paris, https://dx.doi.org/10.1787/9789264248571-en.

OECD DAC (2016), Compendium of members' recent efforts to support countries most in need, https://www.oecd.org/dac/financing-sustainable-development/DAC-Compendium-membersefforts-support-countries-most-in-need.pdf.

Portugal - Cabo Verde (2017-2021), Programa Estrategico de Cooperacao, http://www.institutocamoes.pt/images/cooperacao/pec cv 1721.pdf.

SDSN and SDG Center for Africa (2018), SDG Index and Dashboards Report 2018, http://unsdsn.org/wp-content/uploads/2018/06/AFRICA-SDG-2018-Final-SummaryReport.pdf.

UN Economc Analysis \& Policy Division (2018), LDC Identification Criteria \& Indicators, https://www.un.org/development/desa/dpad/least-developed-country-category/ldccriteria.html.

UNDP (2017), LAUNCHING A DIASPORA BONDS PROGRAMME IN CABO VERDE.

UNDP (2013), Gini Coefficient Data, http://hdr.undp.org/en/content/income-gini-coefficient. 
UNECA (2016), Country Profile: Cabo Verde,

UNIDO (2016), Fisheries Value Chain Analysis and Cluster Mapping, Cabo Verde, http://dx.doi.org/10.13140/RG.2.2.23000.29442.

United Nations (2015), Addis Ababa Action Agenda, http://www.un.org/esa/ffd/wpcontent/uploads/2015/08/AAAA Outcome.pdf.

United Nations Committee for Development Policy (2016), Trade Preferences for Least Developed Countries. Are they Effective? Preliminary Econometric Evidence, http://www.un.org/en/development/desa/policy/cdp/cdp_news_archive/2016_Member_Trade Preferences_Klasen.pdf.

UN-OHRLLS (2017), A Guide to Least Developed Country Graduation, http://unohrlls.org/customcontent/uploads/2017/11/UN_Graduation_Booklet_2017_LowRes.pdf.

US Department of State (2018), 2018 Investment Climate Statement - Cabo Verde, https://www.state.gov/e/eb/rls/othr/ics/2018/af/281394.htm.

World Bank (2018), Program Information Document, http://documents.worldbank.org/curated/en/125621531480106694/pdf/Concept-ProgramInformation-Document-PID-Cabo-Verde-Disaster-Risk-Management-Development-PolicyCredit-and-Loan-with-Cat-DDO-P160628.pdf.

World Bank (2018), SOE related Fiscal Management Project, http://documents.worldbank.org/curated/en/288831528342274274/pdf/Cabo-Verde-PADSECPO-Edit-vF-05152018.pdf.

World Bank (2018), World Development Indicators (WDI), https://datacatalog.worldbank.org/dataset/world-development-indicators.

World Bank (2014), Country Partnership Strategy for the Republic of Cabo Verde, http://documents.worldbank.org/curated/en/857221468020338544/pdf/922480REVISED00UP DATE0BOARD0NUMBERS.pdf.

World Bank Group (2019), Doing Business 2019: Training for Reform - Economy Profile - Cabo Verde, http://www.doingbusiness.org/content/dam/doingBusiness/country/c/caboverde/CPV.pdf.

World Bank Group (2017), Cabo Verde: Access to Finance for MSMEs, http://documents.worldbank.org/curated/en/825171511262268770/pdf/Project-InformationDocument-Integrated-Safeguards-Data-Sheet-Cabo-Verde-Access-to-Finance-for-MSMEsP163015-Sequence-No-00.pdf.

World Bank Group (2013), PROJECT INFORMATION DOCUMENT (PID), http://documents.worldbank.org/curated/en/126681468020366096/pdf/PID-Appraisal-PrintP126516-04-12-2013-1365770552842.pdf. 
World Bank Group (2011), Remittance Markets in Africa, World Bank group, http://siteresources.worldbank.org/EXTDECPROSPECTS/Resources/4768821157133580628/RMA FullReport.pdf.

World Bank Group (2007), , https://data.worldbank.org/indicator/SI.POV.GINI?locations=CABO VERDE.

World Economic Forum (2017), The Global Competitiveness Report 2017-2018, http://www.weforum.org/gcr. 


\section{Annexes}

\section{Mapping of transition finance groups and diagnostics}

This table provides an overview of the various agencies and groups that aim to support LDC graduation and transition in Cabo Verde.

\begin{tabular}{|c|c|}
\hline $\begin{array}{l}\text { UN DESA/ } \\
\text { COMMITTEE } \\
\text { FOR } \\
\text { DEVELOPMENT } \\
\text { POLICY (CDP) }\end{array}$ & $\begin{array}{l}\text { - Responsible for LDC graduation, criteria and carrying out } \\
\text { triennial reviews of LDC graduates. } \\
\text { - The latest monitoring report on Cabo Verde was completed in } \\
2012 \text { to "assess any signs of deterioration in the development } \\
\text { progress". } \\
\text { - A Vulnerability and Resilience Country Profile (VRCP) Project } \\
\text { is currently being carried out by DESA. }\end{array}$ \\
\hline $\begin{array}{l}\text { CABO VERDE } \\
\text { BUDGET } \\
\text { SUPPORT GROUP } \\
\text { (BSG) }\end{array}$ & $\begin{array}{l}\text { - The BSG is comprised of the African Development Bank, the } \\
\text { European Union, Luxembourg, Portugal and the World Bank. } \\
\text { Spain left the BSG in } 2015 \\
\text { - The BSG works jointly with the government and on general } \\
\text { progress reviews. }\end{array}$ \\
\hline $\begin{array}{l}\text { GROUPE D'APPUI } \\
\text { À LA } \\
\text { TRANSITION } \\
\text { (GAT) }\end{array}$ & $\begin{array}{l}\text { - The GAT was constituted by the Government of Cabo Verde } \\
\text { and its main development partners: Austria, Spain, US, France, } \\
\text { Netherlands, Luxembourg, Portugal, China, African } \\
\text { Development Bank, World Bank, European Commission and } \\
\text { the United Nations system. } \\
\text { - The GAT was disbanded however due to a lack of structure, } \\
\text { planning and resources. Donors phased out shortly after its } \\
\text { creation. }\end{array}$ \\
\hline $\begin{array}{l}\text { ENHANCED } \\
\text { INTEGRATED } \\
\text { FRAMEWORK } \\
\text { (EIF) }\end{array}$ & $\begin{array}{l}\text { - Carried out a Diagnostic Trade Integration Study (DTIS) in } \\
\text { Cabo Verde, five years following accession to the WTO. } \\
\text { - The DTIS provides a concrete table of actions and indicators to } \\
\text { evaluate progress. }\end{array}$ \\
\hline $\begin{array}{l}\text { IMF ARTICLE IV } \\
\text { CONSULTATIONS }\end{array}$ & $\begin{array}{l}\text { - Article IV consultations result in a ranking of the risk of a } \\
\text { country's debt distress based on the Debt Sustainability } \\
\text { Assessment (DSA) and provide recommendations to improve } \\
\text { debt sustainability. }\end{array}$ \\
\hline $\begin{array}{l}\text { WORLD BANK } \\
\text { COUNTRY } \\
\text { PARTNERSHIP } \\
\text { STRATEGY FY15- } \\
17\end{array}$ & $\begin{array}{l}\text { - The CPS is carried out on a biannual basis and provides an } \\
\text { overview of the major development challenges and presents a } \\
\text { strategy for co-ordination of development partners. }\end{array}$ \\
\hline $\begin{array}{l}\text { WORLD BANK } \\
\text { SYSTEMATIC } \\
\text { COUNTRY } \\
\text { DIAGNOSTIC } \\
\text { (SCD) }\end{array}$ & $\begin{array}{l}\text { - Carried out a Systematic Country Diagnostic (SCD) aimed to } \\
\text { "identify the binding constraints as well as the opportunities for } \\
\text { reducing extreme poverty and raising the welfare of the poorest } \\
40 \text { percent of Cabo Verde's population in a sustainable manner". }\end{array}$ \\
\hline
\end{tabular}


UNDP

UN-DESA

UNCTAD

INVESTMENT

POLICY REVIEW
- UNDP is specifically involved in the Delivering as One $(\mathrm{DaO})$ UN Program which is piloted in Cabo Verde and aims to harmonise the different UN programs in Cabo Verde; The work program primarily aimed at addressing the implications of Cabo Verde's LDC graduation (MPTF)

- Establishment of a Joint Office including UNDP, UNICEF and UNFPA to reduce overall and transaction costs of UN programs

- Cape Verdean Transition Funds (Cabo VerdeTF) administered by the UNDP Multi-Partner Trust Fund Office; the fund seeks to provide new resources assisting the ONE UN program

- Background paper focussing on developing productive capacities that draws on Cabo Verde as LDC graduate and comparing to Botswana, Bhutan, Maldives, Samoa, Vanuata and Solomon Islands (UN-DESA 2018);

- The reviews evaluate the country's legal, regulatory and institutional framework to attract foreign direct investment (FDI) and further seeks to address how its benefits can be maximised (UNCTAD 2018) 
Description of LDC criteria

\begin{tabular}{|c|c|c|}
\hline Criteria & Description & $\begin{array}{l}\text { Graduation } \\
\text { threshold }\end{array}$ \\
\hline $\begin{array}{l}\text { Gross } \\
\text { National } \\
\text { Income per } \\
\text { capita (GNI } \\
\text { per capita) }\end{array}$ & $\begin{array}{l}\text { Gross national income is the sum of } \\
\text { all residents' value-added, product } \\
\text { taxes (subtracting subsidies) not } \\
\text { included in the valuation of output as } \\
\text { well as net receipts of primary } \\
\text { income from abroad. The latter can } \\
\text { take the form of compensation from } \\
\text { residents employed abroad or } \\
\text { income from foreign property held } \\
\text { by residents. The level of GNI per } \\
\text { capita indicates the overall income } \\
\text { status of a country. As LDC criteria, } \\
\text { it is calculated according to the } \\
\text { World Bank Atlas method to reduce } \\
\text { the impact of short-term exchange } \\
\text { rate fluctuations. } \\
\text { Its role of criteria of LDC graduation } \\
\text { is twofold. Passing the lower } \\
\text { threshold is sufficient for graduation } \\
\text { if the two other criteria are met } \\
\text { accordingly. If this is not the case, } \\
\text { the country still graduates from the } \\
\text { LDC category when its three year } \\
\text { average GNI pc lies above the } \\
\text { second, higher threshold. }\end{array}$ & $\begin{array}{l}1230 \text { USD } \\
\text { (Atlas } \\
\text { method) } \\
\text { or } \\
2460 \text { USD } \\
\text { (Atlas } \\
\text { method, } \\
\text { income- } \\
\text { only } \\
\text { graduation) }\end{array}$ \\
\hline $\begin{array}{l}\text { Human } \\
\text { Asset Index } \\
\text { (HAI) }\end{array}$ & $\begin{array}{l}\text { The HAI is a composite index } \\
\text { measure combining five individual } \\
\text { indicators to depict the level of } \\
\text { human capital within a country. A } \\
\text { greater level of human capital is } \\
\text { reflected in higher HAI scores. To } \\
\text { construct the index, three health } \\
\text { related indicators and two education } \\
\text { related indicators are merged using a } \\
\text { max-min procedure that takes into } \\
\text { account the distribution among all } \\
\text { developing countries. } \\
\\
\text { Health indicators } \\
\text { Under-five mortality rate } \\
\text { - Percentage of population } \\
\text { undernourished } \\
\text { Maternal mortality ratio } \\
\text { Education indicators }\end{array}$ & 66 or higher \\
\hline
\end{tabular}




\begin{tabular}{|c|c|c|}
\hline & $\begin{array}{ll}\text { - } & \text { Gross secondary school enrolment } \\
& \text { ratio } \\
\text { - } & \text { Adult literacy rate }\end{array}$ & \\
\hline $\begin{array}{l}\text { Economic } \\
\text { Vulnerability } \\
\text { Index (EVI) }\end{array}$ & $\begin{array}{l}\text { The EVI captures the degree to } \\
\text { which a country's economic } \\
\text { development is vulnerable towards } \\
\text { external economic and } \\
\text { environmental shocks (Cariolle } \\
\text { 2010) with high value indicating } \\
\text { greater structural vulnerability. The } \\
\text { measure is composed of eight } \\
\text { individual indicators that are merged } \\
\text { using a max-min procedure. The } \\
\text { eight indicators can broadly be } \\
\text { categorised into an exposure index } \\
\text { as well as a shock index. } \\
\text { Exposure indicators } \\
\text { - Population size } \\
\text { - Remoteness of geographic } \\
\text { location } \\
\text { - Merchandise export } \\
\text { concentration } \\
\text { - Share of agriculture, hunting, } \\
\text { forestry and fishing in GDP } \\
\text { - Population share in low } \\
\text { elevated coastal zones } \\
\text { Shock indicators } \\
\text { - Instability of exports of goods } \\
\text { and services } \\
\text { - Victims of natural disasters } \\
\text { - Instability of agricultural } \\
\text { production }\end{array}$ & 32 or lower \\
\hline
\end{tabular}




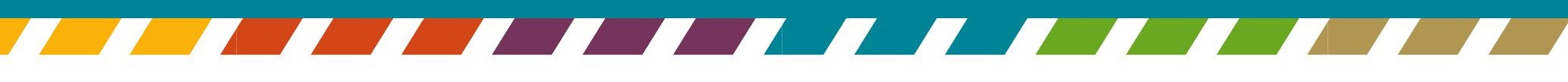

